\author{
Universidade de São Paulo \\ Instituto de Física
}

\title{
Controle de Caos e Saltos entre Atratores em um Sistema com Impactos
}

\author{
Everton Santos Medeiros \\ Orientador: Prof. Dr. Iberê Luiz Caldas
}

Dissertação de mestrado apresentada ao Instituto de Física para a obtenção do título de Mestre em Ciências.

Prof. Dr. Iberê Luiz Caldas - IFUSP (Orientador)

Prof. Dr. Antonio Marcos Batista - UEPG

Prof. Dr. Edson Denis Leonel - Unesp/IGCE - Rio Claro

São Paulo

2010 


\section{Agradecimentos}

Aos meus avós Seu Otávio e Dona Nica, in memoriam. Serei eternamente grato.

À tia Lú, pelo carinho e confiança que sempre depositou em mim.

Ao meu irmão Marcelo, por tudo que já fez por mim.

À toda minha família, pelo constante apoio e torcida.

Ao Prof. Dr. Iberê Luiz Caldas pela orientação, apoio, incentivo e atenção ímpar que teve comigo ao longo da iniciação científica e do mestrado.

Ao Prof. Dr. Silvio L. T. de Souza pela co-orientação e idéias que contribuíram com este trabalho.

Ao Dr. Rene O. Medrano-T. pelas discussões sobre espaço de parâmetros que me ajudaram no desenvolvimento desta dissertação.

Ao meu primo Beto, pela amizade e pelas incontáveis caronas no trajeto Pinhal - São Paulo.

Aos meus grandes amigos: Daniel, Dorival, Reinaldo e Ricardo.

Aos meus colegas do grupo de caos e da sala 125A: Alberto, Danilo, Dennis, Elton, Gustavo, Julio, Rafael, Raul e Zwinglio. A todos sou grato pelo aprendizado e convivência diária.

Às secretárias, sempre prestativas, Eleonora, Inês e Lia.

Aos desenvolvedores de software livre. Suas apostilas e tutoriais online ajudaram nas tarefas diárias.

À Priscila, minha noiva, companheira desde meus quinze anos de idade.

Agradeço ao CNPq e Capes pelo suporte financeiro concedido. 


\section{Resumo}

Em um sistema mecânico, descrito pelo modelo par de impactos, estudamos o controle de caos, através de uma perturbação paramétrica, e os saltos entre trajetórias de dois atratores. Para esse sistema não integrável, obtivemos numericamente e analisamos a evolução das suas variáveis, para um grande conjunto de condições iniciais e parâmetros de controle. Para essa análise foram obtidos planos de fase, seções de Poincaré, diagramas de bifurcação, bacias de atração, expoentes de Lyapunov e espaços bidimensionais de parâmetros. Um controle paramétrico foi implementado somando uma perturbação senoidal, com amplitude e frequência definidas, ao forçamento original do sistema. O controle de caos foi analisado no espaço bidimensional de parâmetros do sistema. Observamos nesse espaço a formação de janelas periódicas (camarões) na vizinhança das janelas previamente existentes. Constatamos que, nas novas janelas, os atratores controlados possuem periodicidade e forma iguais as dos atratores presentes em janelas previamente existentes. Os saltos entre as trajetórias de dois atratores coexistentes foram analisados, com o sistema perturbado por uma simulação de um ruído branco com uma banda de frequências. Mostramos que a frequência dos saltos aumenta com a amplitude do ruído e a intensidade da dissipação, devido à mudança que esses fatores causam nas bacias de atração dos dois atratores. 


\section{Abstract}

For a mechanical system, described by the impact-pair model, we studied the control of chaos by a parametric perturbation and the basin-hopping phenomeno. For this nonintegrable system, we obtained numerically the evolution of its dynamical variables for a large set of initial conditions and control parameters. For this analysis, we used phase planes, Poincaré sections, bifurcation diagrams, basin of attractions, Lyapunov exponents, and bidimensional parameter spaces. A parametric control was implemented by adding an external perturbation with defined amplitude and frequency. The control of chaos was analized in the two-dimensional parameter space. In the parameter space, we observed the formation of new periodic windows (shrimps) in the neighborhood of previously one. In the new periodic windows, the new controlled attractors have the same shape and periodicity of those in the original windows. For two attractors, the basin-hopping was analyzed for a white noise with frequency band. We showed that the hop frequency increases with the noise amplitude and the dissipation intensity. This occurs due to changes in the basins of attraction. 


\section{Conteúdo}

1 Introdução $\quad 9$

2 Modelo Par de Impactos e Métodos de Análise 17

2.1 Modelo Par de Impactos . . . . . . . . . . . . . . . . . . . . . 18

2.2 Séries Temporais . . . . . . . . . . . . . . . . . 20

2.3 Plano de Fase . . . . . . . . . . . . . . . . . . . . . . . . . . . . . . . . . . 21

2.4 Mapa de Poincaré e Mapa Estroboscópico . . . . . . . . . . . . . . . . . . 24

2.5 Diagrama Unidimensional de Parâmetros . . . . . . . . . . . . . . . . 27

2.6 Expoentes de Lyapunov . . . . . . . . . . . . . . . . . . . . . 30

2.7 Diagrama Bidimensional de Parâmetros . . . . . . . . . . . . . . 35

2.8 Bacias de Atração . . . . . . . . . . . . . . . . . . . . . . . . . . . 39

3 Surgimento de Janelas Periódicas no Espaço de Parâmetros 41

3.1 Dinâmica Sem Perturbação . . . . . . . . . . . . . . . . . . 41

3.2 Perturbação Paramétrica . . . . . . . . . . . . . . . . . . . 45

3.3 Atratores Controlados . . . . . . . . . . . . . . . . . . . 49

4 Salto Entre Trajetórias de Diferentes Atratores $\quad 55$

4.1 Coexistência de Atratores . . . . . . . . . . . . . . . . 55

4.2 Perturbação Simulando o Ruído . . . . . . . . . . . . . . . . . . . . 60

4.3 Salto Entre Bacias de Atração . . . . . . . . . . . . . . . . . . . . . . . 62

$\begin{array}{lll}5 & \text { Conclusões } & 67\end{array}$ 
Referências Bibliográficas 


\section{Capítulo 1}

\section{Introdução}

Em 1963, Edward N. Lorenz observou que as soluções de um sistema de equações diferenciais não lineares, não integráveis, conhecido como sistema de Lorenz, podem apresentar sensibilidade à variação das condições iniciais [1]. Este fato motivou, nos anos seguintes, uma série de experimentos para verificar a existência real dessa sensibilidade. Essa propriedade foi observada em diversos experimentos tais como, convecção de Rayleigh-Bénard, a reação química de Belousov-Zhabotinskii, sistema de Couette-Taylor e em circuitos eletrônicos não lineares [2]. As soluções dos sistemas não lineares que exibem sensibilidade à variação das condições iniciais foram chamadas de caóticas ou que exibem caos.

Os resultados de Lorenz motivaram a utilização de modelos matemáticos para estudar o surgimento de soluções caóticas em diversas áreas. Assim, o estudo desse tipo de solução tornou-se interdisciplinar, abrangendo sistemas físicos [3, 4], biológicos [5], químicos [6], meteorológicos [1] e de engenharia [7].

Após o trabalho de Lorenz, muitos trabalhos foram dedicados à identificação de soluções numéricas caóticas. Para caracterizar essas soluções, diferentes métodos foram desenvolvidos e utilizados [8-11]. Atualmente os expoentes de Lyapunov fornecem boa indicação para distinguir entre os comportamentos caótico e regular (periódico ou quasiperiódico) das soluções. Os expoentes de Lyapunov indicam a sensibilidade das soluções através da divergência ou convergência de uma função exponencial. Pode-se determinar um expoente para cada direção considerada no espaço de fase. Para expoentes de Lyapu- 
nov positivos, duas condições iniciais suficientemente próximas levam a soluções bastante diferentes, indicando a sensibilidade dos sistema e consequentemente a solução caótica. Para expoentes de Lyapunov negativos, o sistema não exibe sensibilidade e as soluções são regulares.

O comportamento caótico ou periódico de um modelo pode ser alterado com a variação dos parâmetros de controle do sistema. Essa variação pode ser visualizada em um espaço de parâmetros. Nesse espaço o comportamento periódico ou caótico do sistema é classificado através dos expoentes de Lyapunov para uma grade de parâmetros. Dependendo do valor do maior expoente de Lyapunov obtido para a órbita correspondente a um par de parâmetros, o ponto correspondente a esse par de parâmetros é marcado em uma cor na grade. Assim, obtem-se um degradê de cores variando desde expoentes de Lyapunov negativos (solução regular) até expoentes de Lyapunov positivos (solução caótica). Parâmetros exibindo soluções periódicas formam janelas periódicas no espaço de parâmetros $[12]$.

As janelas periódicas no espaço de parâmetros possuem forma peculiar, composta por uma área central com quatro extremidades alongadas. Uma das primeiras realizações numéricas que explorou a forma destas janelas foi obtida para uma combinação de dois mapas logísticos, com dois parâmetros combinados. Neste trabalho, devido à forma, a janela foi chamada de andorinha (Swallow-Shaped) [13]. Mas, o primeiro estudo sistemático das janelas ocorreu no sistema de Hénon, onde características de periodicidade e bifurcações foram discutidas. Neste trabalho a janela ganhou o nome que é mais conhecido atualmente, camarão (Shrimp-Shaped) [12].

Frequentemente as soluções numéricas de um conjunto de equações diferenciais não lineares, não integráveis, como as do sistema de Lorenz, são representadas no espaço de fase. Nesse espaço introduzimos um sistema de coordenadas onde os eixos representam a solução das variáveis das equações diferenciais do sistema [14]. Um ponto no espaço de fase é referido como estado do sistema e um conjunto de pontos é chamado de órbita ou trajetória [15]. Em sistemas dissipativos, trajetórias tendem para conjuntos limites no espaço de fase, chamados de atratores [16]. As soluções que apresentam a sensibilidade à variação das condições iniciais são representadas no espaço de fase por um atrator caótico. 
A ocorrência de atratores caóticos em diversas aplicações é observada para intervalos de parâmetros acima de valores críticos. Abaixo desses limites críticos o sistema apresenta comportamento regular. Em muitas aplicações os sistemas são mantidos no intervalo de parâmetros no qual o sistema é regular [17]. Mas, existe a necessidade de desenvolvimento destes sistemas tornando a utilização de um intervalo maior de parâmetros, com soluções caóticas, indispensável. Para regularizar essas soluções, muitos estudos são voltados para mecanismos de controle dos atratores caóticos [18, 19].

Na literatura existem duas principais técnicas de controle de caos. O método OttGrebogi-Yorke (OGY) consiste na estabilização de órbitas periódicas instáveis imersas no atrator caótico, sem alterações desse atrator [20]. Este método é implementado inicializando o sistema em qualquer condição inicial dentro do atrator caótico. Quando a trajetória aproximar-se de uma órbita regular instável, ela sofre uma intervenção de modo a permanecer nesta. A partir daí, a trajetória é monitorada e à medida que se afasta da órbita instável ela sofre novas intervenções [20,21]. No outro método, uma perturbação paramétrica altera o comportamento do atrator caótico para periódico. Este método consiste em um desvio permanente dos parâmetros, provocado pela perturbação, de modo que o atrator caótico assume a periodicidade de um atrator vizinho [20].

Além das soluções caóticas, os modelos matemáticos apresentam outros fenômenos bastante importante envolvendo os atratores. A existência de mais de um atrator para um conjunto de parâmetros tem sido alvo de diversos estudos [22]. Essa coexistência de atratores, também chamada de multiestabilidade, é encontrada em diversas áreas de aplicação de sistemas dinâmicos [23-29]. Esses sistemas multiestáveis apresentam alguns fenômenos interessantes, quando submetidos a uma perturbação [30, 31], como o salto entre as trajetórias de diferentes atratores (basin hopping). Nesse mecanismo o sistema é inicializado para condições iniciais na bacia de um dos atratores e, assim, a trajetória converge para esse atrator. Mas, com a influência de uma perturbação, a trajetória abandona este atrator e permanece certo tempo no outro atrator, que coexiste com o primeiro. Este efeito se repete durante a evolução temporal do sistema.

A utilização de modelos no estudo de sistemas dinâmicos é fundamental para estudar a sua evolução. Nesse trabalho propomos o estudo do controle de caos e do salto entre as 
trajetórias de diferentes atratores em um modelo matemático para um sistema mecânico.

O modelo não integrável considerado simula os impactos existentes em diversos sistemas de engenharia mecânica. Geralmente, os sistemas mecânicos que funcionam acoplados possuem uma folga entre as partes móveis para fins de lubrificação e expansão termodinâmica. Os impactos que ocorrem devido a essas folgas são descritos por sistemas não lineares [32]. Esses sistemas impactantes podem apresentar comportamento caótico. Um exemplo é o sistema caixa de engrenagens, com engrenagens tipo espora, que apresenta comportamento caótico para intervalos de parâmetros do sistema [33, 34]. Este sistema é encontrado, por exemplo, em motores movidos a diesel onde uma grande folga é deixada entre dentes das engrenagens para permitir lubrificação [32].

O estudo do controle de caos e de saltos entre diferentes trajetórias é importante em sistemas com impactos, pois a presença destes fenômenos pode mudar repentinamente a evolução do sistema. Assim, vários trabalhos experimentais e teóricos investigaram a influência de parâmetros em sistemas com impactos [35, 36].

O modelo de impactos, que investigamos, descreve os impactos que ocorrem no sistema caixa de engrenagens. O modelo par de impactos é constituído por uma bola deslocandose livremente dentro de uma caixa em movimento. Um forçamento é aplicado à caixa e a bola sofre impactos sucessivos nas paredes. Cada impacto que a bola sofre simula os impactos entre dentes consecutivos do sistema caixa de engrenagens. Os parâmetros envolvidos na formulação do modelo são a distância entre as paredes da caixa, o coeficiente de restituição dos impactos e os parâmetros do forçamento que movimenta a caixa.

No modelo par de impactos, para obter a trajetória da bola dentro da caixa, integramos numericamente as equações de movimento. A cada impacto com a parede da caixa, a trajetória é reinicializada segundo uma regra de impactos. A regra utilizada na reinicialização é denominada regra de Newton para impactos. A nova velocidade inicial da solução é a velocidade imediatamente antes do impacto, multiplicada pelo coeficiente de restituição. Devido a esse mecanismo de reinicialização o sistema par de impactos é não-suave, ou seja, a solução não é contínua [34, 37]. Este tipo de sistema possui uma grande riqueza de fenômenos do ponto de vista da dinâmica caótica. O modelo par de impactos foi bastante estudado na literatura [38-40], tendo sido desenvolvido um método 
para calcular os expoentes de Lyapunov de suas trajetórias [40]. Sistemas com impactos aparecem em várias outras áreas, como no conhecido modelo de E. Fermi para explicar a aceleração de partículas cósmicas entre as galáxias [41, 42].

A obtenção dos expoentes de Lyapunov é bem conhecida para sistemas suaves, ou seja, para sistemas onde a solução é conhecida em todos os pontos através de uma equação de diferenças (mapas) ou através da solução de equação diferencial [43]. Para sistemas não-suaves, como o modelo de impactos, a obtenção dos expoentes de Lypunov exige a utilização de métodos especiais. O método do mapa transcendental fornece boa estimativa para os expoentes de Lyapunov em sistemas com impactos [40]. Este método consiste em considerar a solução entre cada impacto, mas tomar como elementos do mapa as variáveis nos instantes de impactos.

No capítulo dois, introduzimos o modelo par de impactos e os principais métodos de análise que utilizaremos, nos capítulos seguintes, na análise do controle de caos e nos saltos entre atratores. Obtemos a solução da equação de movimento do sistema par de impactos, com o auxílio da regra de Newton para impactos e obtemos o mapa transcendental utilizado no cálculo dos expoentes de Lyapunov. Em seguida, avaliamos o transiente da solução, para diferentes parâmetros, através de séries temporais. Para verificar a presença de atratores obtemos planos de fase e mapas de Poincaré. Obtemos, ainda, os diagramas de bifurcação para avaliar as alterações dos atratores em função dos parâmetros de controle.

Nesse capítulo, utilizamos o método do mapa transcendental para obter os expoentes de Lyapunov. Para verificar a precisão deste método comparamos a distinção entre atratores baseada no maior expoente de Lyapunov e na análise dos diagramas de bifurcação. Obtemos o espaço bidimensional de parâmetros para observar a presença de janelas periódicas (camarões) e verificar os tipos de bifurcações envolvidos em sua criação. Escolhemos intervalos com coexistências de atratores. Calculamos bacias de atração desses atratores e comparamos bacias dos atratores periódicos e caóticos coexistentes.

No capítulo três, avaliamos a resposta do modelo par de impactos ao controle de caos através de uma perturbação paramétrica. Sem aplicação da técnica de controle, escolhemos um intervalo dos parâmetros do sistemas par de impactos para analisar suas 
trajetórias. Para esses parâmetros obtivemos diagramas de bifurcação e calculamos os expoentes de Lyapunov. Também verificamos, neste intervalo, a presença de coexistências de atratores em janelas periódicas. Com o auxílio dos diagramas de bifurcação, escolhemos neste intervalo um conjunto de parâmetros com atrator caótico. Para confirmar o carácter caótico do atrator obtemos um mapa de Poincaré e observamos o atrator nesse mapa.

Ainda neste capítulo, definimos e aplicamos, ao modelo par de impactos, a perturbação paramétrica da amplitude de forçamento. Essa perturbação é regida por sua amplitude, pequena quando comparada à amplitude do forçamento natural do sistema. Obtemos um diagrama bidimensional de parâmetros para esse sistema com a amplitude da perturbação nula. Neste diagrama observamos a presença de janelas periódicas (camarões). Em seguida, confeccionamos outro diagrama bidimensional de parâmetros no mesmo intervalo que o anterior, porém com o controle paramétrico. Neste diagrama observamos o surgimento de uma nova janela periódica (camarão) na vizinhança da janela previamente existente. Obtemos outros espaços bidimensionais de parâmetros com amplitudes da perturbação maiores e notamos, nesses diagramas, que as janelas periódicas deslocam-se no espaço de parâmetros a medida que variamos a amplitude da perturbação. A observação do surgimento da nova janela periódica é inédita, pois, em trabalhos anteriores, o controle foi obtido apenas para alguns parâmetros do sistema [44].

No capítulo quatro, observamos o salto entre as trajetórias de dois atratores do sistema par de impactos. Escolhemos, nesse modelo, os parâmetros nos quais o sistema exibe biestabilidade. Obtemos um diagrama de bifurcação com a origem dessa coexistência, bem como sua dependência com os parâmetros do sistema. Obtemos bacias de atração dos atratores coexistentes variando o coeficiente de restituição dos impactos. Notamos que a área contínua da bacia de atração de cada atrator diminui a medida que reduzimos a dissipação. O salto entre trajetórias de diferentes atratores foi observado na literatura sob o efeito de uma perturbação randômica [38]. Porém, neste trabalho, utilizamos uma perturbação caracterizada por um conjunto de harmônicos senoidais com frequências e amplitudes constantes, com mudanças de fases para simular um ruido branco numa banda de frequências. A fase de cada harmônico foi sorteada com auxílio de uma função computacional, para dois pontos na série temporal desta perturbação serem indenpenden- 
tes.

Aplicamos essa perturbação ao modelo par de impactos para dois valores do coeficiente de restituição dos impactos. Verificamos que essa perturbação provoca o salto entre trajetórias dos diferentes atratores da biestabilidade. A medida que reduzimos a dissipação o salto ocorre com menor amplitude da perturbação, pois a área contínua da bacia de atração de cada atrator diminui com a dissipação.

No capítulo cinco, apresentamos as conclusões obtidas para o controle de caos através da perturbação paramétrica e para os saltos entre as trajetórias de diferentes atratores.

Todos os programas envolvidos nas simulações deste trabalho foram desenvolvidos, por nós em linguagem de programação C. Todos os gráficos foram obtidos com GNUPLOT. 


\section{Capítulo 2}

\section{Modelo Par de Impactos e Métodos}

\section{de Análise}

O estudo teórico de sistemas dinâmicos pode ser realizado através de modelos que reproduzem isoladamente aspectos relevantes de sistemas experimentais. Neste capítulo, introduzimos o modelo par de impactos e discutimos seu comportamento dinâmico com auxílio de métodos de análise apropriados. Mostramos a formulação matemática do modelo e obtemos a solução numérica das equações de movimento, utilizando a regra de Newton para impactos. Obtemos as séries temporais das soluções e avaliamos a duração do comportamento transitório. Obtemos os atratores e os analizamos com o emprego de planos de fase e mapas de Poincaré. A dependência dos atratores com relação aos parâmetros de controle é apresentada em diagramas de bifurcação. Considerando as variáveis nos instantes de impacto, obtemos o mapa transcendental, e com esse mapa obtemos os expoentes de Lyapunov. As janelas periódicas (camarões) existentes para intervalos de parâmetros são apresentadas em diagramas bidimensionais de parâmetros. Obtemos as bacias de atração de coexistência de atratores periódicos e caóticos e discutimos como essas bacias variam com os parâmetros. 


\subsection{Modelo Par de Impactos}

Descrevemos aqui o modelo matemático do sistema com impactos a ser estudado, ilustrado na Figura 2.1 [45-47]. Além disso, mostramos como obter um mapa de impactos.

Esse sistema é composto por uma caixa (sendo $\nu$ a distância entre as paredes), que oscila no tempo de acordo com uma função harmônica Asen $\left(\omega_{0} t\right)$, e uma bola de massa $m$ que se movimenta livremente dentro da caixa onde ela está contida.

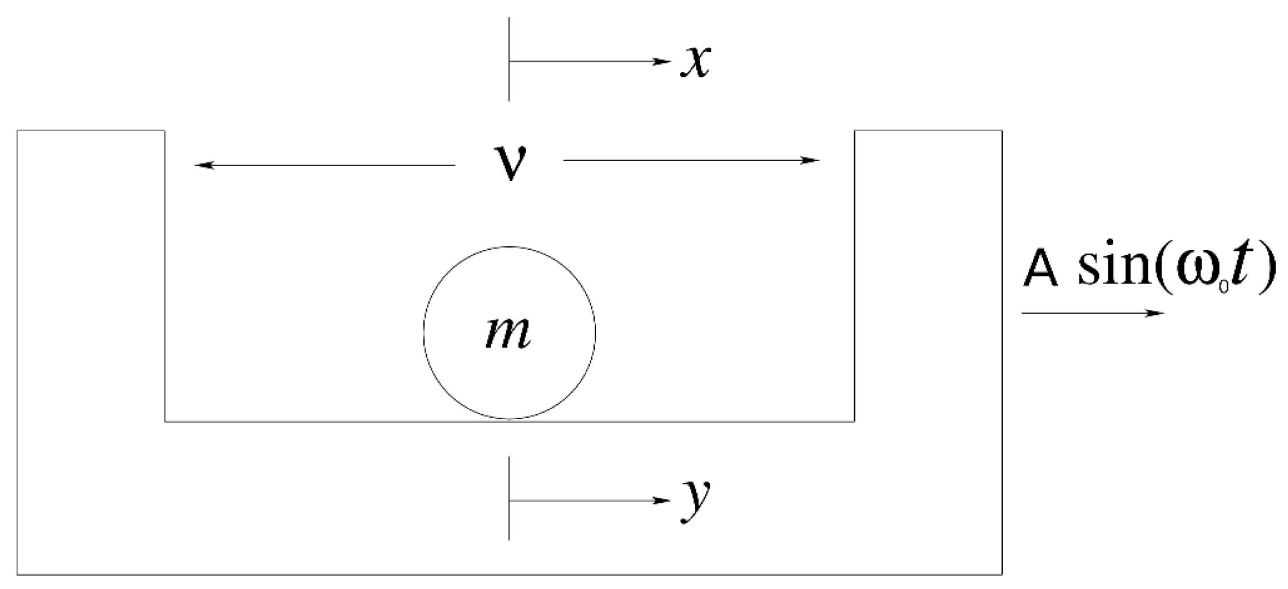

Figura 2.1: Esquema do sistema com impactos.

A equação do movimento da bola de massa $m$, entre os impactos, no referencial em repouso (referencial do laboratório) é dada por:

$$
\ddot{x}=0 \text {. }
$$

Denotando o deslocamento da massa $m$, em relação à caixa, por $y$ temos:

$$
x=y+A \operatorname{sen}\left(\omega_{0} t\right)
$$

Substituindo a Equação (2.2) na Equação (2.1), a equação de movimento é dada por:

$$
\ddot{y}=A \omega_{0}^{2} \operatorname{sen}\left(\omega_{0} t\right) \text { para }-\frac{\nu}{2}<y<\frac{\nu}{2} .
$$

Integrando a Equação (2.3) para as condições iniciais $y\left(t_{0}\right)=y_{0}$ e $\dot{y}\left(t_{0}\right)=\dot{y}_{0}$, o deslocamento $y(t)$ e a velocidade $\dot{y}(t)$, entre os impactos, são: 


$$
\begin{gathered}
y(t)=y_{0}+A \operatorname{sen}\left(\omega_{0} t_{0}\right)-A \operatorname{sen}\left(\omega_{0} t\right)+\left[\dot{y}_{0}+A \omega_{0} \cos \left(\omega_{0} t_{0}\right)\right]\left(t-t_{0}\right) . \\
\dot{y}(t)=\dot{y}_{0}+A \omega_{0} \cos \left(\omega_{0} t_{0}\right)-A \omega_{0} \cos \left(\omega_{0} t\right)
\end{gathered}
$$

Os impactos ocorrem para $y=\nu / 2$ e $y=-\nu / 2$. Depois de cada impacto, introduzimos nas Equações (2.4) e (2.5) as novas condições iniciais.

$$
\begin{gathered}
t_{0}=t, \\
y_{0}=y, \\
\dot{y}_{0}=-r \dot{y} .
\end{gathered}
$$

onde $r$ é o coeficiente de restituição com $r \in[0,1]$.

Caso $r=1$ identifica choques totalmente elásticos ao passo que $r=0$ denota choques totalmente inelásticos.

Por conseguinte, podemos estudar a dinâmica do sistema a partir das Equações (2.4), (2.5) e (2.6). Para isso, devemos variar os parâmetros de controle que são $A, r, \nu$ e $\omega_{0}$. Estudamos como a evolução numérica das variáveis é afetada por variações dos parâmetros.

Na equação (2.2) as coordenadas $x$ e $y$, bem como a amplitude $A$ são adimensionais, ou seja, os seus valores foram divididos pela distância $\nu$. Além disso, usaremos a frequência do forçamento como $\omega_{0}=1$ e, consequentemente, o período do forçamento será $2 \pi / \omega_{0}$.

A partir da solução analítica e da regra de impacto, podemos obter um mapa de impactos, também denominado de mapa transcendental [40]. O mapa é obtido quando registramos as variáveis $\dot{y}_{n}$ e $t_{n}$, que correspondem às variáveis $\dot{y}$ e $t$ no instante imediatamente antes do impacto. As variáveis $\dot{y}_{n+1}$ e $t_{n+1}$ são obtidas das Equações (2.4) e (2.5), para as condições iniciais:

$$
t_{0}=t_{n}
$$




$$
\begin{gathered}
y_{0}=y_{n}, \\
\dot{y_{0}}=-r \dot{y_{n} .}
\end{gathered}
$$

Assim sendo, introduzimos o mapa transcendental:

$$
\begin{gathered}
y_{n+1}=y_{n}+A \operatorname{sen}\left(\omega_{0} t_{n}\right)-A \operatorname{sen}\left(\omega_{0} t_{n+1}\right)+\left[-r \dot{y}_{n}+A \omega_{0} \cos \left(\omega_{0} t_{n}\right)\right]\left(t_{n+1}-t_{n}\right) . \\
\dot{y}_{n+1}=-r \dot{y}_{n}+A \omega_{0} \cos \left(\omega_{0} t_{n}\right)-A \omega_{0} \cos \left(\omega_{0} t_{n+1}\right)
\end{gathered}
$$

Esse mapa será utilizado na obtenção dos expoentes de Lyapunov.

\subsection{Séries Temporais}

A evolução dos sistemas dinâmicos não integráveis pode ser obtida a partir de suas séries temporais. Estas são obtidas fixando todos os parâmetros de controle do sistema e calculando as variáveis dinâmicas em cada instante de tempo. A análise das séries temporais é bastante útil, pois através delas é possível verificar a compatibilidade entre experiências em laboratório e simulações. Com as séries temporais classificamos uma órbita quanto ao seu comportamento, podendo este ser periódico ou caótico. Além disso, a evolução das variáveis dinâmicas, em sistemas dissipativos, possui em geral um comportamento transitório inicial. O transitório antecede o comportamento definitivo das variáveis dinâmicas do sistema, que é chamado de atrator, que pode ser, por exemplo, caótico. Com as séries temporais numéricas, identificamos e eliminamos transitórios.

Na Figura 2.2 mostramos para o sistema par de impactos as séries temporais para a posição, $y(t)$, e para a velocidade, $\dot{y}(t)$, ambas obtidas através das Equações (2.4) e (2.5). Nessa figura descontamos as 500 unidades de tempo iniciais. Além da frequência natural do sistema, fixamos o coeficiente de restituição em $r=0.7$ e o comprimento da caixa em $\nu=2$. Para comparar séries temporais regulares e caóticas obtivemos séries temporais para dois valores da amplitude do forçamento $A$. Nas Figuras 2.2(a) e 2.2(c) 
fixamos $A=0.5$. Observamos nestas figuras que o deslocamento e a velocidade apresentam comportamento regular, ou seja, identificamos que os picos destas variáveis se repetem com período definido. Nas Figuras 2.2(b) e 2.2(d) fixamos $A=1.5$. Nesse caso as séries temporais não são periódicas. Os picos não se repetem e não identificamos qualquer período.
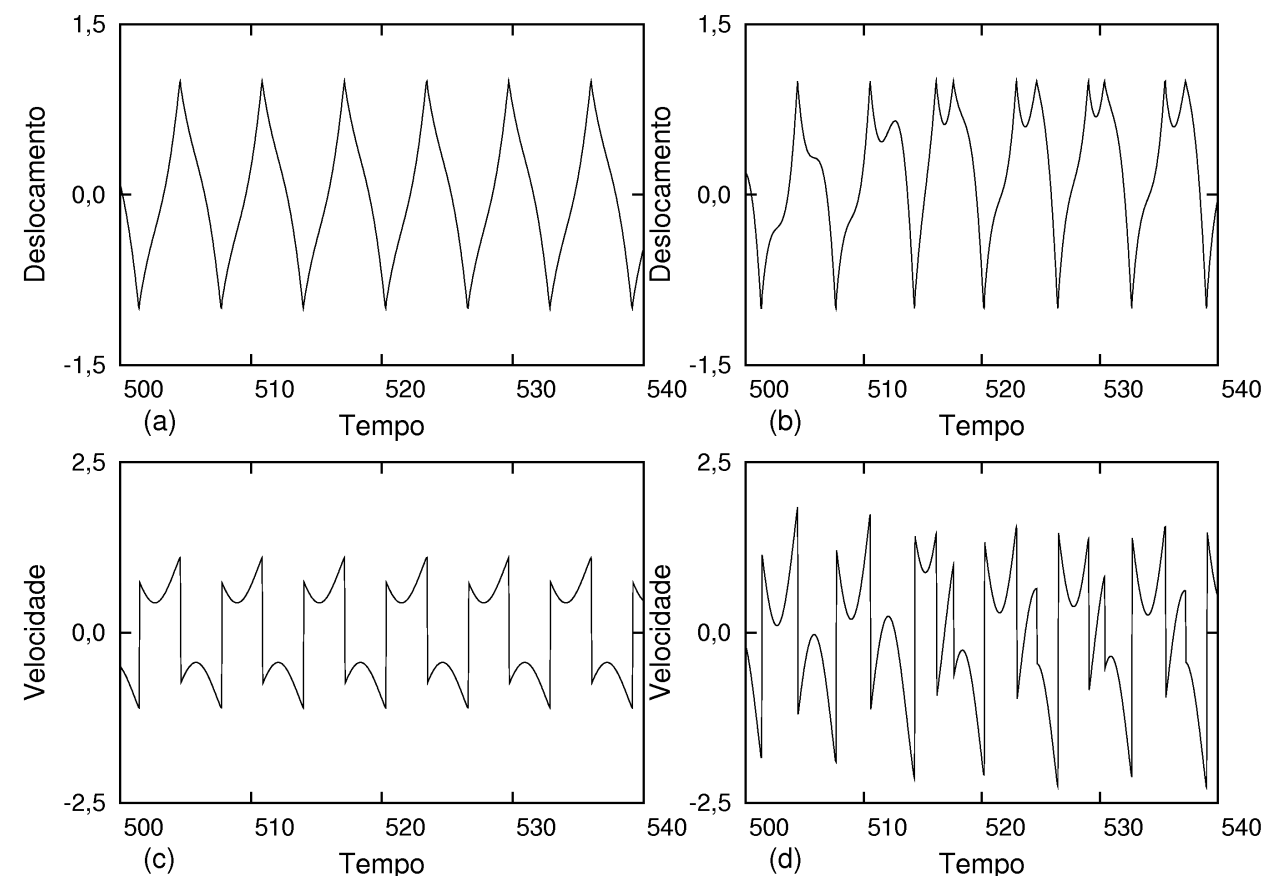

Figura 2.2: Séries temporais do modelo par de impactos. (a) Série temporal do deslocamento $y$ para os parâmetros $\omega_{0}=1, \nu=2, r=0.7$ e $A=0.5$. (b) Série temporal do deslocamento $y$ para os mesmo parâmetros de (a) com $A=1.5$. (c) Série temporal da velocidade $\dot{y}$ para os mesmo parâmetros de (a). (d) Série temporal da velocidade para os mesmo parâmetros de (b).

\subsection{Plano de Fase}

No espaço de fase representamos, em cada eixo, uma variável dinâmica obtida da solução das equações diferenciais do sistema. Para um sistema descrito por três equações diferenciais de primeira ordem, o espaço de fase é tridimensional [14]. Por exemplo, um ponto no espaço de fase tridimensional representa a solução simultânea das três equações diferenciais do sistema. Assim essa técnica de análise permite visualizar as trajetórias do 
sistema estudado.

O modelo par de impactos apresenta um grau de liberdade, mas não é autônomo, implicando em um espaço de fase tridimensional com três variáveis dinâmicas: posição, velocidade e tempo. Neste cenário introduzimos o plano de fase que constitui uma projeção em duas dimensões do espaço de fase. O plano de fase é obtido assinalando o par velocidade e posição para cada instante $t$. No plano de fase é possível identificar a natureza da solução quanto a sua periodicidade e forma.

Na Figura 2.3, mostramos quatro planos de fase obtidos para diferentes amplitudes do forçamento $A$. Nestas figuras observamos a descontinuidade da solução em $|y|=1$. Na Figura 2.3(a) observamos que o sistema exibe uma órbita de período 1. Na Figura 2.3(b), com um incremento no valor da amplitude de forçamento, obervamos que o sistema exibe o dobro de período da figura anterior. Na Figura 2.3(c), o período é novamente duplicado com a variação de $A$. Finalmente na Figura 3.2(d), a trajetória parece não se repetir indicando um possível comportamento caótico.

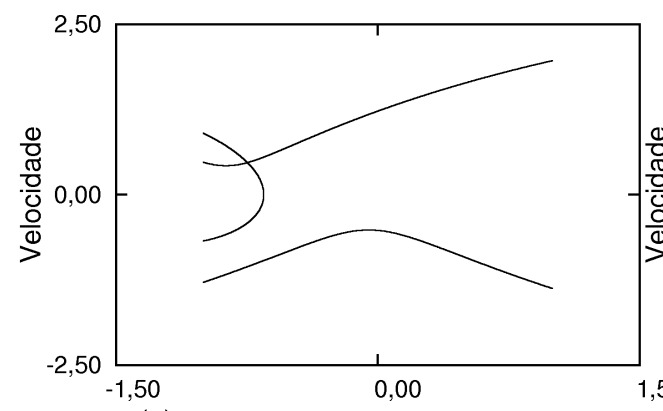

(a)

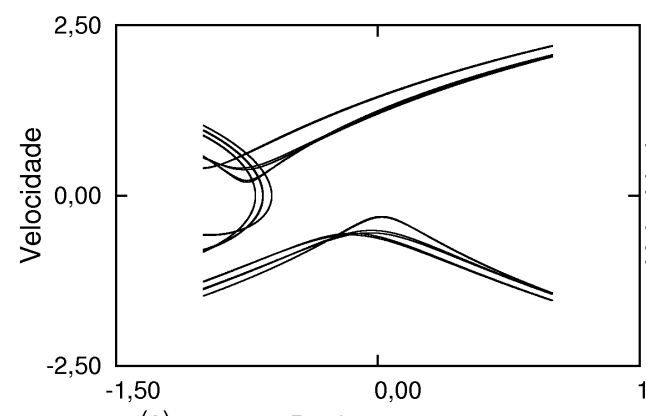

(c)

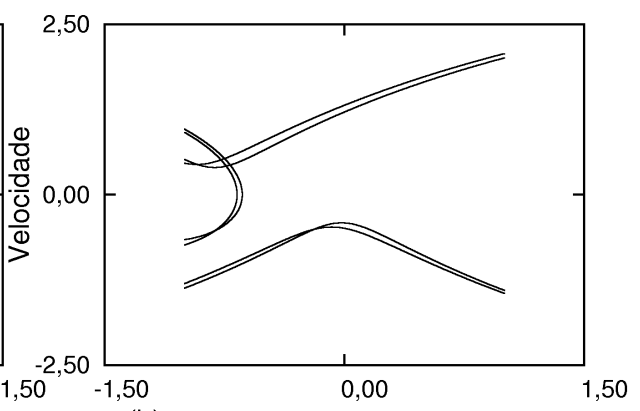

(b)

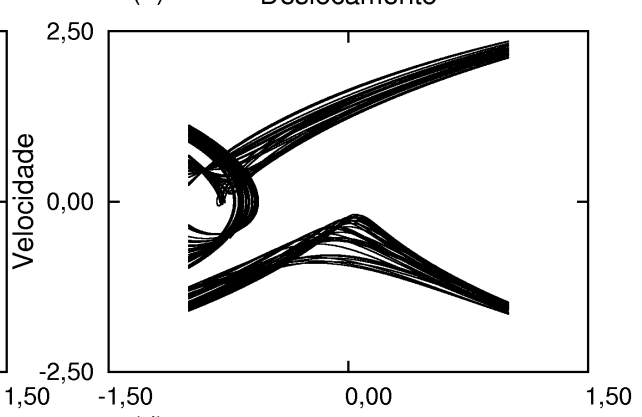

(d) Deslocamento

Figura 2.3: Sequiência de planos de fase enfatizando uma rota para o caos. (a) $\omega_{0}=1, \nu=2, r=0.7 \mathrm{e}$ $A=1.2$. (b) Mesmos parâmetros de (a) $\operatorname{com} A=1.3$. (c) $A=1.385$. (b) $A=1.5$.

Assim verificamos a utilidade do plano de fase para distinguir órbitas periódicas e 
caóticas. No entanto, com a utilização de apenas planos de fase, podem surgir dificuldades em distinguir órbitas caóticas, periódicas e quase-periódicas. Nesse caso é necessário a utilização dos expoentes de Lyapunov visto Seção 2.6. 


\subsection{Mapa de Poincaré e Mapa Estroboscópico}

O conceito de mapa de Poincaré tem origem no século XIX quando Henri Poincaré estudou a estabilidade do sistema solar. A obtenção da trajetória desse sistema no espaço de fase era complicada devido ao número de graus de liberdade. Então, Poincaré propôs a análise do sistema conhecendo como a trajetória intersecciona um plano transversal previamente escolhido. A imagem deixada pela trajetória na seção foi chamada de mapa de Poincaré.

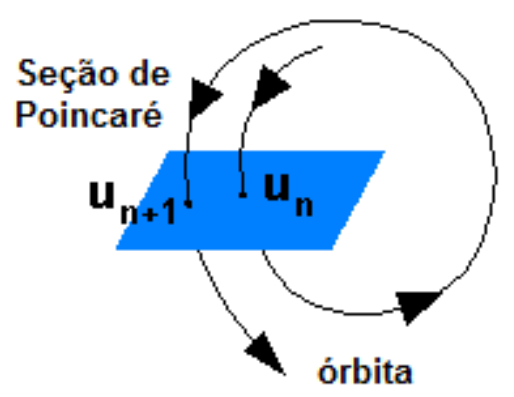

Figura 2.4: Ilustração de uma seção de Poincaré.

Muitas informações são obtidas analisando a imagem deixada pela trajetória na seção transversal. Na seção de Poincaré, os pontos são coletados escolhendo o cruzamento em um sentido da trajetória. A principal aplicação é decidir se a órbita é periódica ou caótica. Para uma órbita de período 1, observamos 1 ponto na seção de Poincaré, pois a trajetória depois de executar o período passa pela seção no mesmo ponto que havia passado anteriormente. Para uma órbita de período 2, a informação deixada pela trajetória na seção de Poincaré são 2 pontos, um para cada revolução executada, assim sucessivamente para períodos maiores. Então, em uma seção de Poincaré de uma trajetória periódica obtemos informação da periodicidade da órbita. Para uma órbita caótica, a imagem deixada pela trajetória na seção de Poincaré é bastante peculiar, pois a trajetória sempre cruza a seção de Poincaré em pontos diferentes.

Dependendo do sistema, a introdução da seção de Poincaré é feita de diferentes maneiras . Isto basicamente consiste em coletar as variáveis dinâmicas do sistema em posições 
ou tempos definidos. Em sistema com impactos é comum coletarmos a velocidade no instante imediatamente anterior ao impacto. Para sistemas com um período de excitação, uma possível seção de Poincaré é coletar a variável dinâmica de interesse a cada período, sendo essa seção também chamada de mapa estroboscópico. Nesta seção obtivemos, para o sistema par de impactos, o mapa de Poincaré tomando a velocidade e o tempo no instante imediatamente antes do impacto, e o mapa estroboscópico tomando a velocidade e a posição a cada período do sistema.

Na Figura 2.5, mostramos as seções de Poincaré de duas trajetórias. Em cada seção coletamos a velocidade, $\dot{y}$ pelo tempo $\bmod (2 \pi)$ imediatamente antes do impacto. No eixo $x$ dessa figura colocamos os valores da variável temporal, tempo $\bmod (2 \pi)$, pois esta seção de Poincaré está colacada na posição $|y|=1$. Para evidenciar a utilidade da seção de Poincaré para determinar se o sistema é caótico ou periódico, comparamos as Figuras 2.5(a) e 2.5(b). Na Figura 2.5(a) observamos que as trajetórias cortam a seção de Poincaré em quatro pontos que se repetem periodicamente. Esse é um atrator periódico. Na Figura 2.5(b) a trajetória corta a seção em diversos pontos indicando uma trajetória caótica para esses parâmetros. O atrator observado nesta figura é chamado de atrator caótico.

Na Figura 2.6 mostramos o mapa estroboscópico, para as mesmas trajetórias da Figura 2.5. Na Figura 2.6 mostramos a velocidade e a posição y obtidas em tempos sucessivos múltiplos do período do sistema. Para expressar esta operação tomamos $t$ como múltiplo de $2 \pi($ Tempo $-2 \pi)$, já que o período do sistema é fixado em $T_{0}=2 \pi\left(\omega_{0}=1\right)$. Na Figura 2.6(a), observamos que a trajetória corta a seção de Poincaré em apenas dois pontos indicando a periodicidade do sistema. Na Figura 2.6(b) repete-se o comportamento da Figura 2.5(b), ou seja, os pontos não são periódicos indicando a presença de caos no sistema para esses parâmetros.

Na Figura 2.5(a), observamos quatro pontos e na Figura 2.6(a) apenas dois pontos. Como estas figuras são para os mesmos parâmetros, esses resultados devem ser correspondentes. A Figura 2.5(a) exibe o dobro de pontos devido ao fato de existirem dois impactos em cada parede. Enquanto que na Figura 2.6(a) a trajetória corta apenas um plano. Após essas considerações constatamos a compatibilidade de periodicidade entre as 

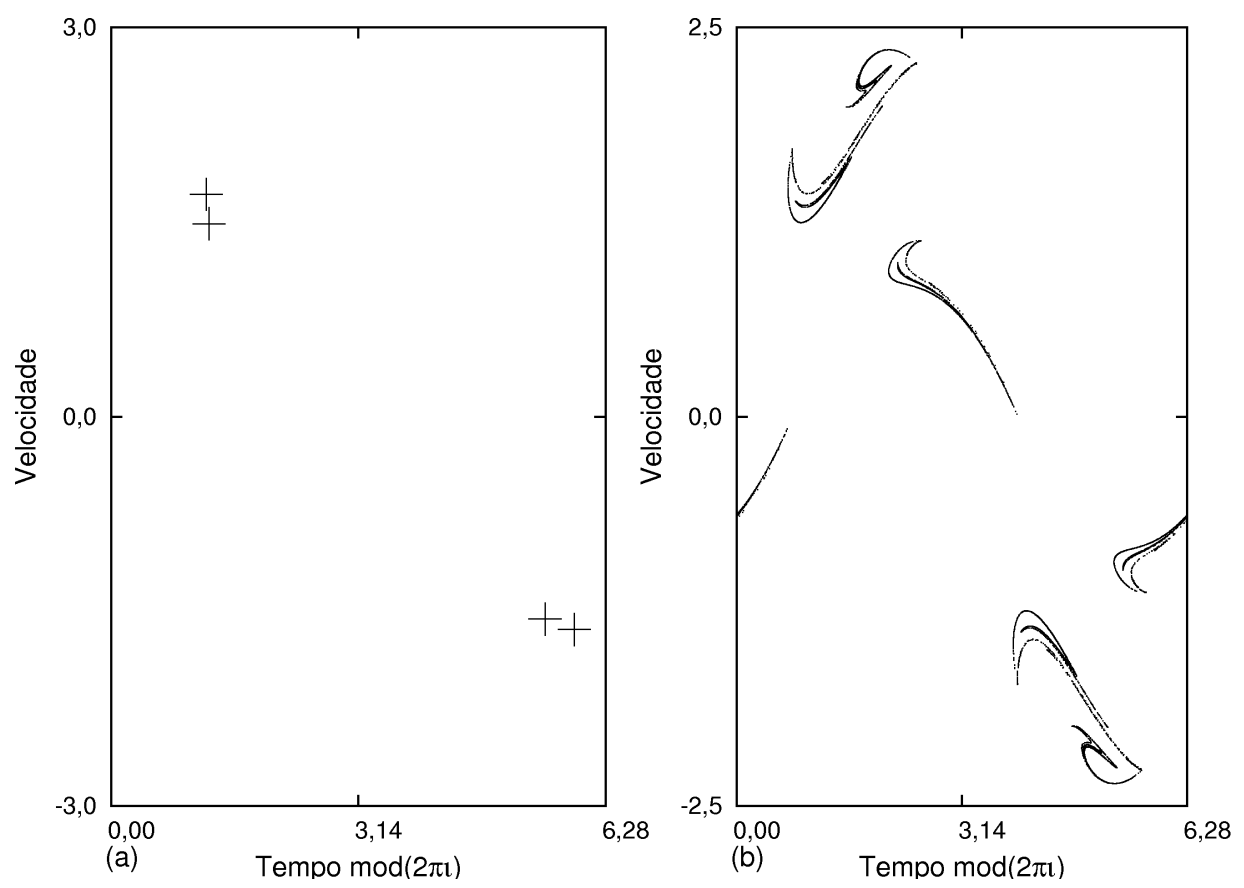

Figura 2.5: Seção de Poincaré, coletando a velocidade e o tempo $\bmod (2 \pi)$, no instante imediatamente antes do instante de impacto. (a) $\omega_{0}=1, \nu=2, r=0.7$ e $A=1$. (b) Mesmos parâmetros de (a) com $A=1.5$.

duas seções de Poincaré. 


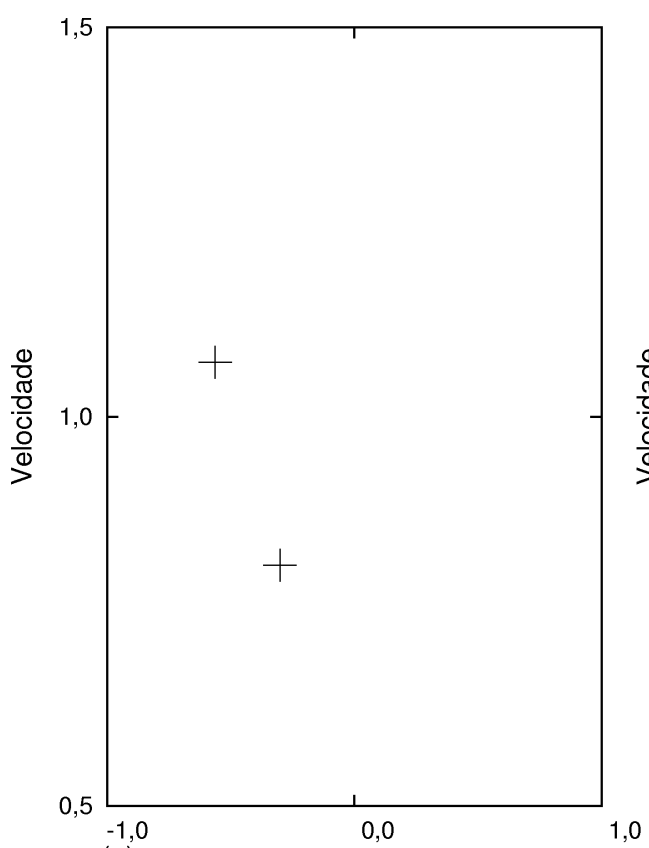

(a) Deslocamento

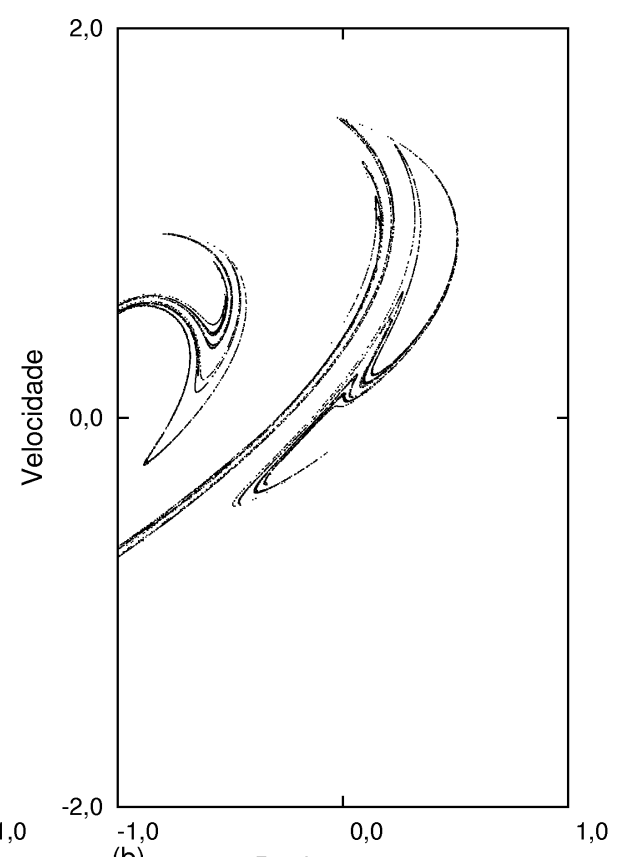

(b) Deslocamento

Figura 2.6: Seção estroboscópica, tomando a velocidade e a posição, no (tempo $-2 \pi)$. (a) $\omega_{0}=1, \nu=2$, $r=0.7$ e $A=1.0$. (b) mesmo parâmetros de (a) com $A=1.5$.

\subsection{Diagrama Unidimensional de Parâmetros}

Como os sistemas dinâmicos dependem dos parâmetros de controle, várias técnicas foram desenvolvidas para explicar essa dependência. Vários fenômenos da dinâmica não linear são observados a partir de variações de parâmetros, tais como mudanças de estabilidade em atratores, rotas para o caos, janelas periódicas etc. Diagramas unidimensionais de parâmetros ou simplesmente diagramas de bifurcação fornecem subsídios para a observação desses fenômenos. Esses diagramas geralmente são confeccionados coletando em uma seção de Poincaré uma das variáveis dinâmicas do sistema. Esse procedimento é realizado para cada parâmetro em um dado intervalo. Assim, nesses diagramas, os atratores caóticos e regulares são mostrados em função dos parâmetros. Para o modelo par de impactos obtivemos diversos diagramas de bifurcação para conhecer a dependência dos atratores com os parâmetros deste sistema.

Na Figura 2.7(a), mostramos o diagrama de bifurcação para a amplitude, $A$, do forçamento do sistema. Notamos que para amplitudes baixas o forçamento não provoca 
comportamento caótico, fato observado em outros sistemas forçados [32]. Nessa figura, destacamos dois atratores coexistentes marcados em preto e azul. Esta coexistência tem origem em uma bifurcação tipo forquilha (pitchfork), para a qual um atrator perde estabilidade e dois atratores surgem. Os dois atratores possuem rota para o caos por duplicação de período. Dentro do intervalo de parâmetros para o qual o sistema exibe caos, há ocorrência de janelas periódicas conforme a ampliação mostrada na Figura 2.7(b). Nesse intervalo, as janelas periódicas surgem através da perda de estabilidade do atrator caótico, dando origem ao atrator periódico. A seguir, novamente o caos é instaurado por duplicação de período.
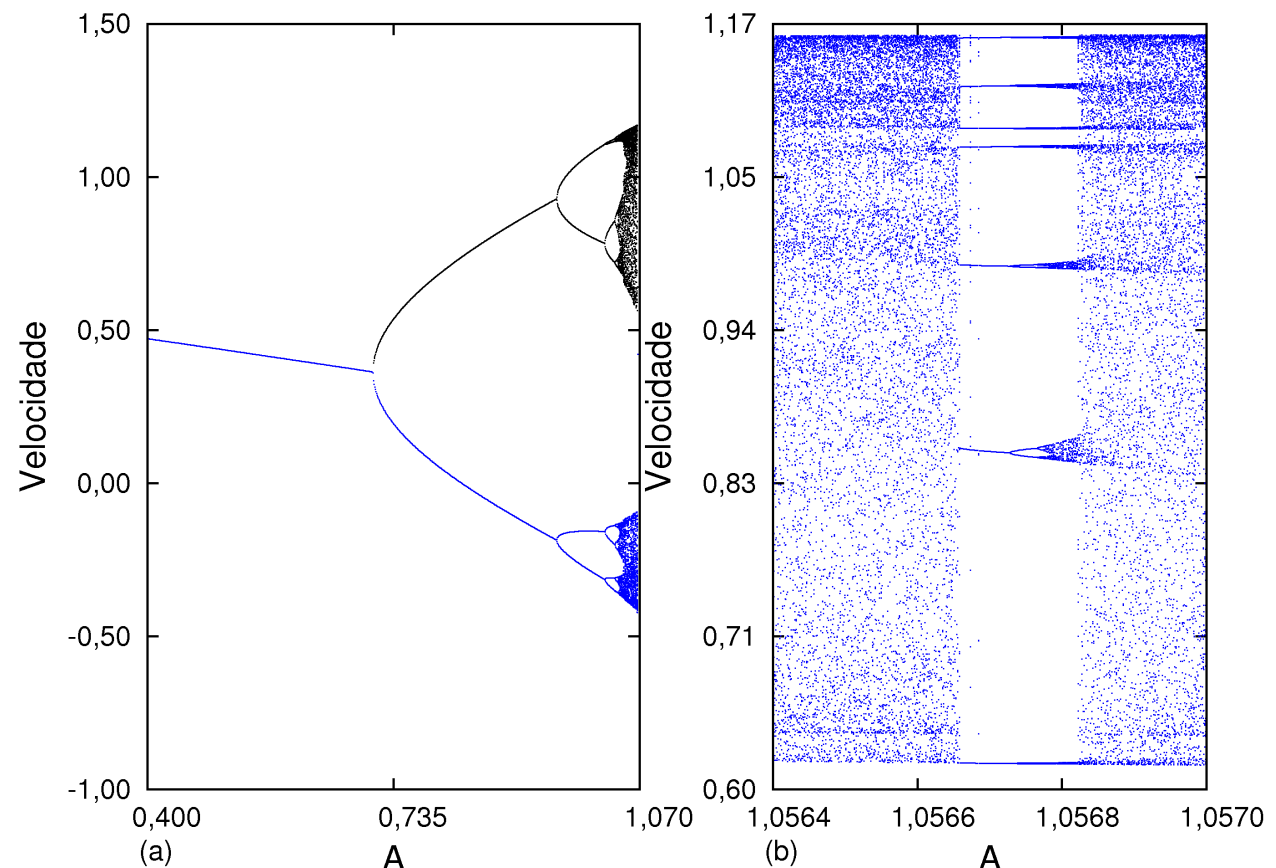

Figura 2.7: Diagrama de bifurcação para a velocidade tomada na seção estroboscópica, variando a amplitude do forçamento $A$, com $\omega_{0}=1, \nu=2$ e $r=0.7$.

Para enfatizar a coexistência de atratores observada na Figura 2.7, obtivemos esses atratores separadamente, nas Figura 2.8(a) e Figura 2.8(b). Para tal, utilizamos o método de seguir o atrator que consiste na utilização das coordenadas do atrator, em um parâmetro, para obter o atrator do parâmetro seguinte.

O coeficiente de restituição $r$ do modelo par de impactos é um importante parâmetro do sistema, pelo seu significado físico e, como veremos, pelos fenômenos de coexistência 


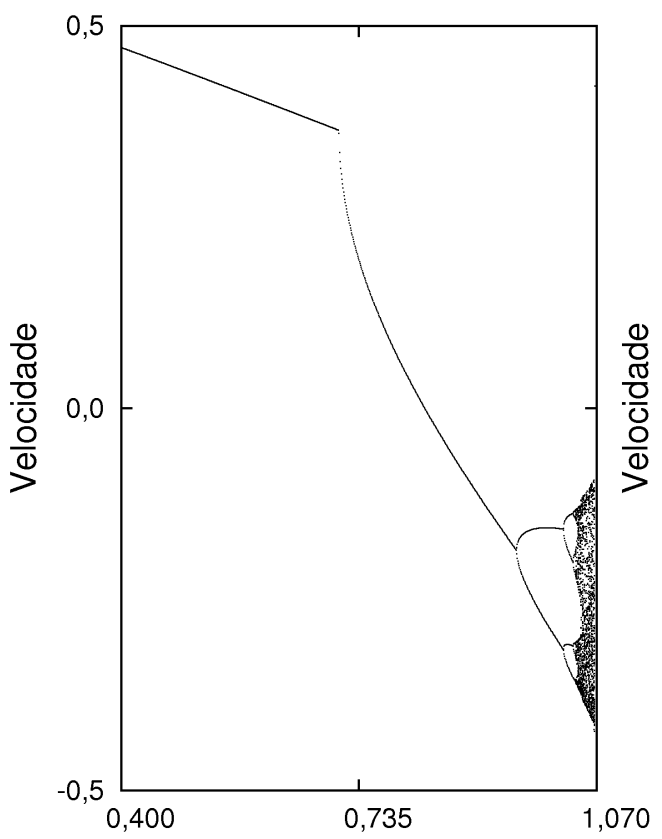

(a)

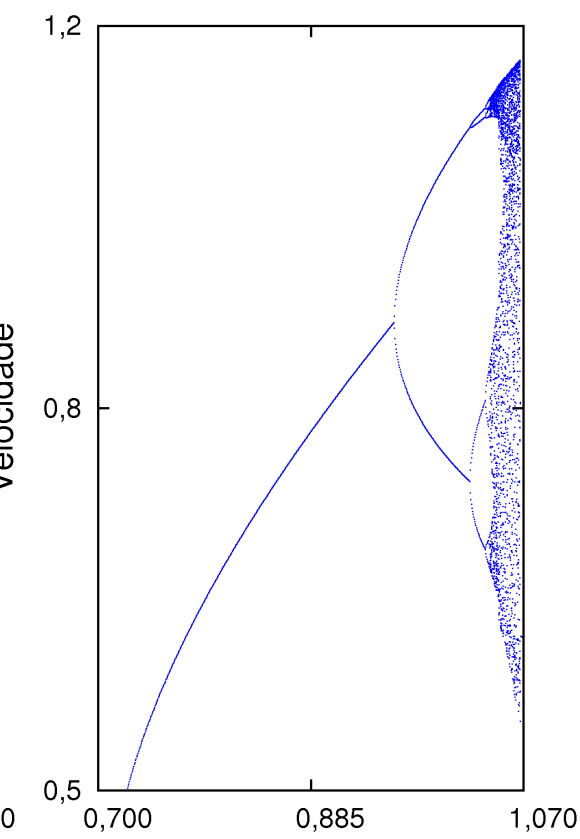

(b)

A

Figura 2.8: Diagrama de bifurcação obtido separadamente utilizando a técnica de seguir o atrator, para os mesmos parâmetros da Figura 2.7. (a) Atrator em preto na Figura 2.7. (b) Atrator em azul na Figura 2.7.

acentuaram-se diminuindo o valor de $r$. Assim, investigamos na Figura 2.9 o comportamento do sistema quando variamos o coeficiente de restituição $r$. Nessa figura fixamos a amplitude de forçamento do sistema em $A=1.2$ e variamos $r$ no intervalo $[0.5: 0.8]$. Observamos a mesma coexistência com os dois atratores da Figura 2.7, ambos apresentando comportamento similar entre si. Inicialmente os atratores são regulares, duplicações de período levam o sistema ao comportamento caótico. Há ocorrência de janelas periódicas, no intervalo do parâmetro $r$ para os quais o sistema exibe caos.

Na Figura 2.10, apresentamos separadamente os atratores coexistentes da Figura 2.9, obtidos com o mesmo procedimento discutido na Figura 2.8, isto é, seguindo cada atrator. 


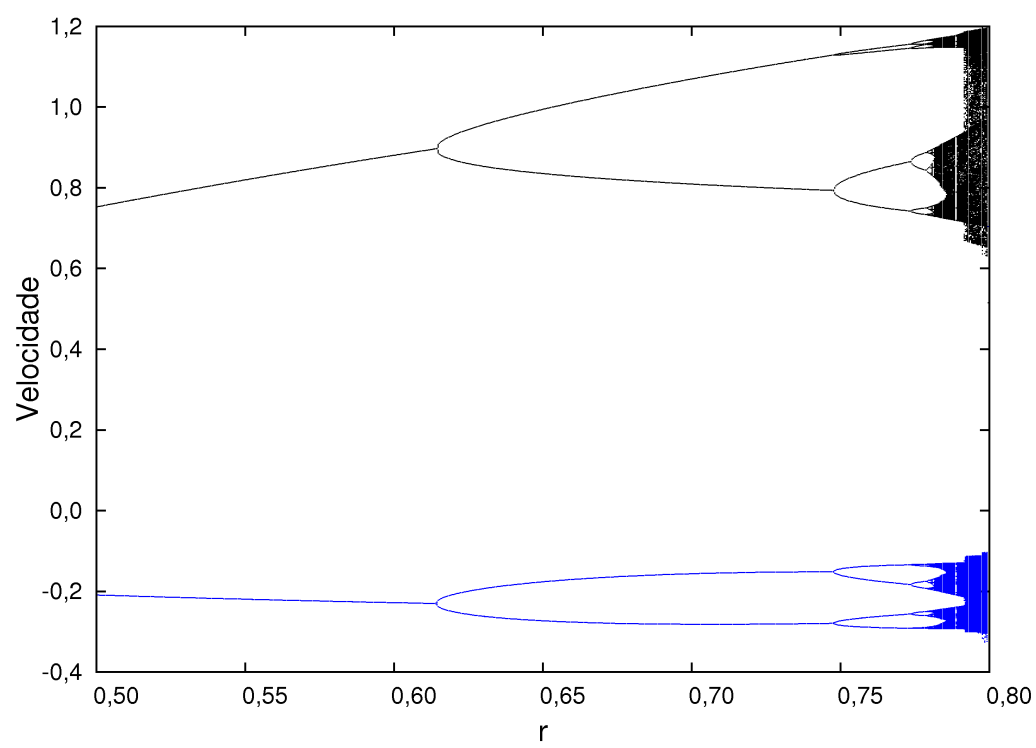

Figura 2.9: Diagrama de bifurcação para a velocidade tomada na seção estroboscópica, fixando $A=1.0$ e variando o coeficiente de restituição em 600 valores, com $\omega_{0}=1$ e $\nu=2$.
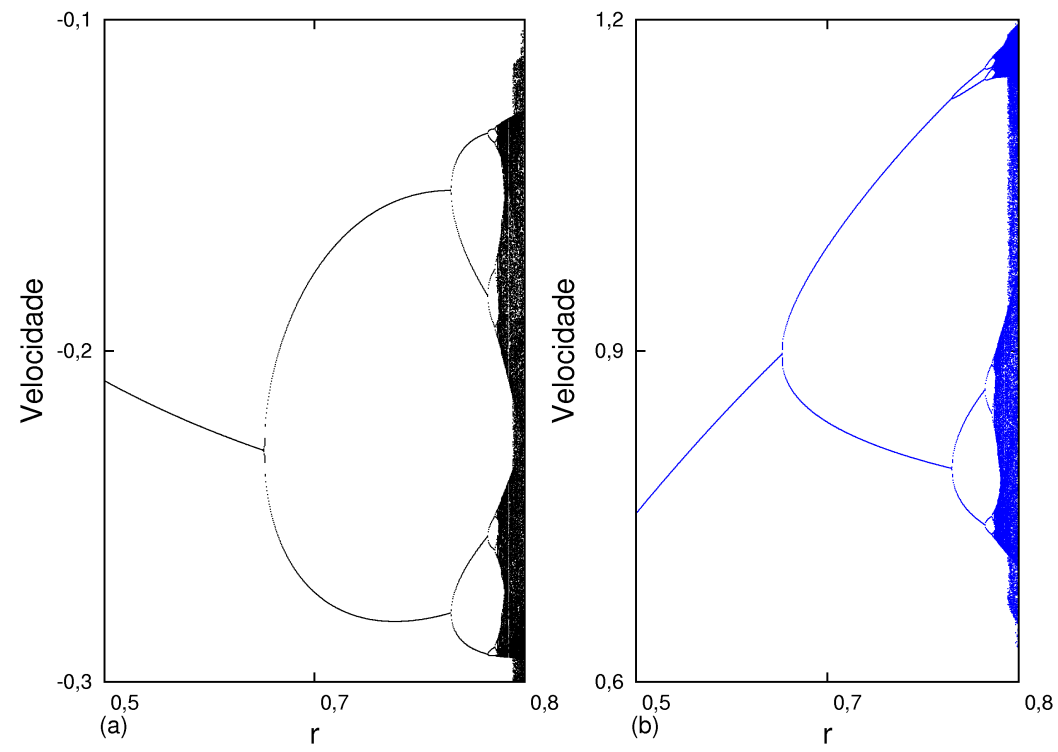

Figura 2.10: Diagrama de bifurcação obtido separadamente utilizando a técnica de seguir o atrator, para os mesmos parâmetros da Figura 2.9. (a) Atrator em preto na Figura 2.9. (b) Atrator em azul na Figura 2.9.

\subsection{Expoentes de Lyapunov}

Os expoentes de Lyapunov indicam a sensibilidade das soluções através da divergência ou convergência de uma função exponencial. Para expoentes de Lyapunov positivos, 
duas condições iniciais suficientemente próximas levam a soluções diferentes, indicando a sensibilidade dos sistema e consequentemente a solução caótica. Para expoentes de Lyapunov negativos, o sistema não exibe sensibilidade e as soluções são regulares.

A sensibilidade às condições iniciais deve ser avaliada para cada dimensão do sistema. Assim, os expoentes de Lyapunov são obtidos para cada dimensão e a caoticidade é avaliada observando os maiores expoentes de Lyapunov.

Na prática a obtenção dos expoentes de Lyapunov é bem conhecida para sistemas suaves, ou seja, sistemas cuja solução é conhecida continuamente em todos os pontos através de equações diferenciais ou de equações de diferenças (mapas) [33]. Em sistemas não-suaves, ou seja, com descontinuidades da solução, a obtenção dos expoentes de Lyapunov requer uma técnica especial [33]. Implementamos para o modelo par de impactos a técnica do mapa transcendental [40]. Este método consiste em interpretar a solução, contínua entre os impactos, como um mapa cujas iterações ocorrem a cada impacto. Assim obtemos os expoentes de Lyapunov para sistemas não-suaves da mesma forma que obtemos em mapas bidimensionais.

Dado um mapa bidimensional os expoentes de Lyapunov são obtidos, utilizando a matriz jacobiana, a partir da seguinte expressão [15]:

$$
\lambda_{j}=\lim _{N \rightarrow \infty} \frac{1}{N} \ln \left|\Delta_{j}^{N}\right|, j=1,2 .
$$

onde os $\left|\Delta_{j}^{N}\right|$ são os autovalores da matriz $M$ definida por:

$$
M=\prod_{n=1}^{N} J^{n}
$$

sendo $J$ a matriz jacobiana da $n$ - sima iteração do mapa. Na realização do produtório da matriz jacobiana pode ocorrer um problema numérico. Os elementos da matriz se tornam muito grandes causando sobrecarga de memória. Para resolver este problema escrevemos a matriz jacobiana em uma forma triangular. Assim o produtório da matriz é simplesmente o produto dos elementos da diagonal principal da matriz. Tal procedimento é obtido realizando uma rotação da matriz jacobiana com o auxílio de uma matriz rotação na forma: 


$$
T^{n}=\left[\begin{array}{cc}
\cos \left(\theta_{n}\right) & \operatorname{sen}\left(\theta_{n}\right) \\
-\operatorname{sen}\left(\theta_{n}\right) & \cos \left(\theta_{n}\right)
\end{array}\right]
$$

Obtemos os valores de $\theta$ que fornecem uma matriz triangular impondo a igualdade abaixo:

$$
T^{n+1^{-1}} J^{n} T^{n}=\left[\begin{array}{ll}
a_{n} & b_{n} \\
0 & c_{n}
\end{array}\right]
$$

resultando para $\theta$ :

$$
\begin{gathered}
\tan \left(\theta_{n+1}\right)=\frac{J_{22}^{n} \operatorname{sen}\left(\theta_{n}\right)-J_{21}^{n} \cos \left(\theta_{n}\right)}{J_{11}^{2} \cos \left(\theta_{n}\right)-J_{12}^{12} \operatorname{sen}\left(\theta_{n}\right)} \\
\theta_{0}=0
\end{gathered}
$$

O produto de matrizes na forma triangular é o produto dos elementos da diagonal principal e os autovalores da matriz produtória são seus elementos da diagonal principal. Utilizando a propriedade da função $\log$, a produtória transforma-se em uma somatória e os expoentes de Lyapunov são dados por:

$$
\begin{aligned}
& \lambda_{1}=\lim _{N \rightarrow \infty} \frac{1}{N} \sum_{n=1}^{N} \ln \left|a_{n}\right|, \\
& \lambda_{2}=\lim _{N \rightarrow \infty} \frac{1}{N} \sum_{n=1}^{N} \ln \left|c_{n}\right| .
\end{aligned}
$$

Os coeficientes $a_{n}$ e $c_{n}$ são obtidos a partir dos ângulos que fornecem a rotação:

$$
\begin{aligned}
& a_{n}=\left(J_{11}^{n} \cos \left(\theta_{n}\right)-J_{12}^{n} \operatorname{sen}\left(\theta_{n}\right)\right) \cos \left(\theta_{n+1}\right)-\left(J_{21}^{n} \cos \left(\theta_{n}\right)-J_{22}^{n} \operatorname{sen}\left(\theta_{n}\right)\right) \operatorname{sen}\left(\theta_{n+1}\right) \\
& c_{n}=\left(J_{21}^{n} \operatorname{sen}\left(\theta_{n}\right)+J_{22}^{n} \cos \left(\theta_{n}\right)\right) \cos \left(\theta_{n+1}\right)+\left(J_{11}^{n} \operatorname{sen}\left(\theta_{n}\right)+J_{12}^{n} \cos \left(\theta_{n}\right)\right) \operatorname{sen}\left(\theta_{n+1}\right)
\end{aligned}
$$

A matriz jacobiana $J$ do modelo par de impactos é dada por:

$$
J^{n}=\left[\begin{array}{cc}
\frac{\partial t_{n+1}}{\partial t_{n}} & \frac{\partial t_{n+1}}{\partial \dot{y}_{n}} \\
\frac{\partial \dot{y}_{n+1}}{\partial t_{n}} & \frac{\partial \dot{y}_{n+1}}{\partial \dot{y}_{n}}
\end{array}\right]
$$

As derivadas são obtidas no mapa transcendental discutido na Seção 2.1, deste capítulo: 


$$
\begin{gathered}
\frac{\partial t_{n+1}}{\partial t_{n}}=-\frac{1}{\dot{y}_{n+1}}\left[r \dot{y}_{n}+\ddot{e}\left(t_{n}\right)\left(t_{n+1}-t_{n}\right)\right] \\
\frac{\partial t_{n+1}}{\partial \dot{y}_{n}}=\frac{r}{\dot{y}_{n+1}}\left(t_{n+1}-t_{n}\right) \\
\frac{\partial \dot{y}_{n+1}}{\partial t_{n}}=-\frac{\partial t_{n+1}}{\partial t_{n}} \ddot{e}\left(t_{n+1}\right)+\ddot{e}\left(t_{n}\right) \\
\frac{\partial \dot{y}_{n+1}}{\partial \dot{y}_{n}}=-\frac{\partial t_{n+1}}{\partial \dot{y}_{n}} \ddot{e}\left(t_{n+1}\right)-r
\end{gathered}
$$

A precisão do método utilizado na obtenção dos expoentes de Lyapunov é verificada comparando o valor dos expoentes com diagramas de bifurcação para um conjunto de parâmetros.

Na Figura 2.11(a), obtivemos o diagrama de bifurcação para 600 valores da amplitude de perturbação, utilizando a técnica de seguir o atrator. Na Figura 2.11(b), mostramos o maior expoente de Lyapunov para os mesmos 600 valores da amplitude de forçamento. Notamos boa compatibilidade entre as figuras 2.11(a) e 2.11(b). Para intervalos periódicos na Figura 2.11(a), observamos expoentes de Lyapunov negativos na Figura 2.11(b). As bifurcações são acompanhadas por expoentes de Lyapunov nulos na Figura 2.11(b) e às janelas periódicas no diagrama de bifurcações correspondem a intervalos negativos dos expoentes de Lyapunov na Figura 2.11(b). Dada a independência entre as figuras 2.11(a) e 2.11(b), a concordância observada entre elas nos fornece segurança sobre o cálculo do expoente de Lyapunov.

Para complementar a discussão da Figura 2.11, realizamos para Figura 2.12 a mesma comparação entre os resultados obtidos com diagrama de bifurcação e o maior expoente de Lyapunov. Nesse caso, fixamos a amplitude do forçamento em $A=1.2$ e variamos o coeficiente de restituição $r$. Novamente verificamos boa concordância na identificação dos atratores nos diagramas observando as posições das janelas periódicas e das bifurcações. 


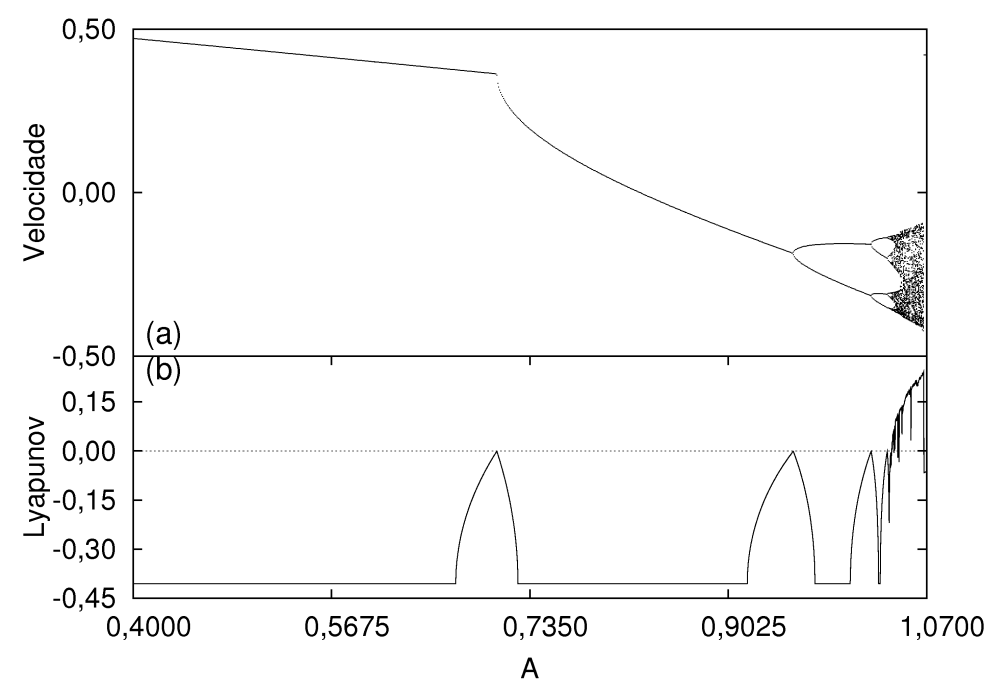

Figura 2.11: Comparação entre o diagrama de bifurcação e expoentes de Lyapunov para atratores no mesmo intervalo de parâmetros (a) Diagrama de bifurcação, obtido seguindo o atrator, variando amplitude do forçamento $A$ com $\omega_{0}=1, \nu=2$ e $r=0.7$ (b) Maior expoente de Lyapunov para os mesmos parâmetros de (a).

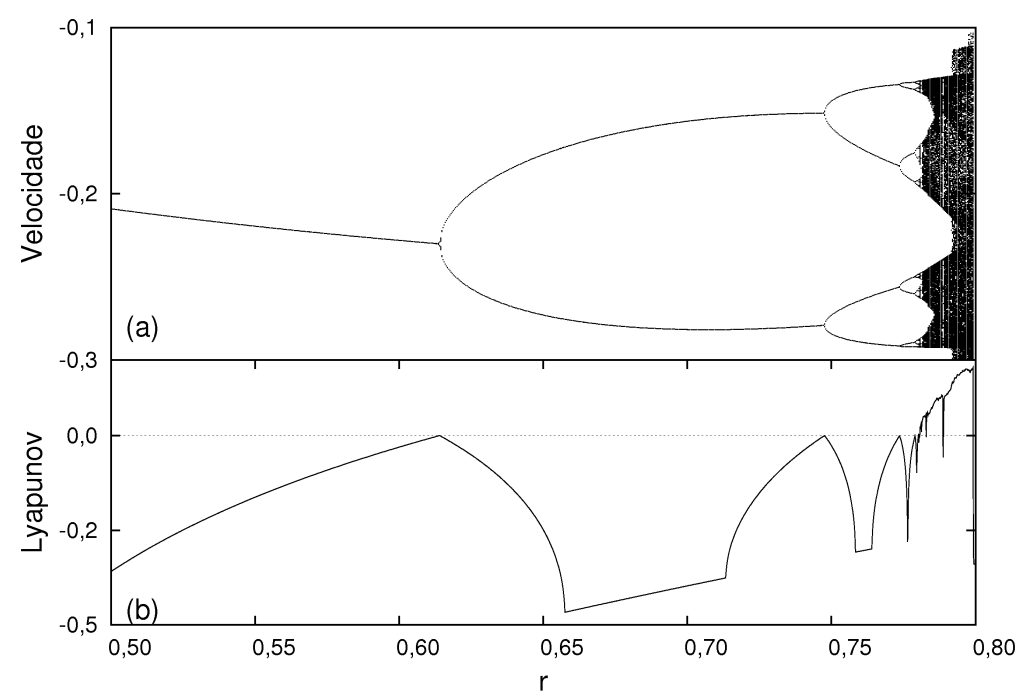

Figura 2.12: Comparação entre o diagrama de bifurcação e expoentes de Lyapunov para atratores no mesmo intervalo de parâmetros (a) Diagrama de bifurcação, obtido seguindo o atrator, variando o coeficiente de restituição $r$ com $\omega_{0}=1, \nu=2$ e $A=0.7$ (b) Maior expoente de Lyapunov para os mesmos parâmetros de (a). 


\subsection{Diagrama Bidimensional de Parâmetros}

Os parâmetros são importantes para relacionar o modelo matemático com a realidade física. Por exemplo, no sistema de equações diferenciais do circuito de Matsumoto-Chua os parâmetros são os valores dos elementos de circuito como os capacitores, indutores e resistências [48]. A evolução dos sistemas dinâmicos depende dos valores dos parâmetros. Em geral, a integração do sistema é realizada para parâmetros constantes. Em diagramas de parâmetros, como, diagrama de bifurcação, os atratores são obtidos para parâmetros diferentes.

Para estudar os efeitos da variação de parâmetros em sistemas dinâmicos devemos observar com essa variação a evolução das variáveis do sistema. As soluções podem mudar completamente suas características para valores diferentes dos parâmetros de controle. Por exemplo, na Seção 2.5, nos diagramas de bifurcação (diagrama unidimensional de parâmetros) variamos um parâmetro e observamos, para a velocidade, mudanças de estabilidade, rotas para o caos, coexistências de atratores, caos e janelas periódicas.

Alguns sistemas dinâmicos exibem os mesmo efeitos citados acima quando variamos dois parâmetros de controle. Na década de 80 surgiram os primeiros trabalhos com a variação de dois parâmetros do sistema com resultados avaliados em um mesmo diagrama [13]. Esses diagramas receberam o nome de espaço bidimensional de parâmetros. Nesse plano os eixos representam dois parâmetros do sistema. Para cada ponto desse espaço, o comportamento periódico ou caótico do sistema é classificado através do maior expoente de Lyapunov. Dependendo do valor do expoente de Lyapunov obtido para órbitas correspodentes aos respectivos parâmetros, o ponto é marcado em uma cor escolhida. Assim, obtém-se um degradê de cores variando desde expoentes de Lyapunov negativos (solução regular) até expoentes de Lyapunov positivos (solução caótica). Parâmetros exibindo soluções periódicas formam janelas periódicas no espaço de parâmetros [12].

No espaço bidimensional de parâmetros destaca-se a observação de janelas periódicas, cujo primeiro estudo sistemático ocorreu na década de 90 [12]. Inicialmente o estudo das janelas periódicas em espaços bidimensionais de parâmetros ocorreu em mapas. O espaço de parâmetros do mapa de Hénon foi investigado em [12]. Posteriormente, fenômenos 
semelhantes foram observados para fluxos [49-51].

As janelas periódicas no espaço de parâmetros possuem forma e fronteiras bem definidas. Essas estruturas ocupam áreas no espaço de parâmetros com um esqueleto central e quatro extremidades alongadas, com uma forma peculiar semelhante à de um camarão (shrimp-shaped) [52]. Os parâmetros do esqueleto central dos camarões possuem os expoentes de Lyapunov mais negativos do camarão. Essas estruturas são denominadas linhas superestáveis. Os camarões estão cercados por regiões de parâmetros exibindo caos. Há dois tipos de fronteira entre a região caótica e o camarão. Em um lado do camarão ocorre uma bifurcação do tipo tangente, o atrator caótico do lado externo dá origem ao atrator periódico do interior do camarão. No outro lado do camarão, a transição dos atratores periódicos para o caos é feita por duplicação de período.

Na Figura 2.13(a) mostramos uma região do espaço dos parâmetros $A$ e $r$ do modelo par de impactos. Nesse diagrama, marcamos em amarelo os pontos correspondentes a parâmetros que possuem expoentes de Lyapunov positivos, ou seja, para os quais o sistema exibe caos. Notamos, em verde a janela periódica, em forma de camarão, com linha superestável em azul. Nessa figura notamos também outros camarões alinhados com o principal. Discutiremos adiante que diferentes janelas se dispõem paralelamente no espaço de parâmetros. Na Figura 2.13(b), apresentamos uma ampliação do camarão, para ressaltar a linha superestável (azul) em seu interior. Na confecção de diagramas bidimensionais de parâmetros descontamos 60000 impactos do sistema referentes ao transitório inicial das soluções. A faixa desenhada em preto na Figura 2.13(b) na posição de $r=0.78$ indica os valores de parâmetros em um diagrama de bifurcação para este valor de $r$, variando o parâmetro $A$ ao longo dessa faixa apresentado na figura Figura 2.14.

Na Figura 2.14(a), mostramos o diagrama de bifurcação, com $r=0.78$, em função da amplitude do forçamento $A$ ao longo da faixa desenhada na Figura 2.13(b). Notamos no diagrama de bifurcação a perda de estabilidade do atrator caótico, a criação do camarão em uma bifurcação tangente e a transição para o caos através de dobramentos de períodos. Na Figura 2.14(b), apenas para melhor visualização do dobramento de período, realizamos uma ampliação de um dos ramos da Figura 2.14(a)

As janelas periódicas no espaço de parâmetros aparecem alinhadas em uma sequência 


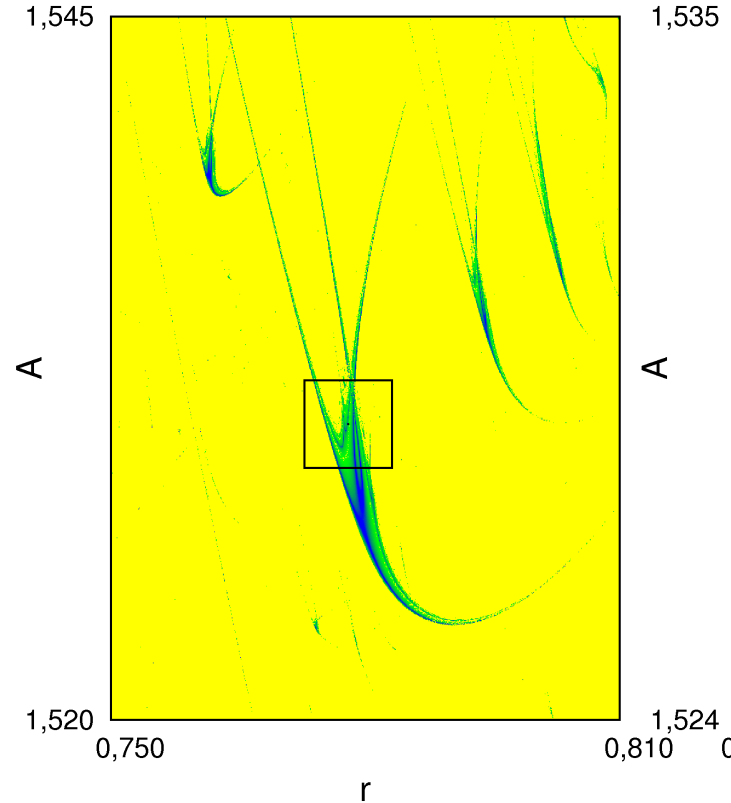

(a)

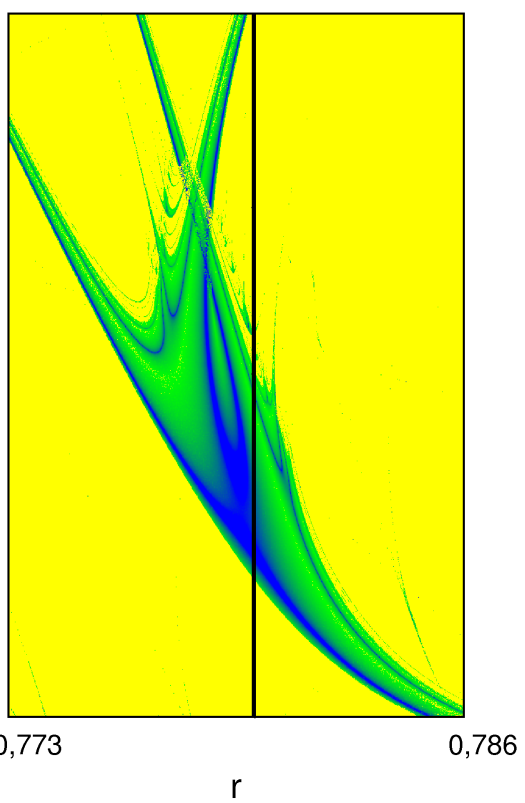

(b)

Figura 2.13: Espaço de parâmetros para uma grade $800 \times 800$ da amplitude do forçamento pelo coeficiente de restituição. (a) $\omega_{0}=1$ e $\nu=2$. (b) Ampliação da região assinalada em (a) a faixa preta indica os parâmetros do diagrama de bifurcação da Figura 2.14 .
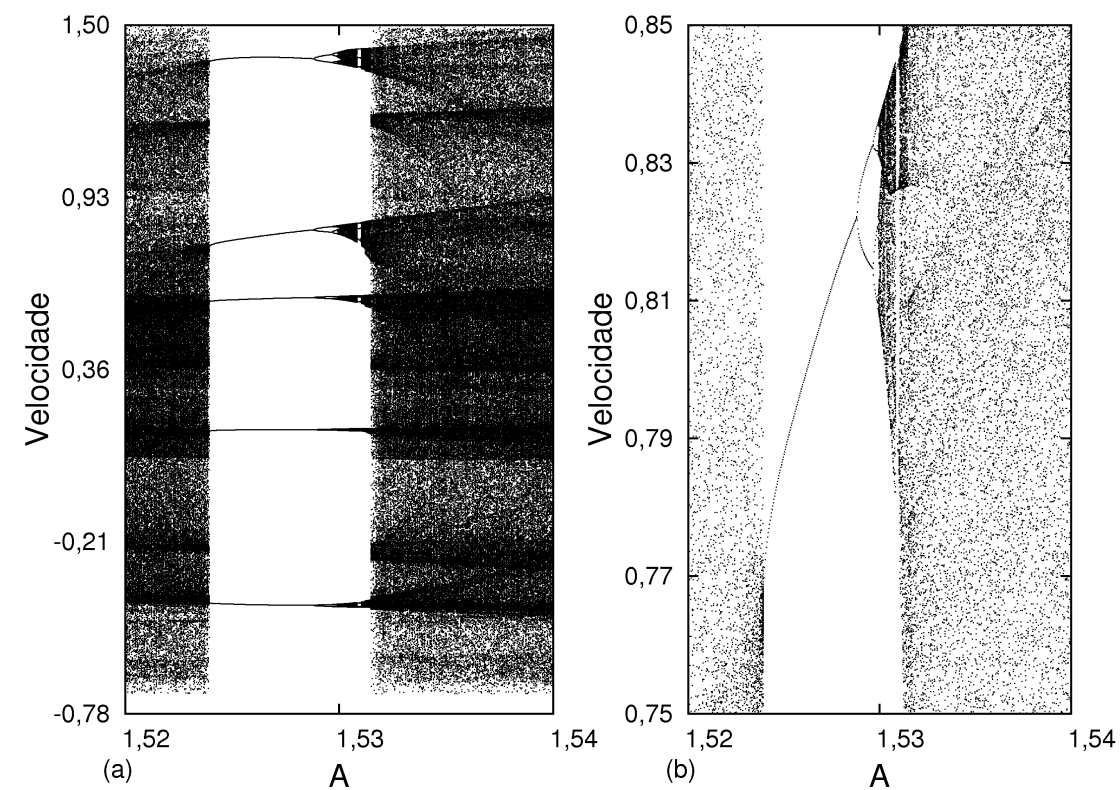

Figura 2.14: (a) Diagrama de bifurcação para parâmetros que interseccionam um camarão no espaço de parâmetros, $\omega_{0}=1, \nu=2$ e $r=0.78$ (b) Ampliação para ilustrar a rota para o caos. 
com uma hierarquia de períodos [52]. Na Figura 2.15(a), mostramos o alinhamento de camarões estendendo-se até o limite de precisão para visualização da figura. A análise da Figura 2.15(b) sugere que entre dois camarões consecutivos há outros camarões alinhados com o principal.

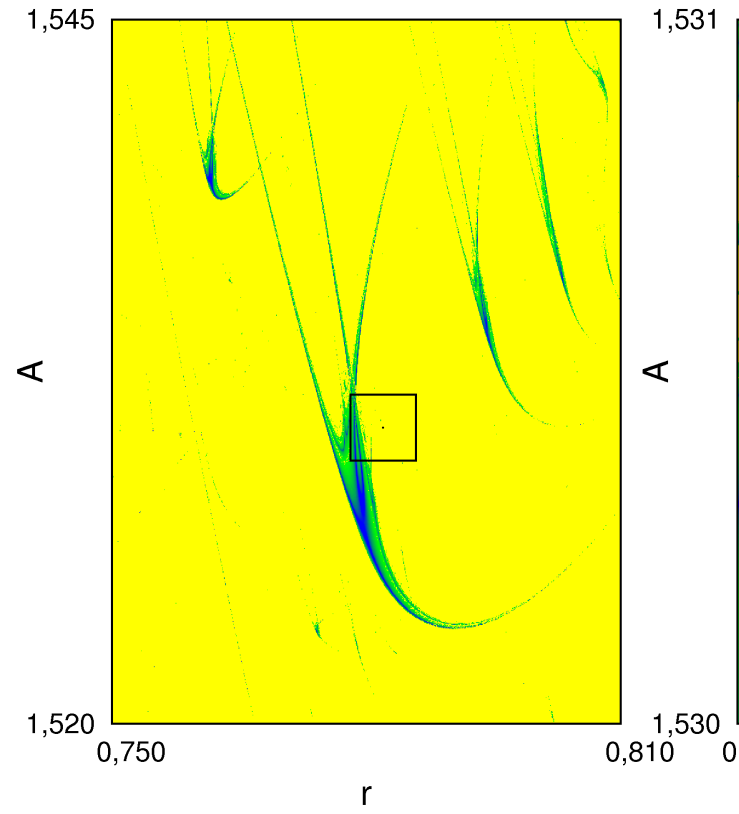

(a)

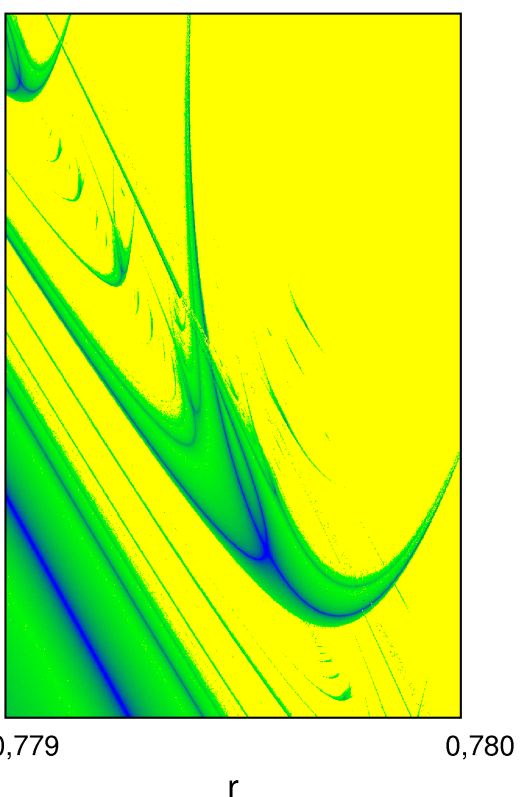

(b)

Figura 2.15: (a) Espaço de parâmetros ilustrando a estrutura de repetição dos camarões, com $\omega_{0}=1 \mathrm{e}$ $\nu=2$. (b) Ampliação assinalada em (a). 


\subsection{Bacias de Atração}

Sistemas dinâmicos não lineares frequentemente apresentam mais de uma solução para o mesmo conjunto de parâmetros. Para determinar para qual atrator a solução é atraída, é necessário seguir a trajetória a partir das condições iniciais. As bacias de atração fornecem o conjunto de condições iniciais que evoluem para os atratores do sistema. É comum a coexistência de atratores caóticos com bacias de atração com fronteiras complicadas, com dificuldade em determinar condições iniciais de um dos atratores [33].

A obtenção das bacias de atração é feita através de uma grade de condições iniciais em um espaço bidimensional. Para cada condição inicial, a solução do sistema é obtida, verificando em qual atrator o sistema se encontra e marcando as condições que levam a cada atrator com uma cor própria.

Para o sistema par de impactos, escolhemos uma coexistência de atratores para diferentes valores da amplitude de forçamento e do coeficiente de restituição. Mostramos na Figura 2.16 um diagrama de bifurcação ilustrando a coexistência e o intervalo do parâmetro $A$ para o qual esta existe.

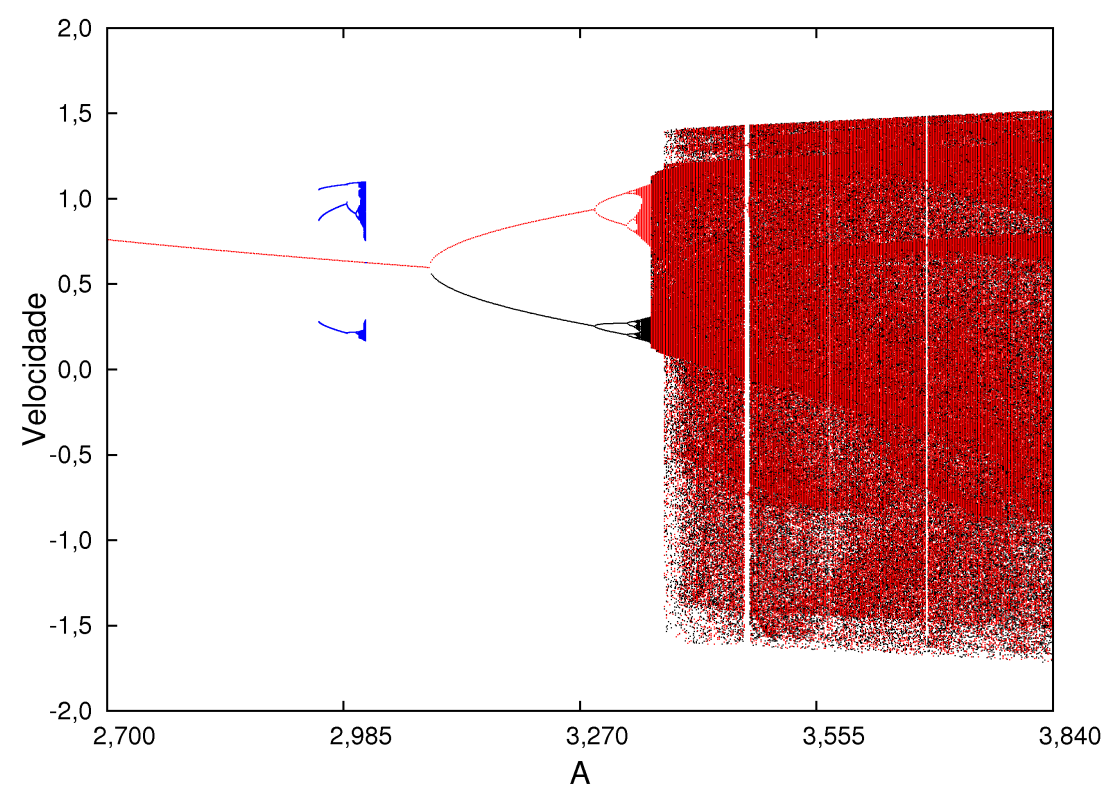

Figura 2.16: Diagrama de bifurcação ilustrando coexistências de atratores no sistema par de impactos para os parâmetros $r=0.8, \omega_{0}=1$ e $\nu=2$. 
Obtivemos as bacias de atração para diferentes parâmetros. Com isso, mostramos a mudança de comportamento das bacias de atração quando variamos os parâmetros de controle do sistema.

Na Figura 2.17(a) mostramos as bacias de atração da coexistência de dois atratores periódicos observados para $A=3.2$ no diagrama de bifurcação da Figura 2.16. As bacias de atração estão marcadas em preto, vermelho e branco. Em preto e vermelho são as bacias dos atratores da Figura 2.16 para $A=3.2$. Em branco mostramos a bacias de dois pontos fixos do sistema par de impactos, equivalentes a massa presa nas paredes da caixa. Na Figura 2.17(b) mostramos as bacias de atração de dois atratores caóticos para $A=3.35$.

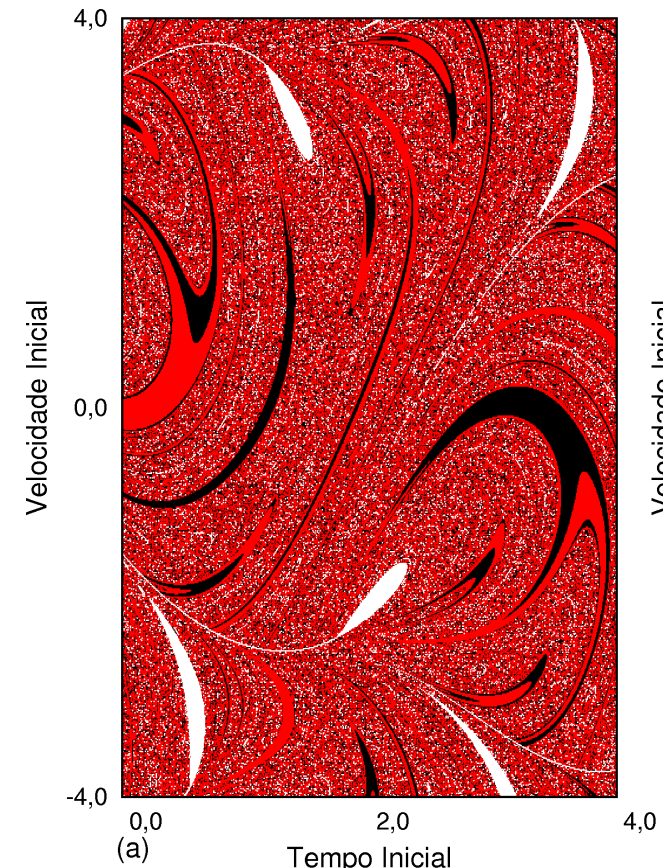

(a) Tempo Inicial

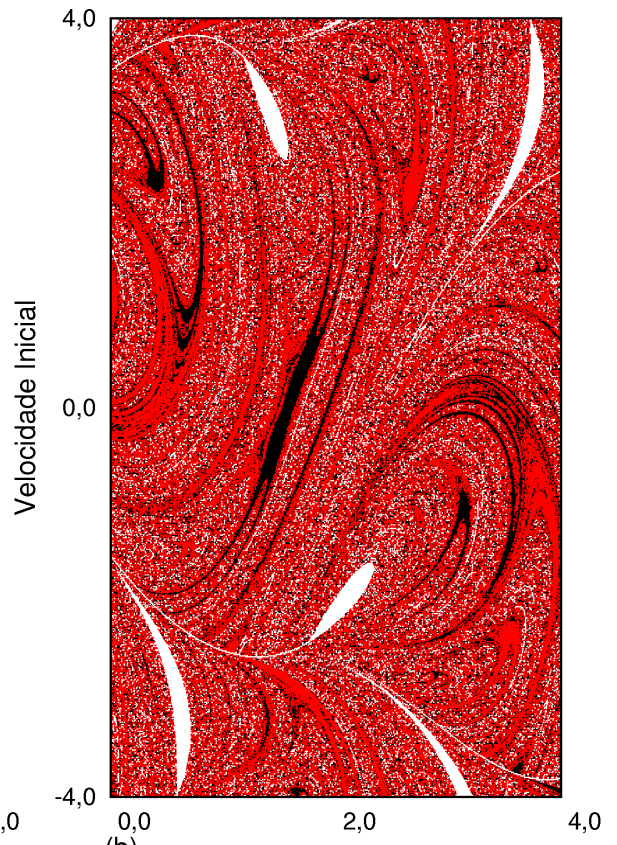

(b) Tempo Inicial

Figura 2.17: (a) Bacia de atração da coexistência periódica da Figura 2.16 para $\omega_{0}=1, \nu=2, r=0.8 \mathrm{e}$ $A=3.2$. (b) Bacia de atração de coxistência caótica da Figura 2.16 para os mesmoas parâmetros de (a) com $A=3.35$. 


\section{Capítulo 3}

\section{Surgimento de Janelas Periódicas no Espaço de Parâmetros}

No capítulo 2, apresentamos o sistema par de impactos e observamos vários fenômenos comuns na sua dinâmica, como formação de atratores periódicos e caóticos, vários tipos de bifurcação, coexistência de atratores e estruturas no espaço de parâmetros. Neste capítulo, investigamos como este oscilador com impactos responde ao controle de caos, especificamente, a uma perturbação paramétrica.

Conforme discutido na introdução, este método consiste em pequenas alterações harmônicas nos parâmetros do sistema e não é realimentado, ou seja, não requer intervenções corretivas adicionais para manter a estabilidade da órbita [20]. Para o modelo considerado, aplicamos uma perturbação senoidal com amplitude pequena em relação à amplitude do forçamento do sistema. Observamos, no espaço de parâmetros do sistema, a periodicidade das órbitas controladas. Pela primeira vez na literatura mostramos que o controle ocorre para um conjunto de parâmetros que formam novas janelas periódicas (camarões), com forma similar às janelas previamente existentes em sua vizinhança.

\subsection{Dinâmica Sem Perturbação}

No capitulo 2 mostramos a dependência dos atratores do sistema a variações dos parâmetros $A$ (amplitude do forçamento original do sistema) e $r$ (coeficiente de restituição 
dos impactos). Fixamos a freqüência do sistema em $\omega_{0}=1$, o comprimento da caixa em $\nu=2$, e descontamos um transiente de 50000 impactos, nas trajetórias, para obter os atratores. Para estudar como o sistema não perturbado responde à variação de parâmetros, utilizamos diagramas de bifurcação. Nesses diagramas é possível observar alterações dos atratores, rotas para o caos, janelas periódicas e coexistências de atratores.

Na Figura 3.1 mostramos um diagrama de bifurcação para o modelo par de impactos. No intervalo de parâmetros considerado, observamos a coexitência de dois atratores marcados em azul e vermelho. Ambos apresentam comportamento similar, presença de janelas periódicas imersas em intervalos de caos, bifurcações tangentes e dobramento de períodos. Conforme discutimos no capítulo 2, a presença de bifurcações tangentes e dobramentos de período é típica da existência de camarões no espaço de parâmetros.

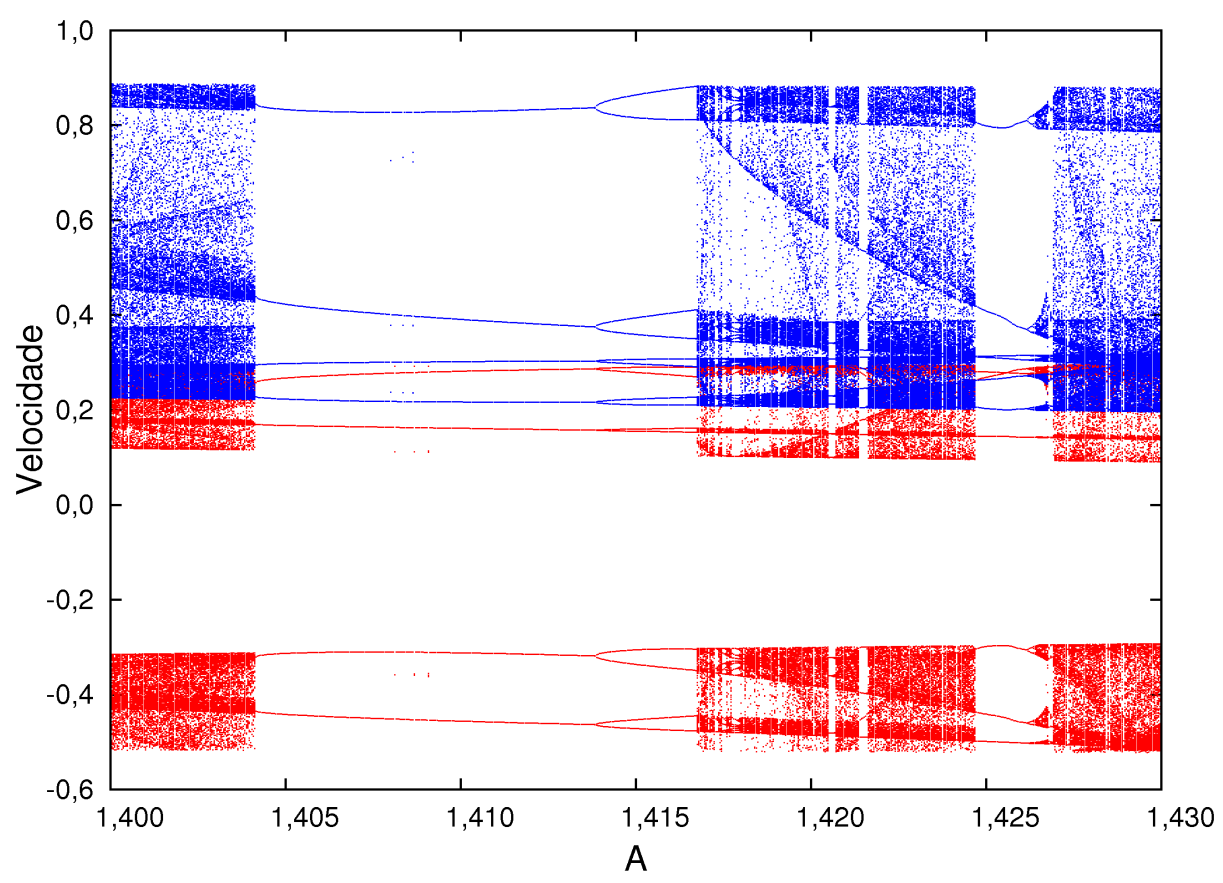

Figura 3.1: Diagrama de bifurcação para a velocidade tomada, para várias condições iniciais, em um mapa estroboscópico (Tempo $-2 \pi$ ), variando $A$, mantendo $r=0.525, \omega_{0}=1, \nu=2$.

O maior expoente de Lyapunov de um sistema dinâmico fornece a informação quanto à periodicidade ou caoticidade do sistema. O cálculo desse expoente de Lyapunov é fundamental para o tipo de análise que pretendemos realizar nesta seção, pois na obtenção do espaço de parâmetros utilizamos o valor do maior expoente de Lyapunov para marcar 
a cor do atrator caótico ou periódico associada a cada parâmetro.

Para verificar a precisão do valor obtido para o expoente, mostramos na Figura 3.2, para o mesmo intervalo do parâmetro $A$, o diagrama de bifurcação para o atrator em vermelho, da Figura 3.2, e calculamos seu correspondente expoente de Lyapunov. O cálculo foi realizado com o mapa transcendental introduzido no capítulo 2.

Comparando as Figuras 3.2(a) e 3.2(b), observamos a concordância quanto à periodicidade ou caoticidade dos atratores, pois a indicação do atrator no diagrama de bifurcação é reproduzido pelo expoente de Lyapunov na Figura 3.2(b). $(\lambda<0$ para atratores periódicos e $\lambda>0$ para caóticos).

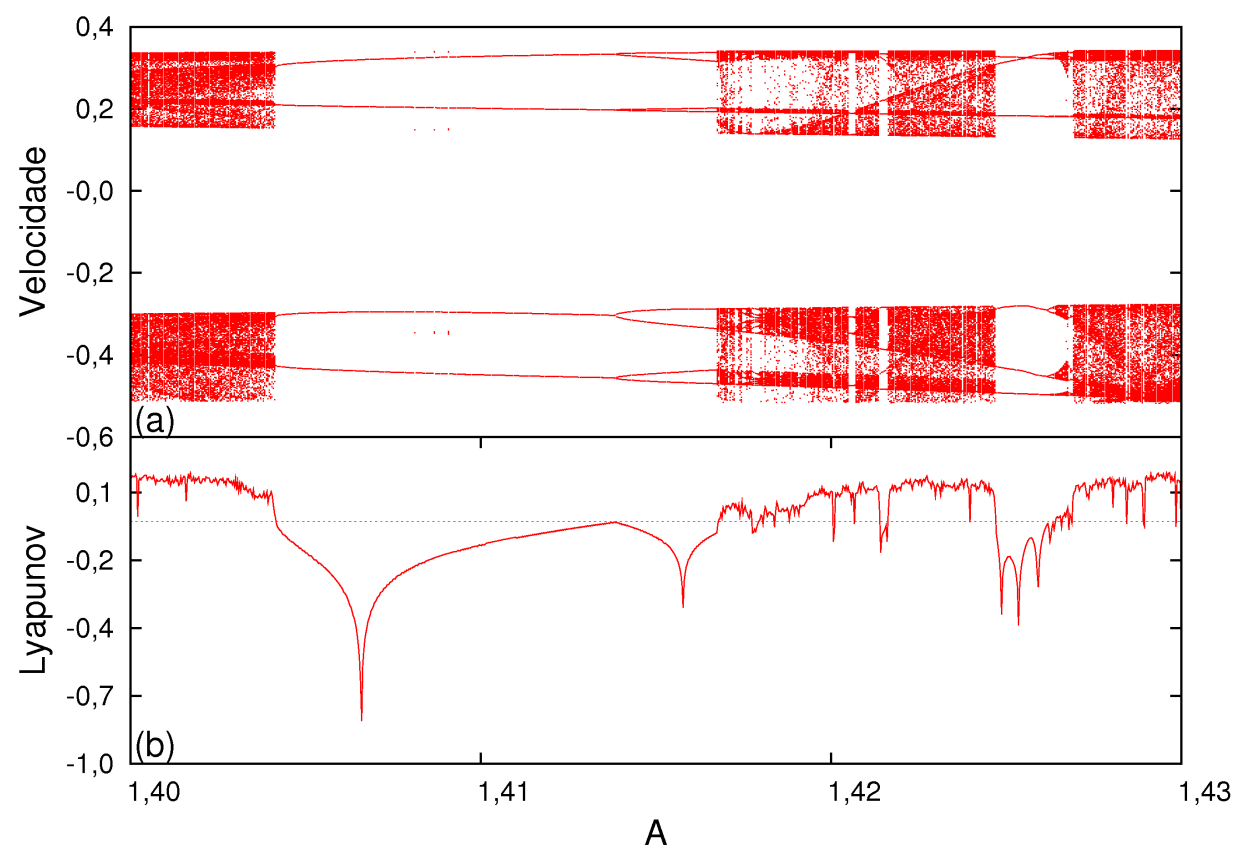

Figura 3.2: (a) Diagrama de bifurcação para a velocidade tomada, seguindo o atrator vermelho, em um mapa estroboscópico (Tempo $-2 \pi$ ), variando $A$, mantendo $r=0.525, \omega_{0}=1, \nu=2$. (b) Expoentes Lyapunov obtidos para mesmos parâmetros de (a) utilizando o método do mapa transcendental.

Na Figura 3.3, apresentamos, no mesmo intervalo do parâmetro $A$, o diagrama de bifurcação para o atrator em azul, da Figura 3.1, e o expoente de Lyapunov. Novamente verificamos concordância entre as indicações dos expoentes de Lyapunov e o diagrama de bifurcação. 


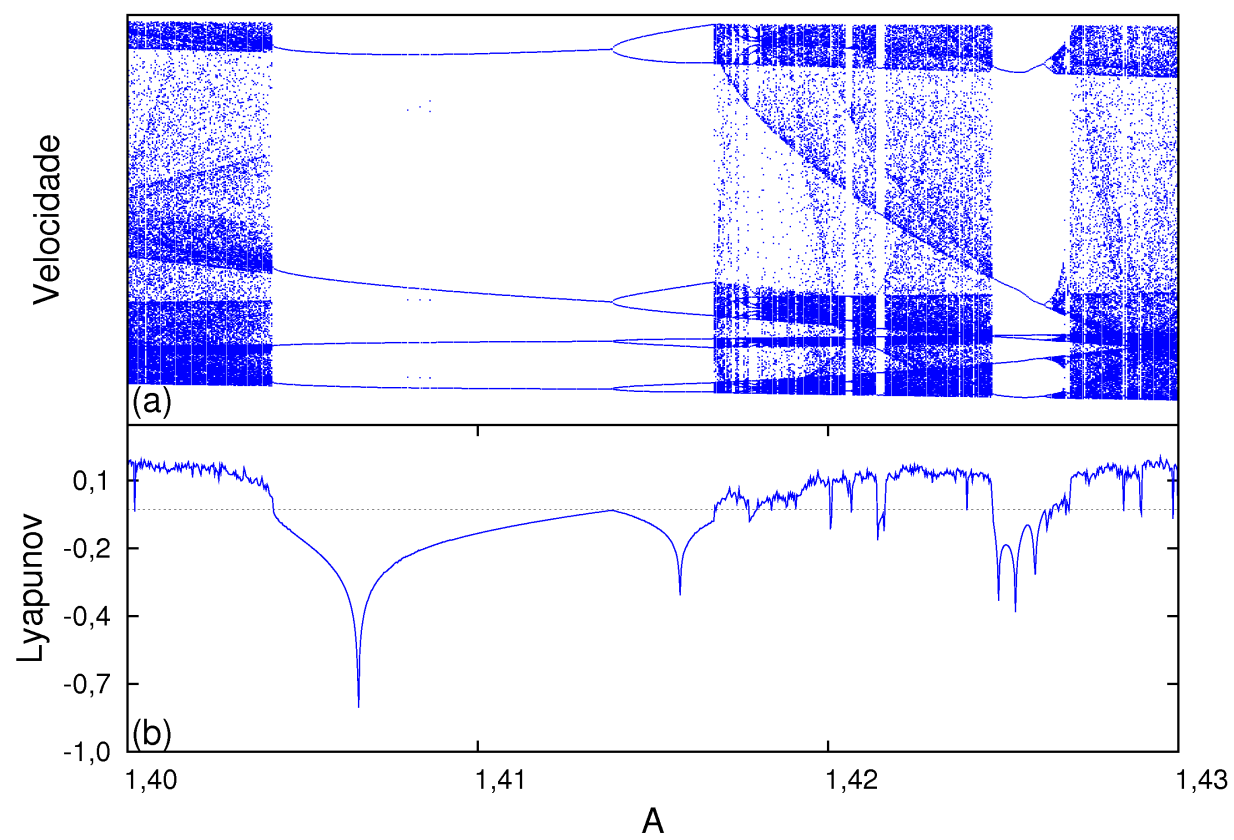

Figura 3.3: (a) Diagrama de bifurcação para a velocidade tomada, seguindo o atrator azul, em um mapa estroboscópico (Tempo $-2 \pi$ ), variando $A$, mantendo $r=0.525, \omega_{0}=1, \nu=2$. (b) Expoentes Lyapunov obtidos para mesmos parâmetros de (a) utilizando método do mapa transcendental.

Nas Figuras 3.2 e 3.3, apresentamos separadamente os dois atratores da coexistência observada na Figura 3.1, e os respectivos expoentes de Lyapunov. Para isso, utilizamos a técnica de seguir o atrator, ou seja, escolhemos como condições iniciais utilizadas para obter um atrator, com um dado $A$, a posição e a velocidade do atrator para o valor de $A$ anterior.

Para o controle, escolhemos, na Figura 3.1, um valor do parâmetro $A$, para o qual o sistema exibe comportamento caótico. Este é um valor apenas de referência, já que estamos interessados no controle de caos para conjuntos de parâmetros $A$ e $r$. Apresentamos na Figura 3.4 o atrator caótico, a ser controlado, em um mapa estroboscópico (Tempo- $2 \pi)$. Nessa figura a velocidade e a posição são tomadas sempre que o tempo é múltiplo de $2 \pi$. 


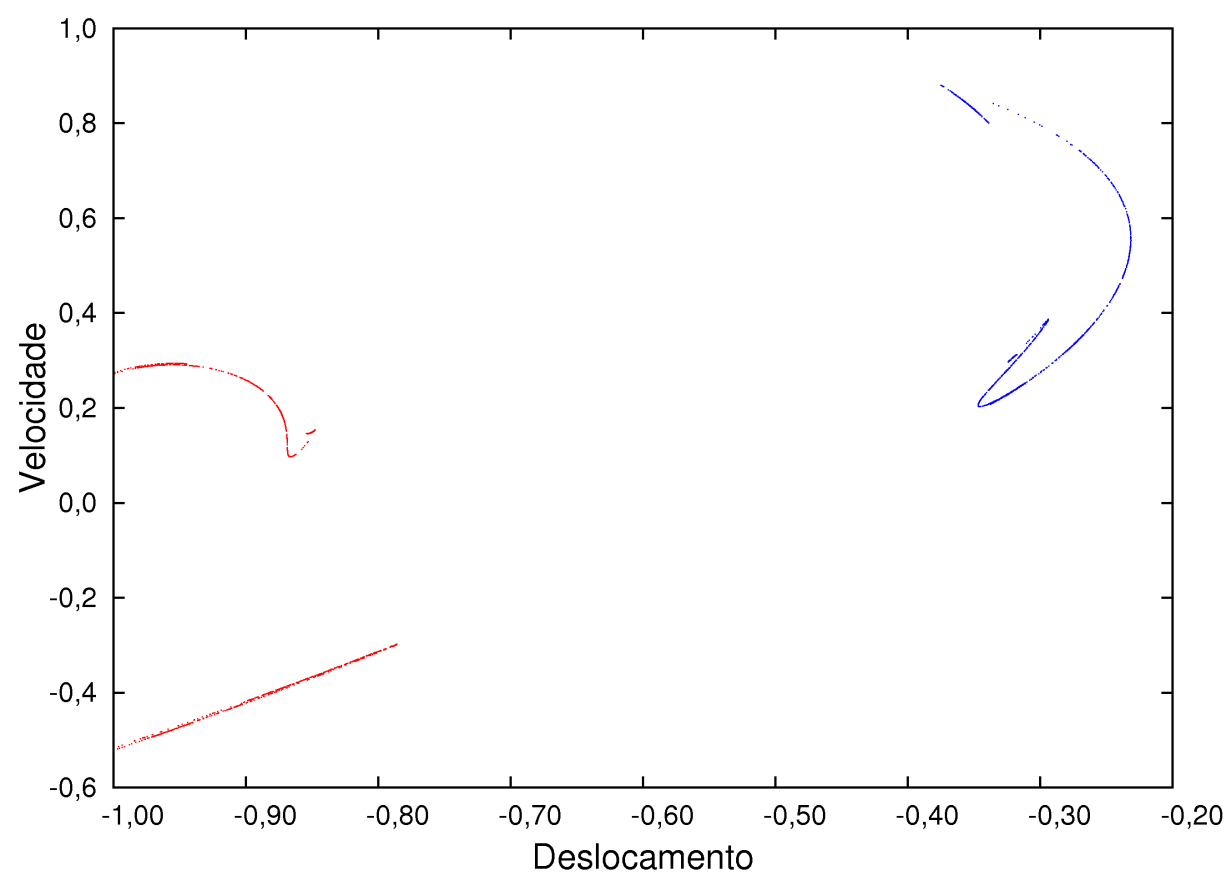

Figura 3.4: Atrator caótico a ser controlado obtido através de um mapa estroboscópico (Tempo $-2 \pi)$, para $A=1.423, r=0.525, \omega_{0}=1$ e $\nu=2$.

\subsection{Perturbação Paramétrica}

O sistema par de impactos possui um forçamento natural com amplitude $A$ e coeficiente de restituição $r$. Conforme visto no capítulo 2, os parâmetros $A$ e $r$, quando variados, geram bifurcações e janelas periódicas. Essa é uma motivação para a amplitude $A$ do forçamento natural ser alvo da perturbação paramétrica. Como condição impomos que a amplitude da perturbação deve ser pequena quando comparada à amplitude do forçamento natural do sistema $[18,19,53]$.

Para implementar a perturbação, inserimos no forçamento original do sistema um segundo termo com pequena amplitude $B$. Assim o forçamento do sistema passa a descrito pela seguinte função:

$$
e(t)=A \sin \left(\omega_{0} t\right)+B \sin (\omega t)
$$

sendo $B<<A$.

Para mostrar a eficiência da variação da amplitude $B$ da perturbação no controle de 
caos, fixamos os demais parâmetros do sistema nos valores do atrator caótico da Figura 3.4, e obtemos um diagrama de bifurcação da velocidade em função amplitude da perturbação $B$, escolhendo $\omega=0.5$. Neste diagrama a velocidade é tomada em um mapa estroboscópico $($ Tempo $-2 \pi)$ para o intervalo considerado de $B$. Observamos a coexistência já comentada na Figura 3.1, a presença de janelas periódicas e, à medida que aumentamos o valor da amplitude da perturbação $B$, obtemos órbitas controladas com períodos menores em relação a valores menores de $B$.

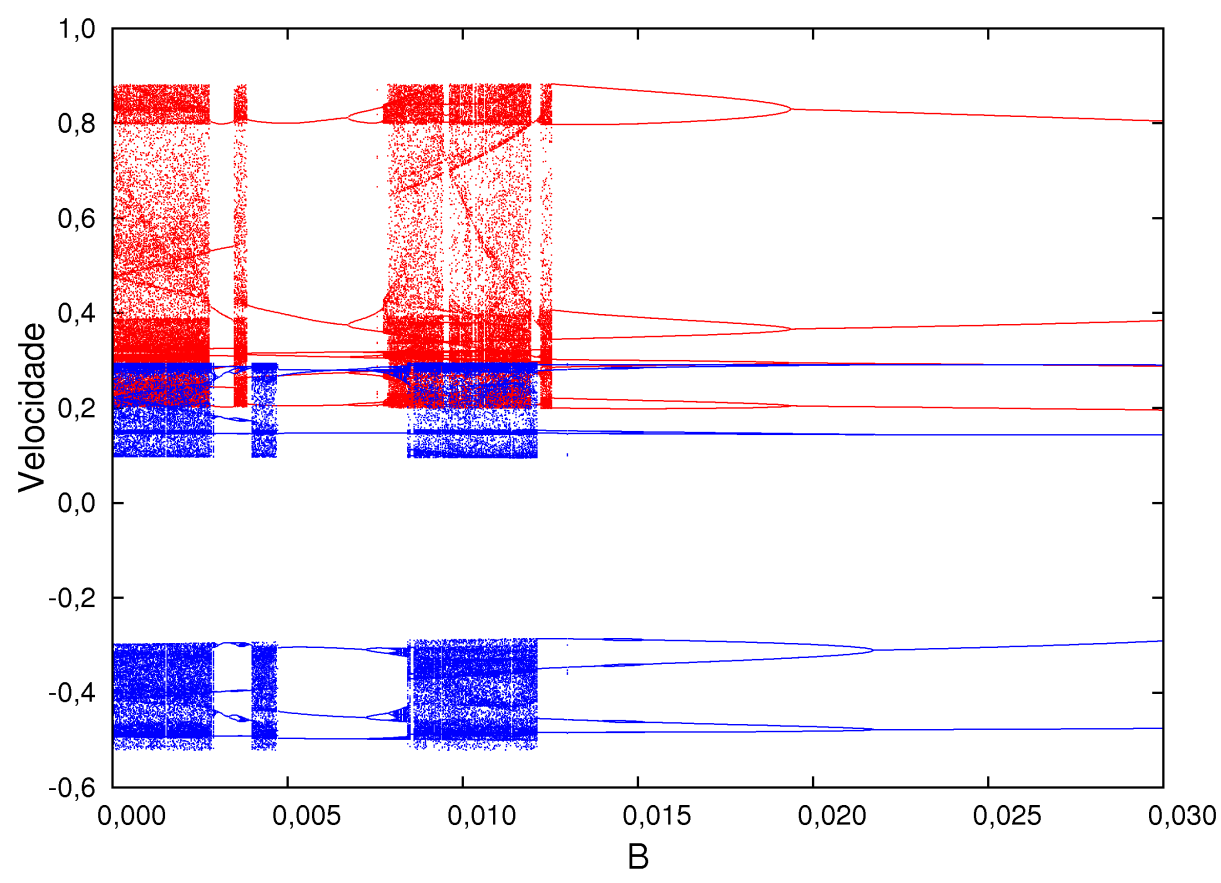

Figura 3.5: Diagrama de bifurcação para a velocidade tomada em um mapa estroboscópico (Tempo $-2 \pi$ ), variando $B$, mantendo $A=1.423, r=0.525, \omega_{0}=1, \nu=2$. A amplitude da perturbação nula, $B=0$, correponde ao atrator da Figura 3.4

Para mostrar a precisão do cálculo do expoente de Lyapunov com a perturbação, obtivemos o expoente de Lyapunov para cada atrator da Figura 3.5.

Na Figura 3.6, mostramos os valores da velocidade para o atrator vermelho em função da amplitude do forçamento $B$ e o respectivo expoente de Lyapunov.

Na Figura 3.7, apresentamos a velocidade e o respectivo expoente de Lyapunov do atrator azul, destaca-se nas Figuras 3.6 e 3.7, a concordância entre método do mapa transcendental para obtenção dos expoentes Lyapunov e os diagramas de bifurcação em 


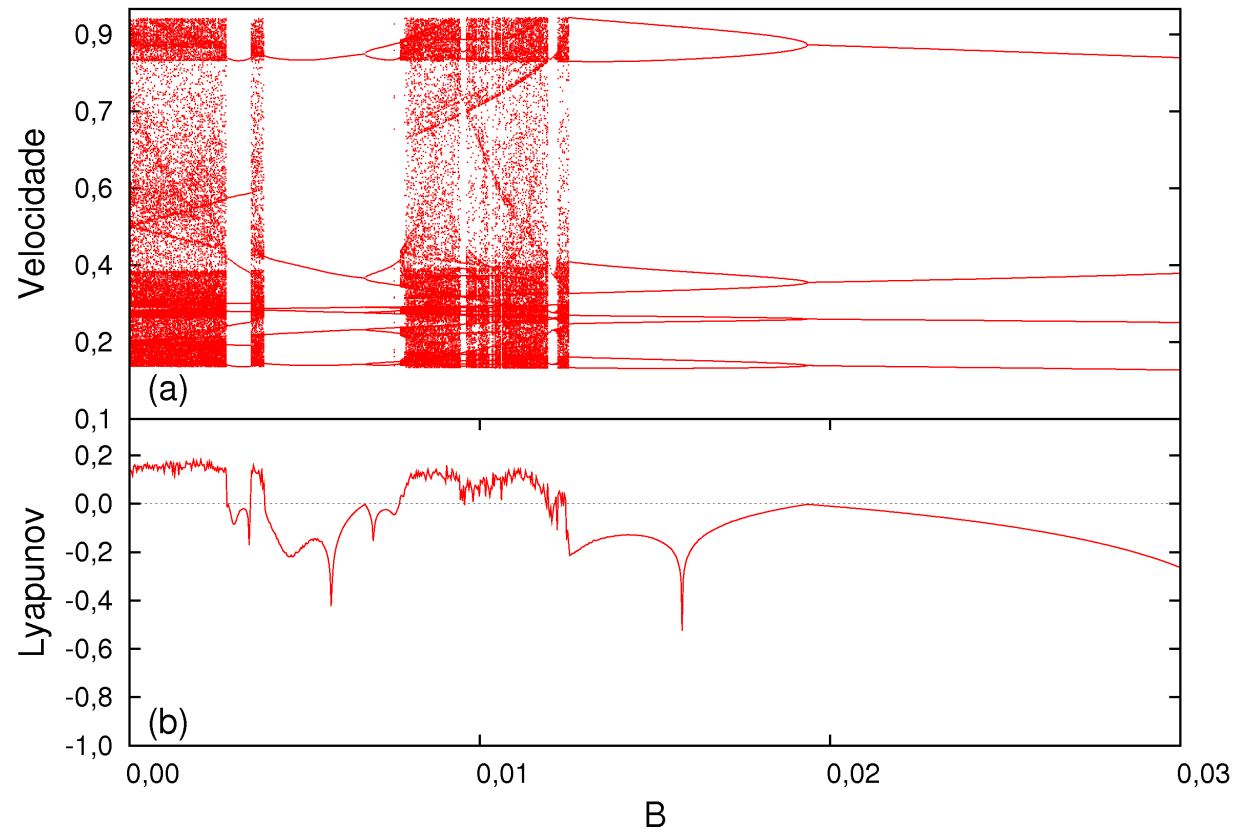

Figura 3.6: (a) Diagrama de bifurcação para a velocidade tomada, seguindo o atrator vermelho, em um mapa estroboscópico (Tempo $-2 \pi$ ), variando $B$, mantendo $A=1.523, r=0.525, \omega_{0}=1, \nu=2$. (b) Expoentes Lyapunov obtidos para mesmos parâmetros de (a) utilizando método do mapa transcendental.

função da amplitude de perturbação $B$.

Mostrada a possibilidade de controle pela variação da amplitude $B$ da perturbação, verificamos na Figura 3.8 quais os melhores valores para a freqüência da perturbação. Fixamos os parâmetros $(r, A)$ do sistema nos valores do atrator caótico da Figura 3.4. Para a amplitude $B$ da perturbação fixamos um valor que conduz a um atrator periódico previamente observado (para $B=0$ ) na Figura 3.3. Assim construímos um diagrama bidimensional de parâmetros de $\omega_{0}$ (frequência de forçamento natural) por $\omega$ (frequência do forçamento adicional) e verificamos as combinações dessas frequências que levam ao controle do atrator caótico escolhido. Conforme discutido no capitulo 2, o diagrama bidimensional de parâmetros é obtido marcando a cor que, pela escala da figura, corresponde ao valor do maior expoente de Lyapunov. Com esse tipo de diagrama verificamos para que combinação das frequências o sistema exibe caos ou é periódico.

Na Figura 3.8, observamos retas cuja inclinação nos fornece uma relação entre a frequência original e a frequência da perturbação. Assim, concluímos que o controle ocorre 


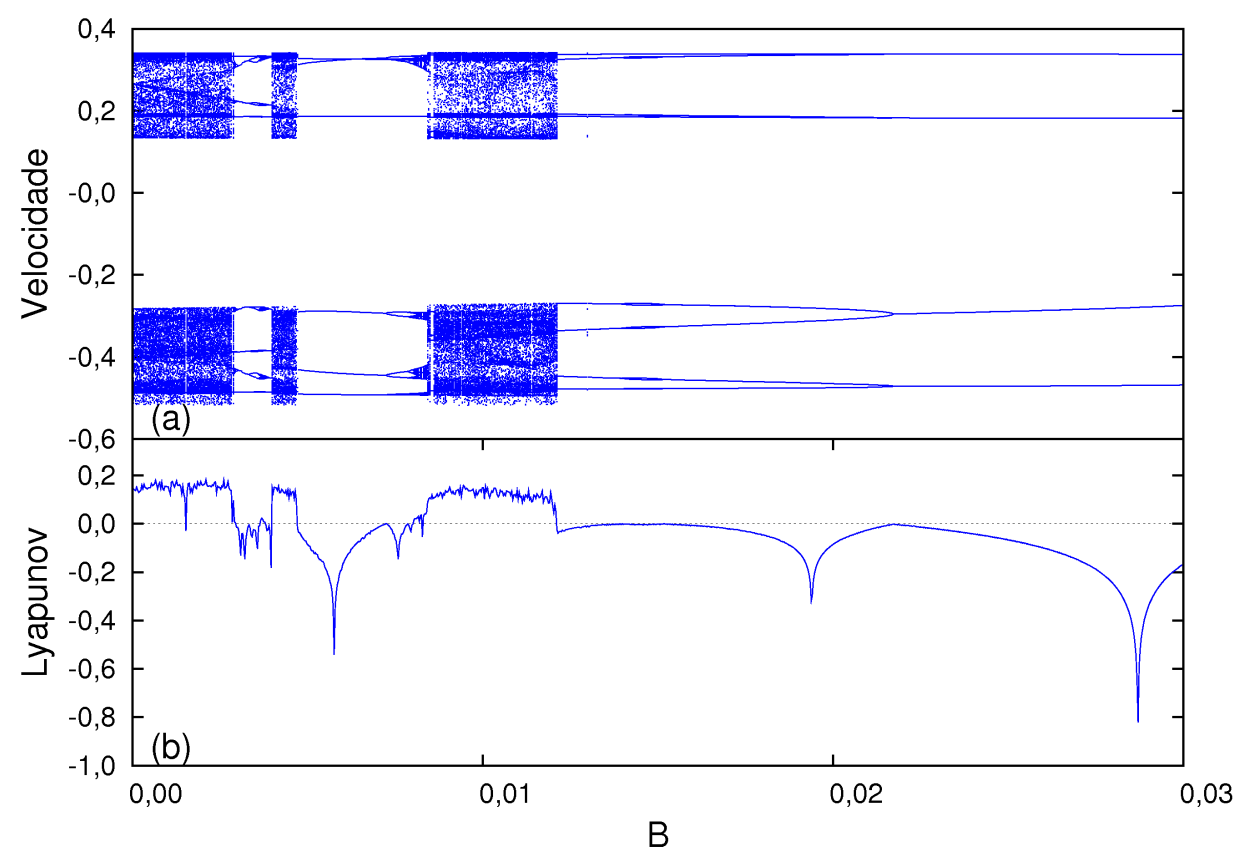

Figura 3.7: (a) Diagrama de bifurcação para a velocidade tomada, seguindo o atrator azul, em um mapa estroboscópico (Tempo $-2 \pi$ ), variando $B$, mantendo $A=1.523, r=0.525, \omega_{0}=1, \nu=2$. (b) Expoentes Lyapunov obtidos para mesmos parâmetros de (a) utilizando método do mapa transcendental.

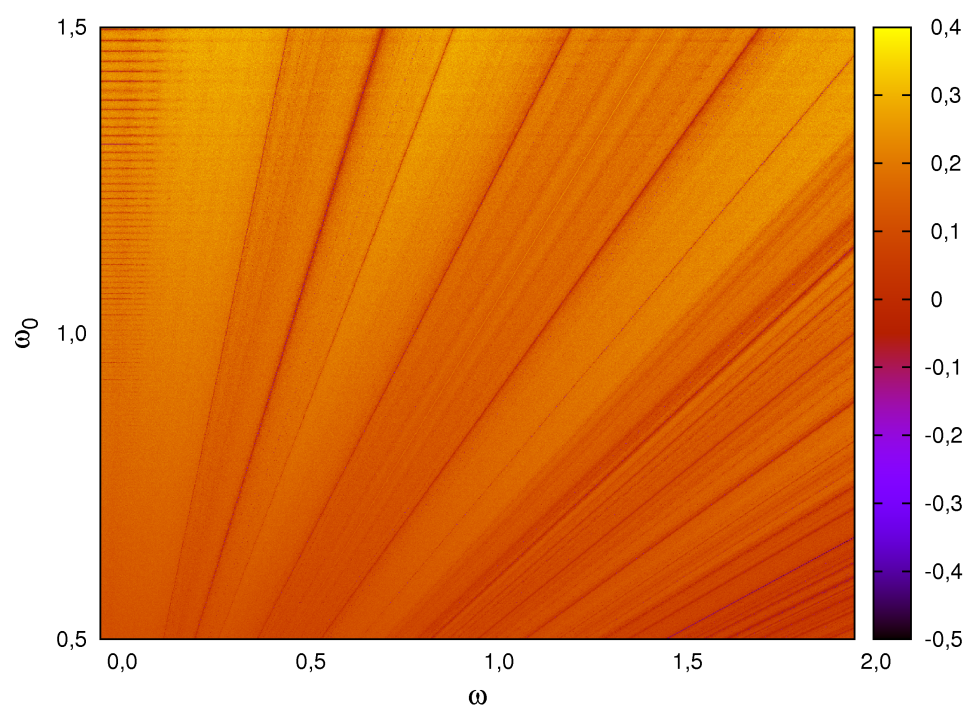

Figura 3.8: Espaço bidimensional de parâmetros para $\omega_{0}$ e $\omega$, obtido através dos expoentes de Lyapunov, para os parâmetros $A=1.423, B=0.0048, r=0.525$ e $\nu=2$. 
para freqüências da perturbação $\omega$ cuja a razão com a freqüência natural do sistema $\left(\omega_{0}\right)$ é um número racional. O fato dessa razão entre as frequências ser uma escolha eficaz para o controle de sistemas caóticos foi também observado em outros modelos forçados harmonicamente $[18,19,53]$.

\subsection{Atratores Controlados}

Conforme comentado no início do capitulo, analisamos o controle do sistema estudado em intervalos dos parâmetros $A$ e $r$. Para visualizar a periodicidade ou a caoticidade do sistema em função desses dois parâmetros, construímos espaços bidimensionais de parâmetros. Conforme discutido no capítulo 2, no espaço de parâmetros o comportamento periódico ou caótico do sistema é classificado através do maior expoente de Lyapunov para uma grade de parâmetros. Dependendo do valor do expoente de Lyapunov obtido para a órbita correspondente a um par de parâmetros, esse par de parâmetros é marcado em uma cor na grade.

As janelas periódicas no espaço bidimensional de parâmetros ocupam áreas com um esqueleto central e quatro extremidades alongadas, com uma forma peculiar semelhante a de um camarão [52]. As características típicas das bifurcações no interior dos camarões foram discutidas no capítulo 2.

Do ponto de vista de controle de caos através de uma perturbação paramétrica, a utilização do espaço de parâmetros é importante, por permitir uma análise da posição das janelas periódicas e de seus períodos fundamentais.

Neste trabalho utilizamos o espaço de parâmetros bidimensional para avaliar os efeitos da perturbação paramétrica. Para cada valor da amplitude de forçamento da perturbação $B$, obtivemos um espaço de parâmetros para o par $A$ (amplitude de forçamento natural) e $r$ (coeficiente de restituição). Com isso, comparamos espaços de $A$ e $r$, com diferentes amplitudes do controle de caos $B$.

Na Figura 3.9, mostramos quatro espaços de parâmetros variando o valor da amplitude $B$ da perturbação. A cruz na Figura 3.9 indica os parâmetros do atrator caótico a ser controlado (mostrado Figura 3.4). Na Figura 3.9(a), o espaço de parâmetros foi 
obtido para amplitude $B=0$ da perturbação. Os parâmetros escolhidos na Figura 3.4 como referência encontram-se na região caótica próxima de uma janela periódica. $\mathrm{Na}$ Figura 3.9(b), para amplitude da perturbação $B=0.0025$, notamos que uma nova estrutura periódica (camarão) surge na vizinhança da estrutura previamente existente. Na Figura 3.9(c), aumentamos o valor da amplitude de perturbação para $B=0.0029$; o novo camarão aproxima-se dos valores dos parâmetros que escolhemos para o atrator a ser controlado. O ponto de referência está na fronteira da janela periódica apresentando comportamento periódico. Na Figura 3.9(d), o ponto de referência está sobre os parâmetros que correspondentes as órbitas superestáveis do camarão. Esses parâmetros possuem o expoente de Lyapunov mais negativo de toda a janela periódica.

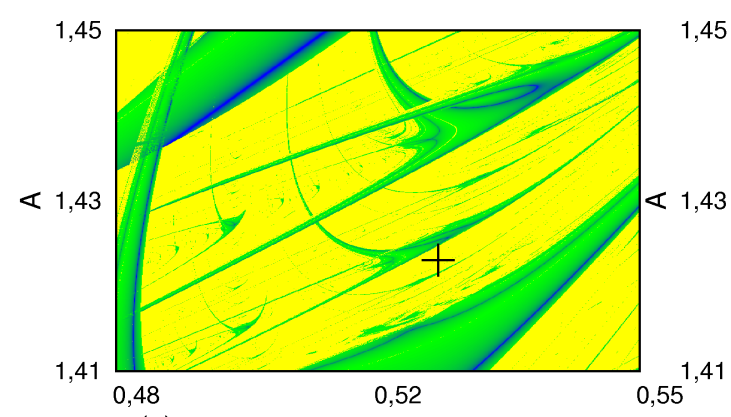

(a)

$r$

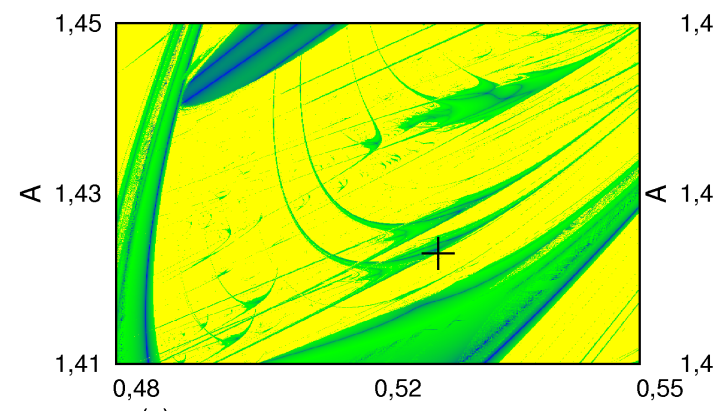

(c)

$r$

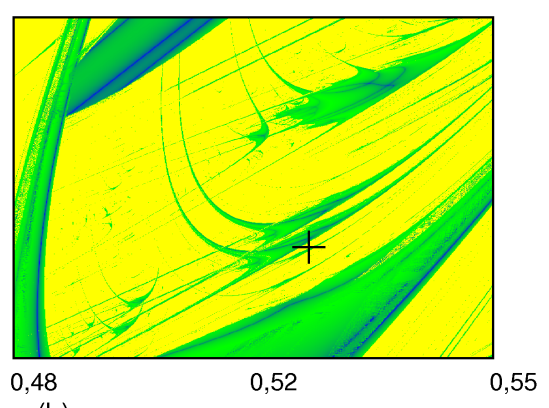

(b)

$r$

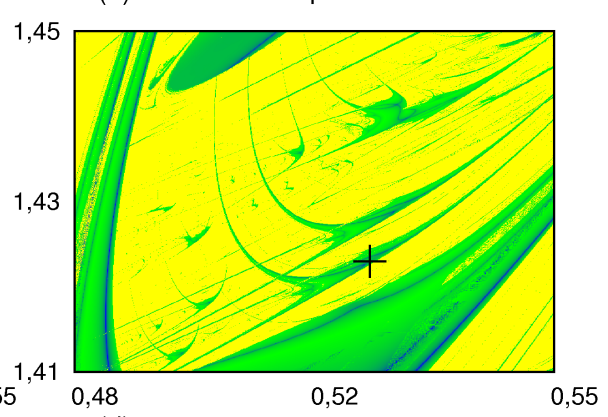

(d)

Figura 3.9: Espaço bidimensional de parâmetros, para $A$ e $r$, obtido através dos maiores expoentes de Lyapunov para os parâmetros $\omega_{0}=1, \omega=0.5, \nu=2$. (a) $B=0$, (b) $B=0.0025$, (c) $B=0.0048$. A cruz indica o atrator escolhido como referência $A=1.423$ e $r=0.525$.

Constatamos na Figura 3.9 que o controle, através de uma perturbação paramétrica, provoca o surgimento de uma nova janela periódica. Aumentando a amplitude $B$ da perturbação, a nova janela periódica desloca-se pelo espaço de parâmetros $A \times r$. Notamos visualmente a semelhança entre as janelas periódicas nova e antiga. Para investigar a simi- 
laridade entre essas janelas, analisamos os atratores periódicos existentes nos parâmetros que compõem as linhas superestáveis de cada camarão.

Para obter os atratores existentes na linha de parâmetros correspondentes a órbitas superestáveis de cada camarão, utilizamos o mesmo procedimento da Figura 3.4, ou seja, tomamos a velocidade e o deslocamento em um mapa estroboscópico. As cores indicam atratores coexistentes em ambas as linhas superestáveis do camarão novo e do antigo. Os círculos preenchidos indicam os dois atratores existentes no novo camarão, as cruzes indicam os dois atratores existentes no camarão antigo.

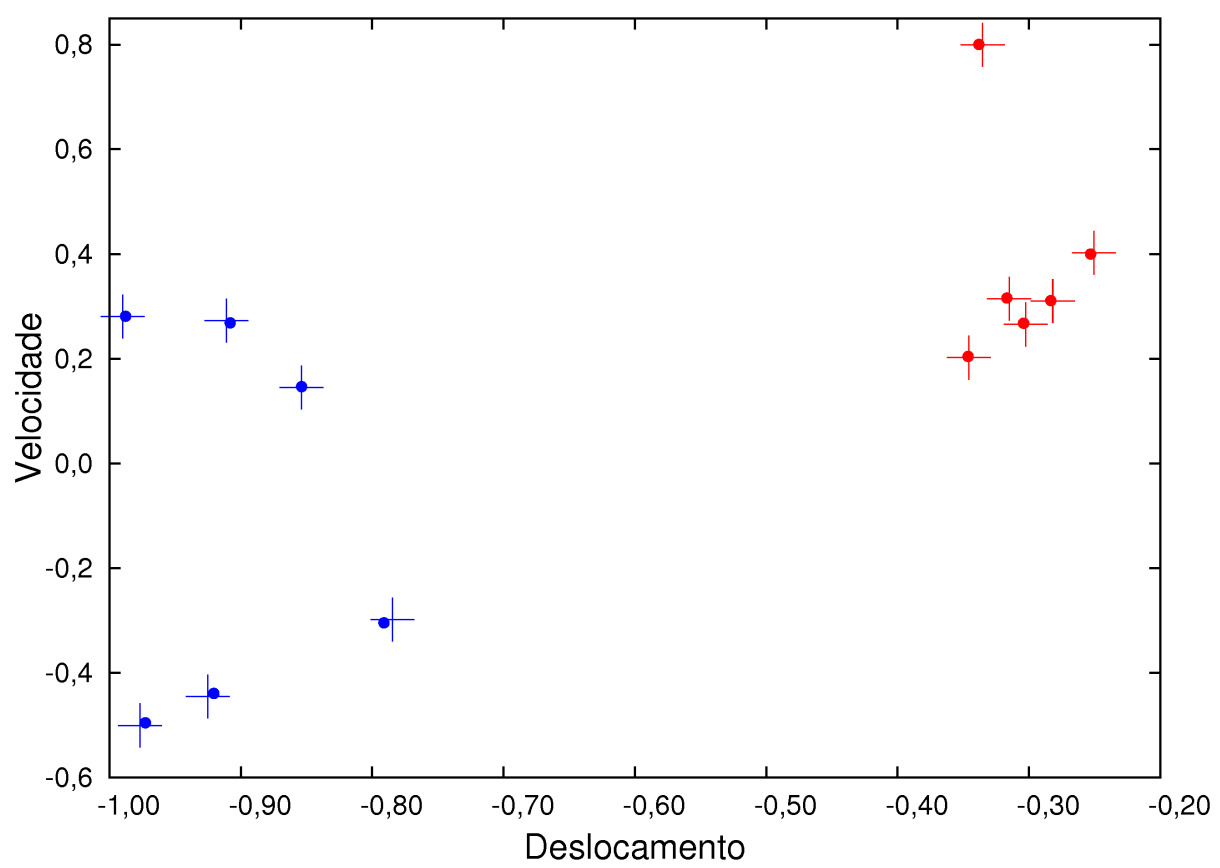

Figura 3.10: Atratores existentes no camarão sem perturbação (verde) $A=1.4256, B=0, r=0.526$, $\omega_{0}=1 \omega=0.5 \nu=2$ e atratores existentes no novo camarão $A=1.423, B=0.0048, r=0.525, \omega_{0}=1 \mathrm{e}$ $\nu=2$ (azul).

Além da semelhança entre as janelas periódicas mostradas na Figura 3.9, observamos na Figura 3.10 a similaridade entre os atratores da janela existente no espaço de parâmetros sem perturbação e os da nova janela que surgiu devido à perturbação. Os atratores dos dois camarões comparados são coincidentes nesta seção de Poincaré. Conforme a Figura 3.9, a nova janela periódica aproxima-se gradualmente do ponto escolhido como referência a medida que aumentamos a amplitude da perturbação paramétrica. 
Ilustramos na Figura 3.11 o comportamento do atrator caótico quando variamos a amplitude da perturbação. Utilizamos planos de fase do atrator periódico existente para parâmetros que compõem a linha com órbitas superestáveis da janela (camarão) sem perturbação (preto), sobrepostos a planos de fase do atrator inicialmente caótico que estamos controlando (vermelho). Na Figura 3.11(a), mostramos o atrator caótico sem controle $(B=0)$, na Figura 3.11(b) com o novo forçamento verificamos a tendência do atrator caótico em concentrar-se na vizinhança do atrator periódico. Na Figura 3.11(c), o atrator, antes caótico, foi controlado e sua forma assume o contorno do atrator periódico. Finalmente na Figura 3.11(d), além do período, o atrator controlado possui a forma similar a do atrator periódico que estamos discutindo.
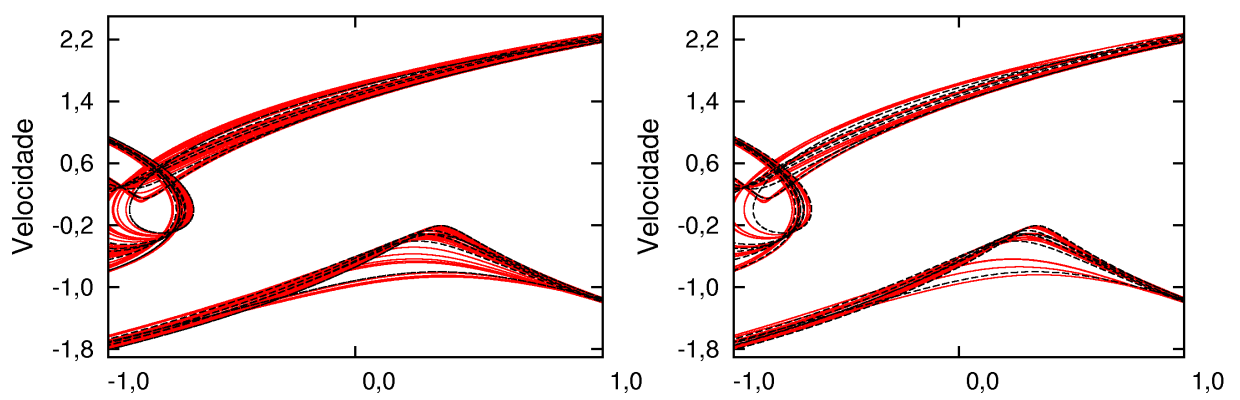

(a)

(b)

Deslocamento

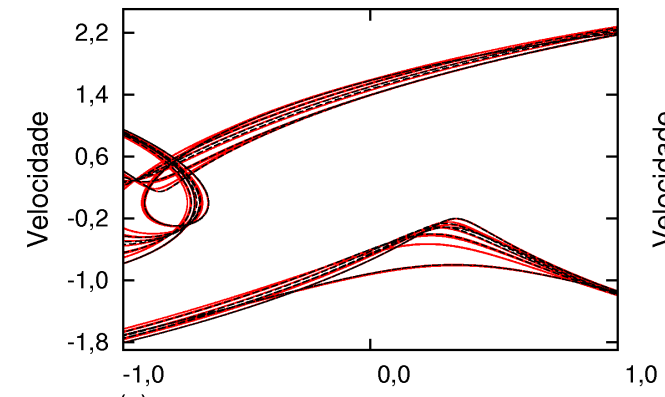

(c) Deslocamento

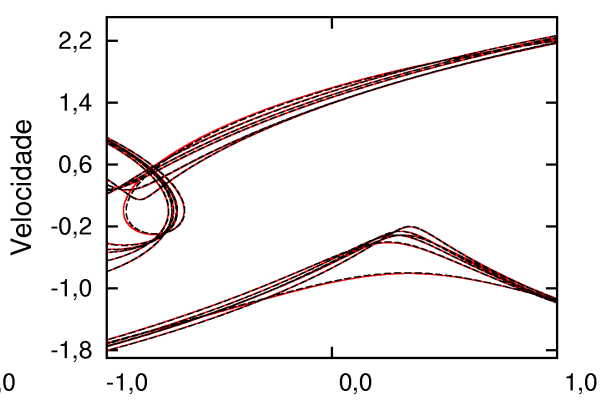

(d) Deslocamento

Figura 3.11: Planos de fase para órbita existente no interior do camarão sem perturbação (preto) com $A=1.4256$ e $r=0.526$, e plano de fase do atrator caótico (vermelho) com mesmos parâmetros de figura 4, porém variando a perturbação (a) $B=0$, (b) $B=0.0025$, (c) $B=0.0029$ e (d) $B=0.0048$ atrator controlado. 
Para reforçar as conclusões obtidas da análise da Figura 3.11, mostramos na Figura 3.12 ampliações dos planos de fase.
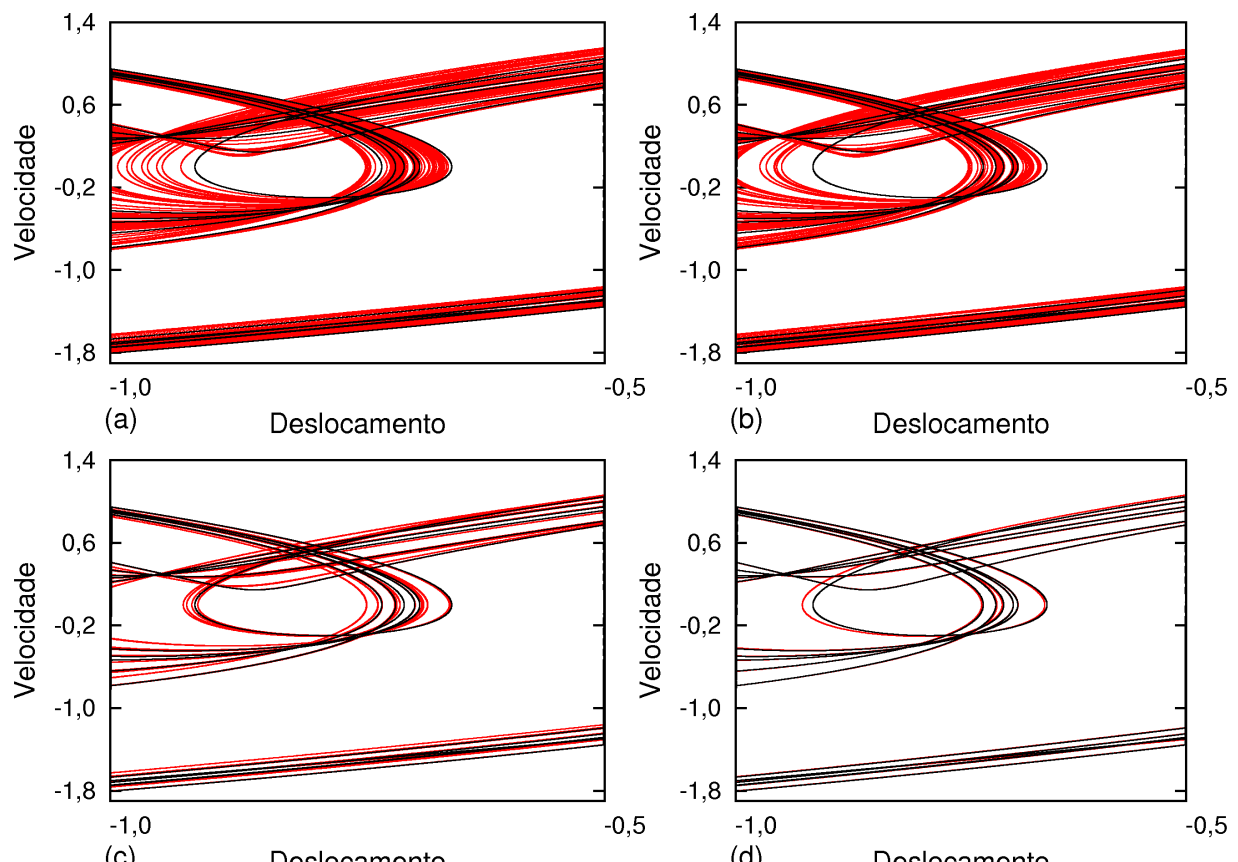

Figura 3.12: Ampliação de segmentos da figura 11, para os mesmos parâmetros.

A despeito das Figuras 3.11 e 3.12, vale discutir que diferentes camarões estão organizados paralelamente no espaço de parâmetros. Cada camarão possui um outro em sua vizinhança mas, não é possível visualizar os camarões menores que estão alinhados com os maiores. Com isso, na Figura 3.9(a), entre o ponto marcado como referência e a janela periódica em sua vizinhança, deve haver outras janelas periódicas menores. Estas não foram observadas devido ao passo da variação insuficiente em $B$ que usamos. 
Conforme discutido no texto, na linha superestável de cada camarão, existem dois atratores coexistentes. Verificamos a forma da bacia de atração dos atratores coexistentes no novo camarão e a comparamos com a bacia de atração dos atratores no camarão sem a perturbação. Constatamos na Figura 3.13 que essas duas bacias são indistinguíveis.
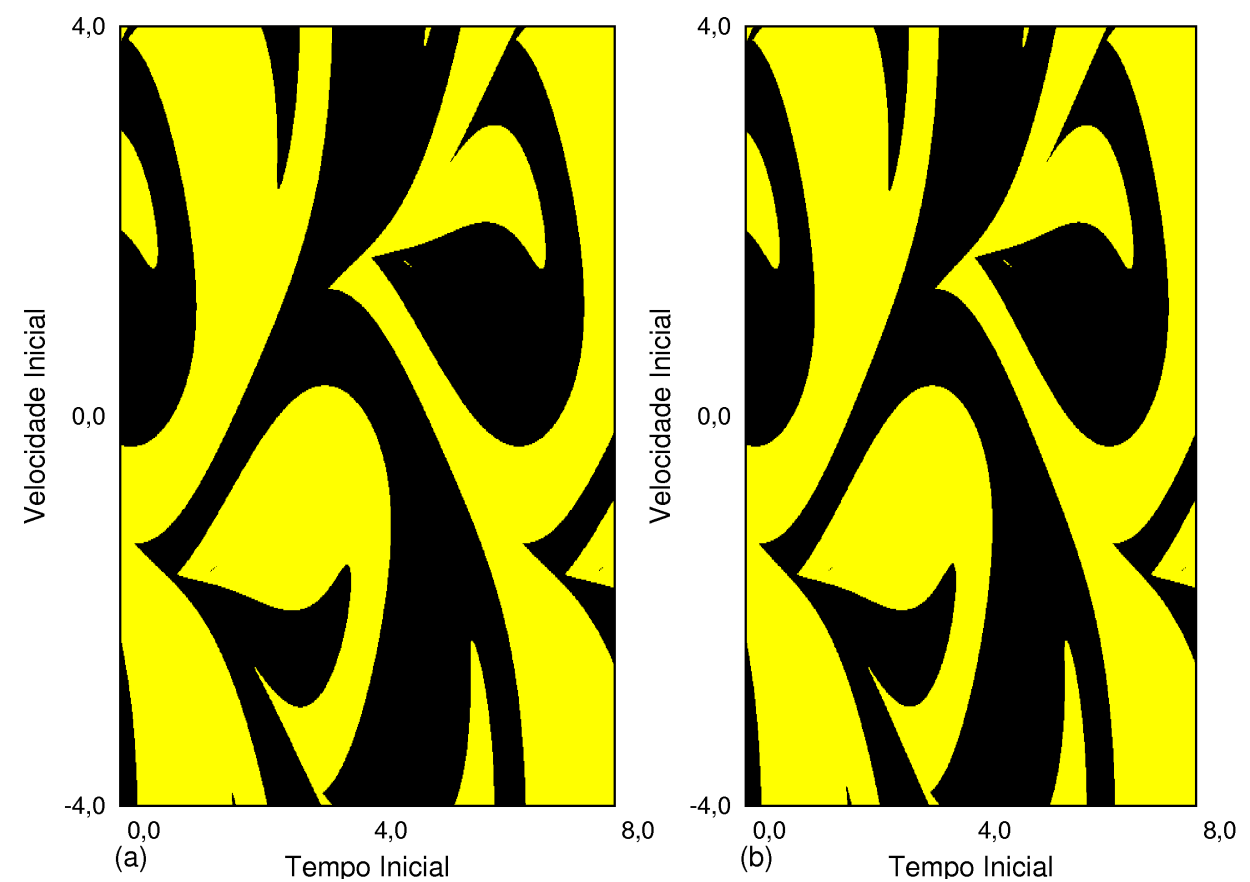

Figura 3.13: Bacias de atração para a coexistência existente na linha superestável (a) do novo camarão para $A=1.423, r=0.525$ e $B=0.0048$, (b) do antigo camarão com parâmetros $A=1.4256, r=0.526$ e $B=0$. 


\section{Capítulo 4}

\section{Salto Entre Trajetórias de Diferentes}

\section{Atratores}

Existe um crescente interesse em sistemas com atratores coexistentes, observado em diferentes sistemas físicos e em diversos campos da ciência [23-29]. Um dos motivos desse interesse é o fato das trajetórias de sistemas com mais de um atrator, sob a presença de ruído, exibirem, eventualemente, saltos entre os atratores coexistentes.

No sistema par de impactos, freqüentemente há ocorrência de vários atratores para os parâmetros $A$ e $r$ fixos. O número de atratores coexistentes aumenta à medida que reduzimos a dissipação $[22,31]$. Nesse capítulo, estudamos os saltos entre dois atratores, quando o sistema par de impactos é submetido a uma perturbação que simula um ruído. Os saltos entre atratores já foram investigados, no sistema par de impactos, para uma perturbação randômica [38]. Neste trabalho aplicamos uma perturbação composta por um conjunto de harmônicos senoidais. A amplitude e a frequência dos harmônicos são constantes e a fase é alterada aleatóriamente após cada impacto.

\subsection{Coexistência de Atratores}

Nesta seção escolhemos um valor da amplitude do forçamento natural do sistema $A$ e do coeficiente de restituição $r$ para qual o sistema exibe a coexistência de dois atratores ou biestabilidade. A coexistência escolhida é bastante robusta, pois ela persiste para diversos 
valores dos parâmetros $A$ e $r$. Para identificar e analisar essa coexistência utilizamos diagramas de bifurcação, pois foi possível acompanhar a estabilidade das trajetórias para diversos parâmetros.

A coexistência escolhida, para proceder com a análise sob a influência de ruído, surge de uma bifurcação forquilha (pitchfork) na velocidade, para o parâmetro $A=3.0878$. Este tipo de bifurcação consiste na perda de estabilidade de um ponto fixo previamente existente e no surgimento de dois novos pontos fixos. Para ilustrar esta discussão, na Figura 4.1 mostramos a bifurcação e a coexistência em questão. Nesta figura cada atrator da coexistência é marcado em diferentes cores, vermelho e preto.

Na Figura 4.1, o diagrama de bifurcação da velocidade foi obtida para 600 valores da amplitude do forçamento $A$, ilustrando a mudança de estabilidade.

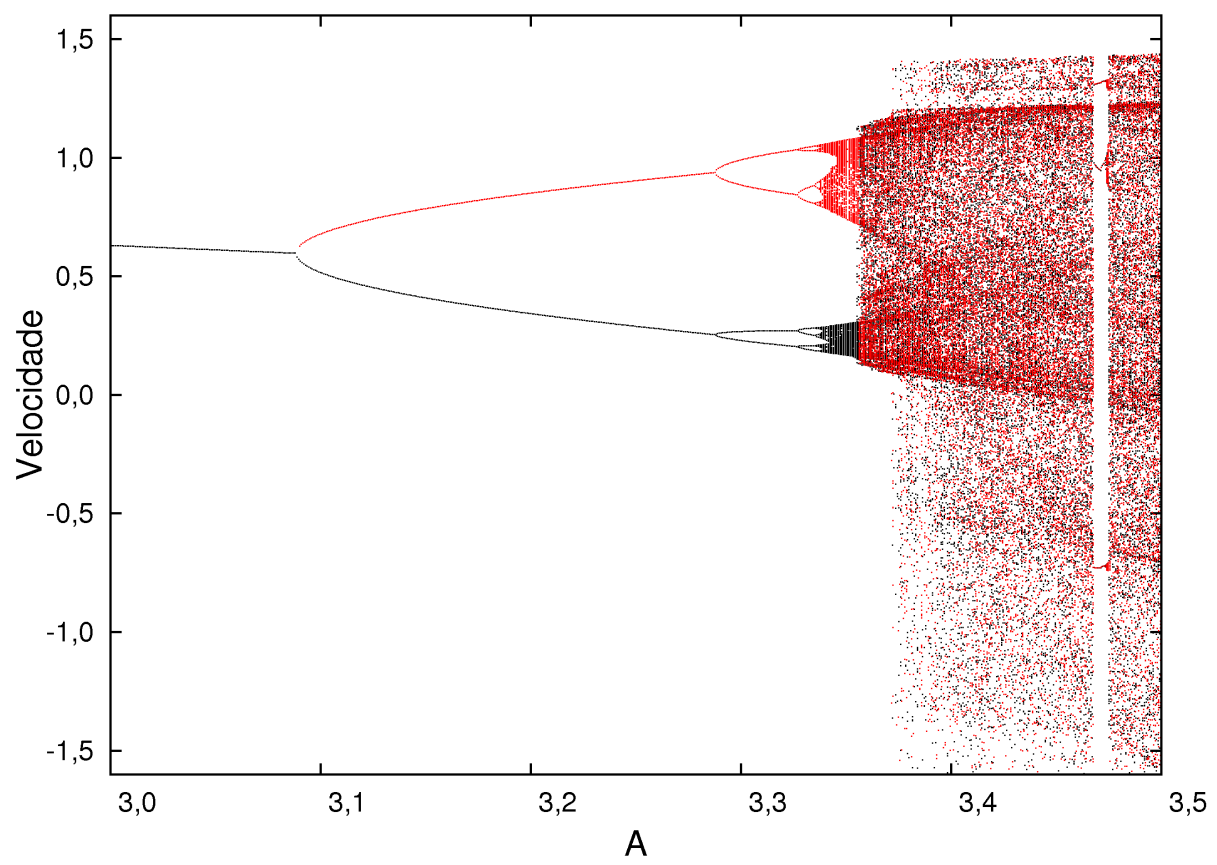

Figura 4.1: Diagrama de bifurcação variando a amplitude forçamento do sistema $A$, com $r=0.8, \nu=2$ e $\omega_{0}=1$. Os atratores estão marcados com cores diferentes, vermelho e preto.

No diagrama de bifurcação da Figura 4.1, cada atrator da coexistência foi obtido com a técnica de seguir o atrator, ou seja, as condições iniciais utilizadas na obtenção de atrator para um parâmetro $A$ são as coordenadas do atrator para o parâmetro anterior. Essa tarefa apresentou-se com certo grau de dificuldade, pois, conforme veremos adiante, as 
bacias de atração de cada atrator são pequenas. Nessa figura notamos que a rota para o caos inicia-se por duplicação de período. Além disso, uma crise provocada pela colisão do atrator instável com o atrator marcado em preto na figura, aumenta o tamanho do atrator caótico. Neste caso, uma segunda maneira de evidenciar a coexistência é através do diagrama de bifurcação para o coeficiente de restituição $r$. Assim, na Figura 4.2 fixamos a amplitude do forçamento $A$ em um valor para o qual existe a coexistência, e mostramos o diagrama de bifurcação com $A=3.25$ e 600 valores do coeficiente de restituição $r$ no intervalo $[0.6: 0.9]$.

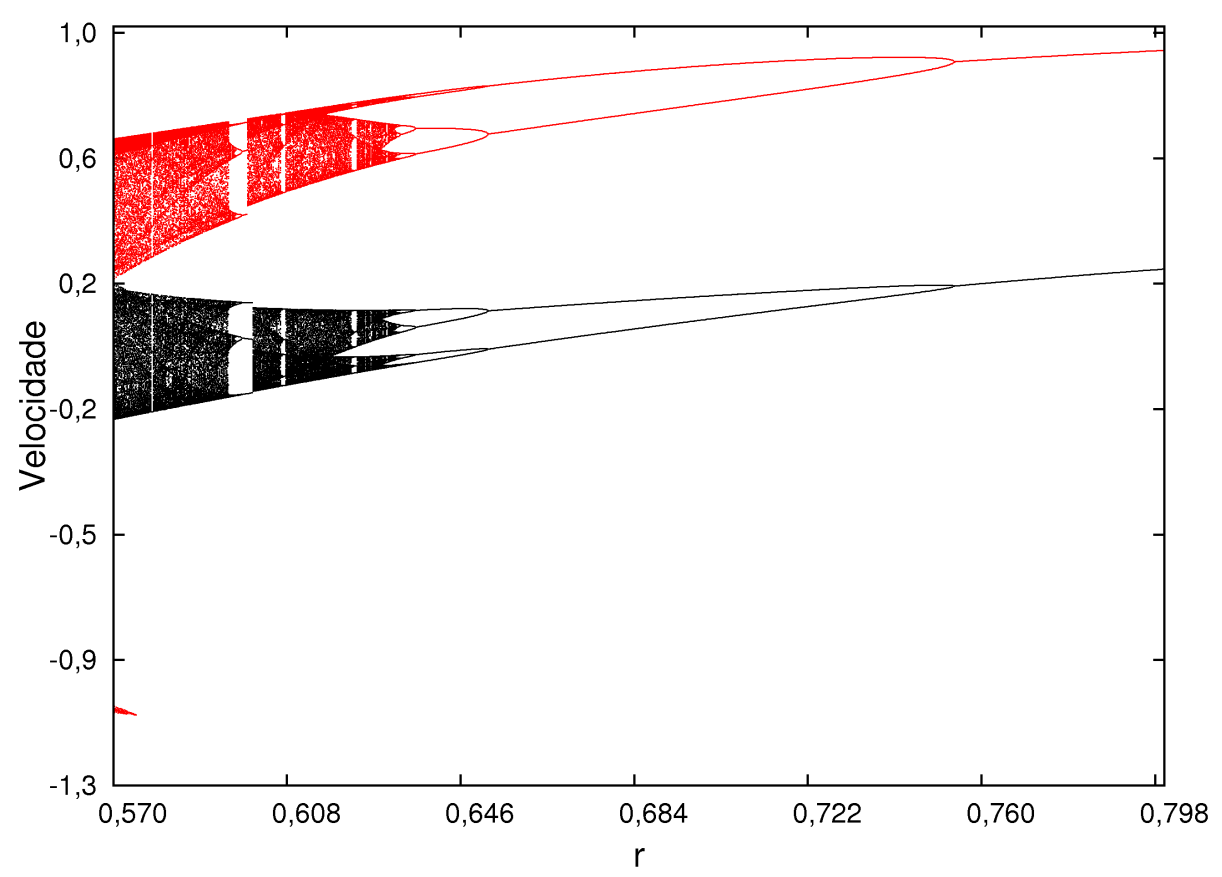

Figura 4.2: Diagrama de bifurcação da velocidade, onde fixamos $A=3.25, \nu=2, \omega_{0}=05$ e variamos $r$ no intervalo $[0.6: 0.9]$.

Na Figura 4.2, observamos que a partir da separação dos ramos caóticos o atrator se torna periódico por bifurcações inversas de período. Nessa figura, notamos certa semelhança entre os atratores, então verificamos o plano de fase de cada atrator.

O espaço de fase deste sistema é tridimensional, $(t, y, \dot{y})$, então representamos a órbita pelos valores da posição e da velocidade para todos valores do tempo no plano de fase $\dot{y} \times y$. Assim na Figura 4.3, fixamos todos os parâmetros do sistema e graficamos a velocidade pela posição. Neste diagrama é possível observar as descontinuidades do sistema para 
$y=1$ e a natureza da solução, ou seja, se o sistema é caótico ou periódico. Observamos na Figura 4.3 que os atratores são simétricos, para uma dada posição as velocidades possuem sinais contrários em cada atrator.

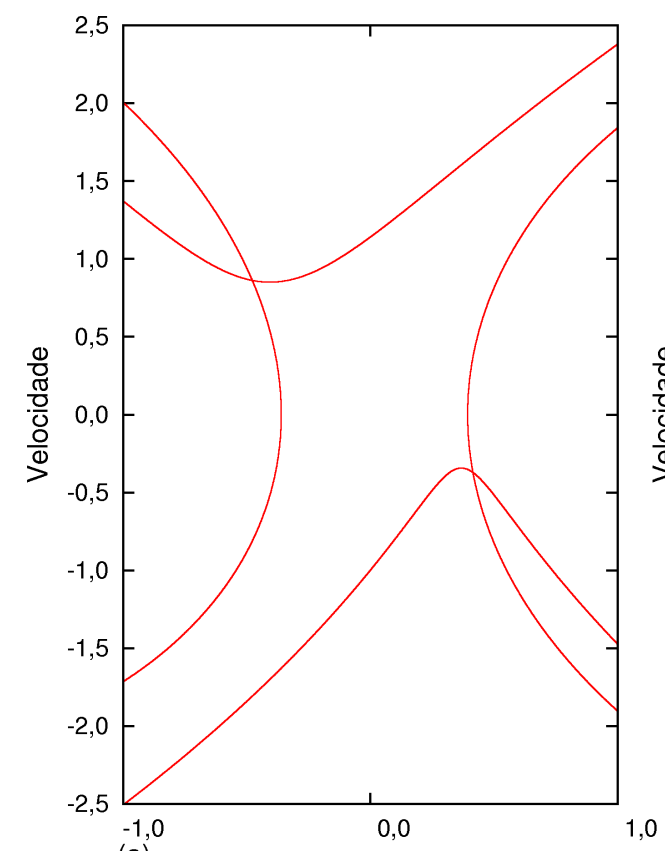

(a) Deslocamento

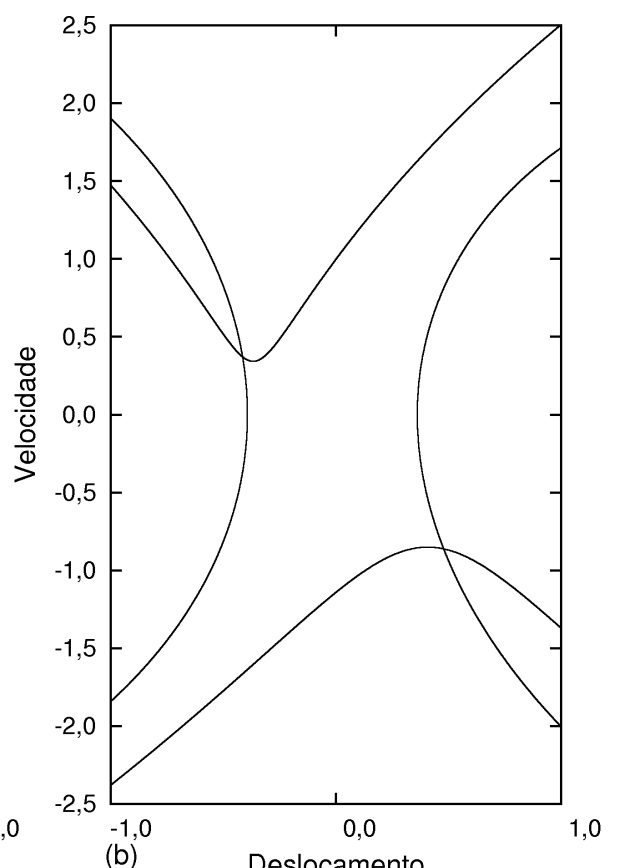

(b) Deslocamento

Figura 4.3: Planos de fase de cada atrator para $A=3.20, r=0.8, \nu=2$ e $\omega_{0}=0.5$. Observamos que dada uma posição às velocidades possuem sinais opostos em cada atrator.

Para completar a discussão sobre a coexistência de atratores discutida nesta seção, obtivemos as respectivas bacias de atração para uma grade de $600 \times 600$ condições iniciais. Após o transiente, verificamos em qual atrator o sistema se encontra, e marcamos na grade, com as cores vermelho e preto, as condições iniciais que levam a cada um dos atratores.

O mecanismo de salto entre as trajetórias de diferentes atratores, conforme mostraremos na Seção 4.3, depende das bacias de atração. Para bacias de atração robustas, onde cada atrator possui grandes áreas, para provocar o salto entre as trajetórias é necessário um ruído com maior intensidade. Na Figura 4.4, mostramos, para diferentes valores do coeficiente de restituição $r$, as bacias de atração da coexistência. 

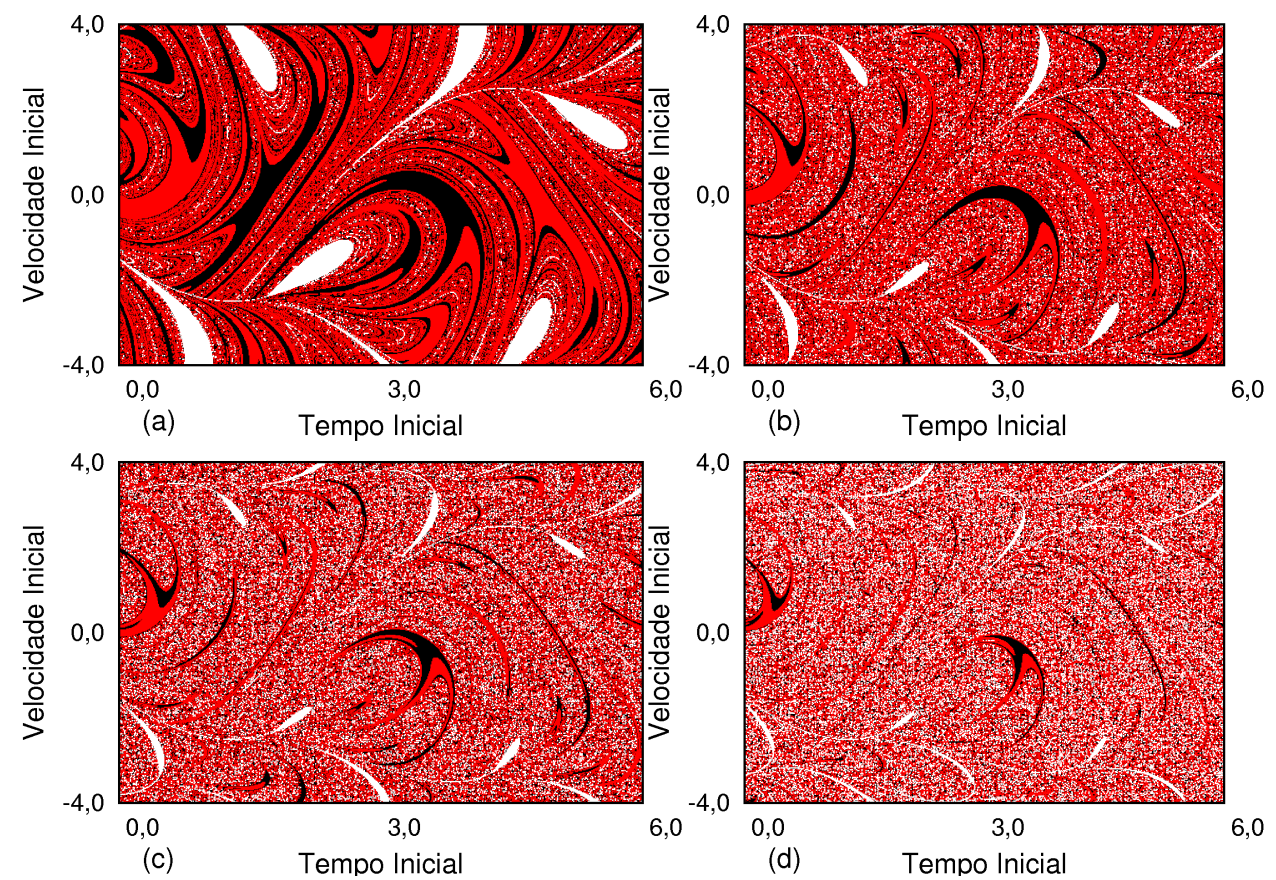

Figura 4.4: Bacias de atração para $A=3.2, \nu=2$ e $\omega_{0}=1$ (a) $r=0.7$. (b) $r=0.8$. (c) $r=0.84$. (d) $r=0.88$.

As fronteiras das bacias de atração de sistemas multiestáveis podem ser lisas ou fractais. A fractalidade das fronteiras implica em auto-similaridade, ou seja, a fronteira contém uma cópia de si mesmo em todas as escalas. Às vezes estas características das fronteiras são de difícil identificação. Mesmo uma fronteira lisa pode sofrer transformações com a variação de algum parâmetro do sistema, tornando-se fractal. Na Figura 4.4, não observamos fractalidade nas fronteiras das bacias dos atratores em questão. Isto é evidenciado claramente pela existência de regiões com fronteiras lisas. Percebemos visualmente na Figura 4.4, que o aumento do coeficiente de restituição $r$ diminui a área contínua das bacias de atração de cada atrator, aumentando a incerteza em definir uma condição inicial. Conforme veremos na Seção 4.3 isso estimula o salto entre as trajetórias, necessitando de uma menor intensidade de ruído. 


\subsection{Perturbação Simulando o Ruído}

Estamos interessados no efeito do ruído sobre uma biestabilidade de atratores do sistema par de impactos, principalmente na competição entre as trajetórias dessa coexistência. Consideramos nesta seção uma perturbação simulando um ruído branco com banda de frequências limitada [20]. Ruído branco é um conjunto de ondas com diferentes freqüências todas com mesma intensidade. Banda limitada implica que as freqüências estão em um intervalo limitado [54]. Nesta seção estamos interessados na independência entre dois pontos diferentes da série temporal do ruído. A banda limitada é definida pela seguinte relação:

$$
S(\nu)= \begin{cases}\frac{s}{\left(\nu_{\max }-\nu_{\min }\right)} & \text { para } \nu \in\left[\nu_{\min }, \nu_{\max }\right] \\ 1 & \text { para } \nu \notin\left[\nu_{\min }, \nu_{\max }\right]\end{cases}
$$

onde $s$ é a intensidade do ruído. O ruído branco com banda limitada pode ser obtido numericamente como uma soma de componentes harmônicas:

$$
q(t)=\sum_{i=1}^{N} A_{i} \cos \left(\nu_{i} t+\phi_{i}\right)
$$

onde $A_{i}$ é constante, $\nu_{i}$ e $\phi_{i}$ são independentes do tempo, a fase $\phi_{i}$ é randômica.

O número de harmônicos considerados é determinante no comportamento do ruído. Utilizamos o valor sugerido na literatura, $N>30$, que oferece boas condições de aleatoriedade [55]. As amplitudes $A_{i}$ do ruído e as freqüências $\nu_{i}$ são obtidas de acordo com o método de Rice [55]:

$$
\begin{gathered}
A_{i}=\sqrt{2 S(\nu) \Delta \nu}, \\
\nu_{i}=(i-0.5) \Delta \nu+\nu_{\min }, \\
\Delta \nu=\left(\nu_{\max }-\nu_{\min }\right) / N \\
i=1, N .
\end{gathered}
$$

Implementamos o ruído no sistema par de impactos somando os harmônicos no forçamento do sistema. Para simular um caráter estocástico para essa função as suas fases são sorteadas aleatoriamente. Sorteamos novas fases, $\phi_{i}$, com sementes diferentes, a cada impacto do sistema. 
Na Figura 4.5, mostramos a série temporal da amplitude do ruído, com as fases sorteadas nos instantes de impacto do sistema par de impacto. Nesta figura fixamos $N=40$, $s=0.015$ e intervalo de frequência $[0: 0.5]$. Notamos que os picos não se repetem e nem identificamos períodos, ilustrando o caráter errático dessa perturbação.

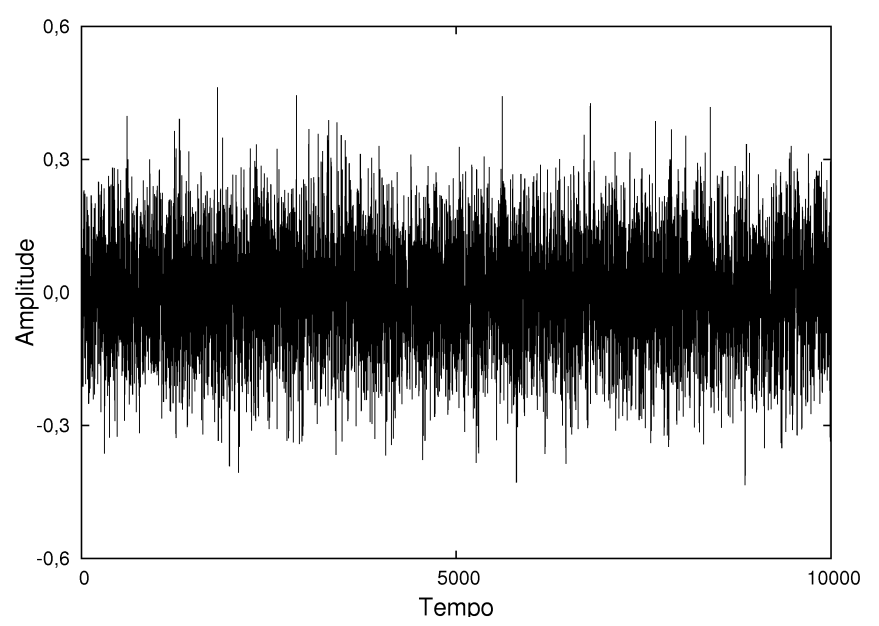

Figura 4.5: Série temporal do ruído estocástico com fases sorteadas no instante de impacto do sistema par de impactos, consideramos $N=40, s=0.015$. 


\subsection{Salto Entre Bacias de Atração}

Sistemas dinâmicos multiestáveis dissipativos sob a influência de ruído exibem saltos entre as trajetórias de atratores com bacias de atração distintas [22]. Em geral sistemas multiestáveis exibem bacias de atração complicadas, como visto para o sistema par de impactos na seção anterior. A presença de ruído acentua a complexidade estimulando o salto [31]. O mecanismo pelo o qual o ruído empurra a órbita para fora da bacia relacionase com os pontos de sela (ponto fixo com estabilidade tracada para direções diferentes) existentes na fronteiras das bacias, e ainda não é completamente conhecido. O fato é que a trajetória escapa de um determinado atrator, migra para uma trajetória de um atrator com bacia vizinha e permanece por algum tempo nessa trajetória. Nesta seção aplicamos ao sistema par de impactos o ruído definido na seção anterior com o objetivo de observar o salto entre as trajetórias dos dois atratores discutidos na Seção 4.1. O ruído definido na Seção 4.2 é implementado ao sistema somando os harmônicos ao forçamento original do sistema. O forçamento é, então, dado por:

$$
e(t)=A \operatorname{sen}\left(\omega_{0} t\right)+\sum_{i=1}^{N} A_{i} \cos \left(\nu_{i} t+\phi_{i}\right),
$$

ao invés do forçamento $A \operatorname{sen}\left(\omega_{0} t\right)$.

O fenômeno de salto entre bacias é provocado pela combinação dos harmônicos descritos na Seção 4.2. A freqüência de ocorrência dos saltos e o intervalo de tempo de permanência em cada bacia dependem dos parâmetros do ruído.

Para os parâmetros fixos do sistema par de impactos, a intensidade $s$ do ruído é o parâmetro de controle dos saltos. Para ilustrar essa afirmação na Figura 4.6 fixamos o número de harmônicos em $N=40$ e o intervalo de freqüências em [0:0.5] e variamos a intensidade $s$ do ruído. Realizamos uma seqüência de simulações para quatro valores diferentes de $s$, os parâmetros do sistema estão fixos em $A=3.2, \nu=2, \omega_{0}=1$ e o coeficiente de restituição está fixo em $r=0.8$.

Apresentamos a seguir os saltos para diferentes valores do coeficiente de restituição $r$. Na Figura 4.6(a) a intensidade do ruído é $s=0.013$ e não observamos saltos entre as trajetórias. Nessas figuras as linhas pretas e azuis indicam a posição dos atratores coexistentes sem a perturbação e em vermelho o atrator que esta sob influência da perturbação. 
Na Figura 4.6(b), o ruído possui intensidade $s=0.022$. Observamos o primeiro salto entre os atratores. Essa trajetória abandona a posição do atrator marcado em preto e permanece por um tempo no atrator marcado em azul. Na Figura 4.6(c), aumentamos a amplitude do ruído para $s=0.045$. Verificamos o salto intermitente entre os atratores e a permanência do atrator em ambas bacias de atração. Na Figura 4.6(d), para $s=0.065$, além da ocorrência do salto entre as bacias, observamos o surgimento de estouros na série. Este comportamento, conforme discutiremos a frente, constitui uma rota para o caos.
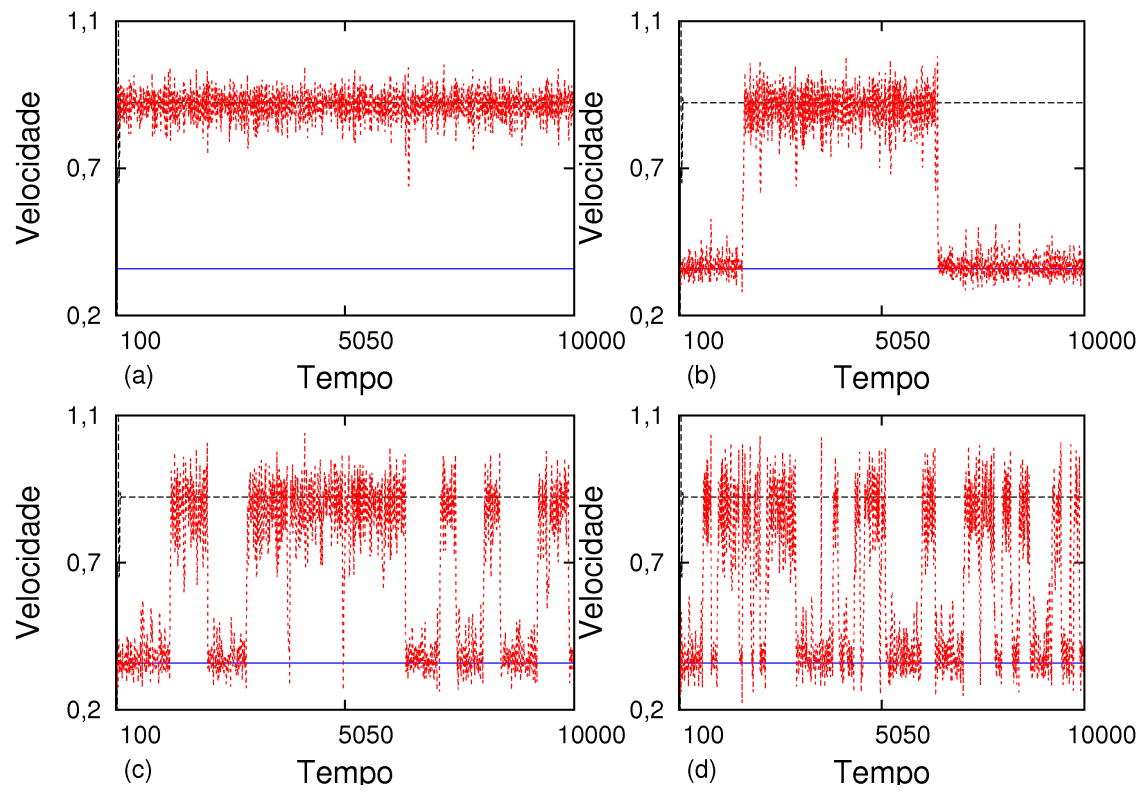

Figura 4.6: Séries temporais com velocidades tomadas em um mapa estroboscópico (Tempo $-2 \pi)$ no sistema par de impactos com parâmetros $A=3.2, r=0.8, \nu=2, \omega_{0}=1$ e quatro diferentes intensidades do ruído. (a) $s=0.013$. (b) $s=0.022$. (c) $s=0.045$. (d) 0.0065 .

Conforme já mencionado, o coeficiente de restituição $r$ tem influência na estrutura das bacias de atração. À medida que aumentamos o coeficiente as bacias perdem área contínua, veja Figura 4.4.

Na Figura 4.7, apresentamos séries temporais similares às da Figura 4.6, mas com o coeficiente de restituição maior, $r=0.84$. A bacia de atração para esse atrator é mostrada na Figura 4.4(c), observamos que os saltos ocorrem para valores menores da intensidade do ruído. 

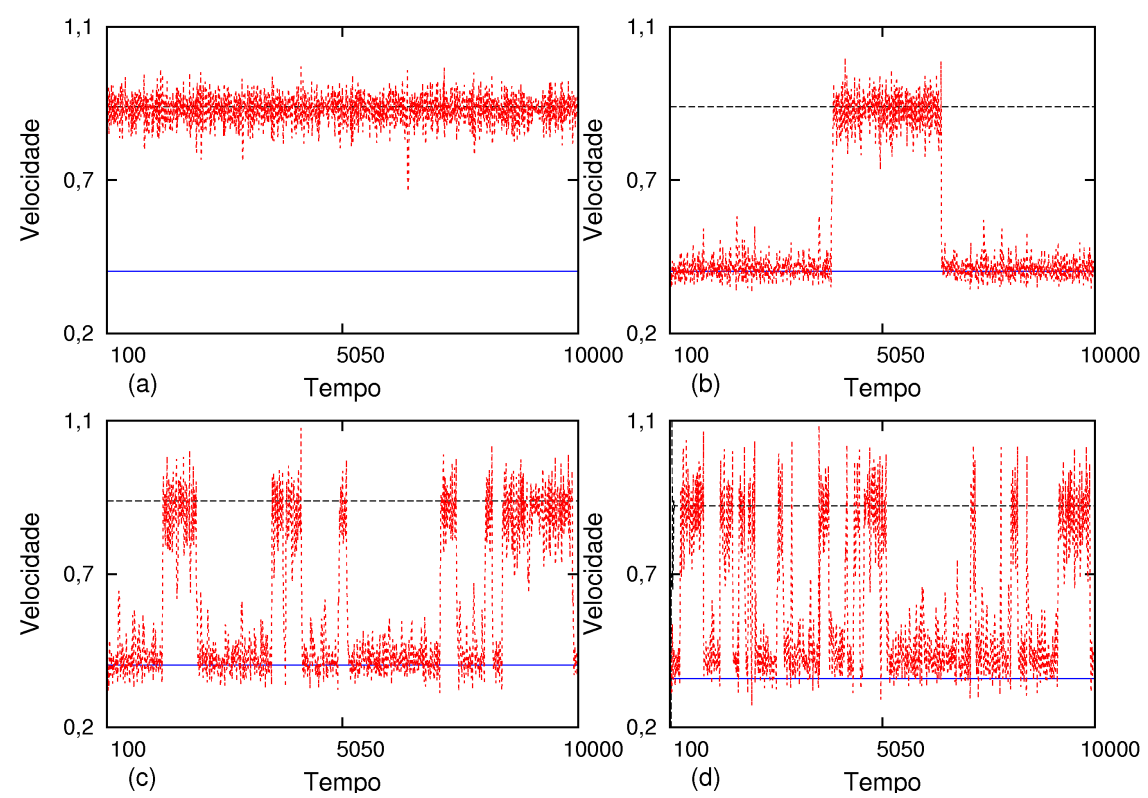

Figura 4.7: Séries temporais com velocidades tomadas em um mapa estroboscópico (Tempo- $2 \pi)$ no sistema par de impactos com parâmetros $A=3.2, r=0.84, \nu=2, \omega_{0}=1$ e quatro diferentes intensidades do ruído (a) $s=0.01$, (b) $s=0.015$, (c) $s=0.035$ e (d) 0.005 .

Na Figura 4.7, notamos que com um coeficiente de restituição maior, $r=0.84$, observamos que os saltos iniciam-se para valores menores da intensidade do ruído. $\mathrm{Na}$ Figura 4.7(b), onde ocorre o primeiro salto, o valor da intensidade é $s=0.015$, consideravelmente menor que o valor do primeiro salto para $r=0.8$ que é 0.0022 .

Todo cenário da coexistência estudada até aqui ocorre para um valor da amplitude de forçamento $A$ que antecede o caos, conforme Figura 4.1 sem ruído. Nesta figura vemos que à medida que aumentamos a amplitude do forçamento $A$ o sistema vai para o caos via bifurcação de período. Para $A=3.35$ o atrator caótico alcançado por bifurcação de período sem ruído é mostrado na Figura 4.8(b). Quando o sistema ainda com a coexistência periódica, com $A=3.2$, é submetido a um ruído com grande intensidade, a ocorrência de estouros já discutida nas Figuras 4.6 e 4.7, cria uma figura que ocupa a mesma região no plano de fase e possui forma similar ao atrator caótico Figura 4.8(a).

Na Figura 4.8, ilustramos que o mecanismo de estouros observados na Figura 4.7(d) e 4.6(d), com o aumento da amplitude de perturbação, antecipa o comportamento caótico existentes para valores maiores do forçamento. 

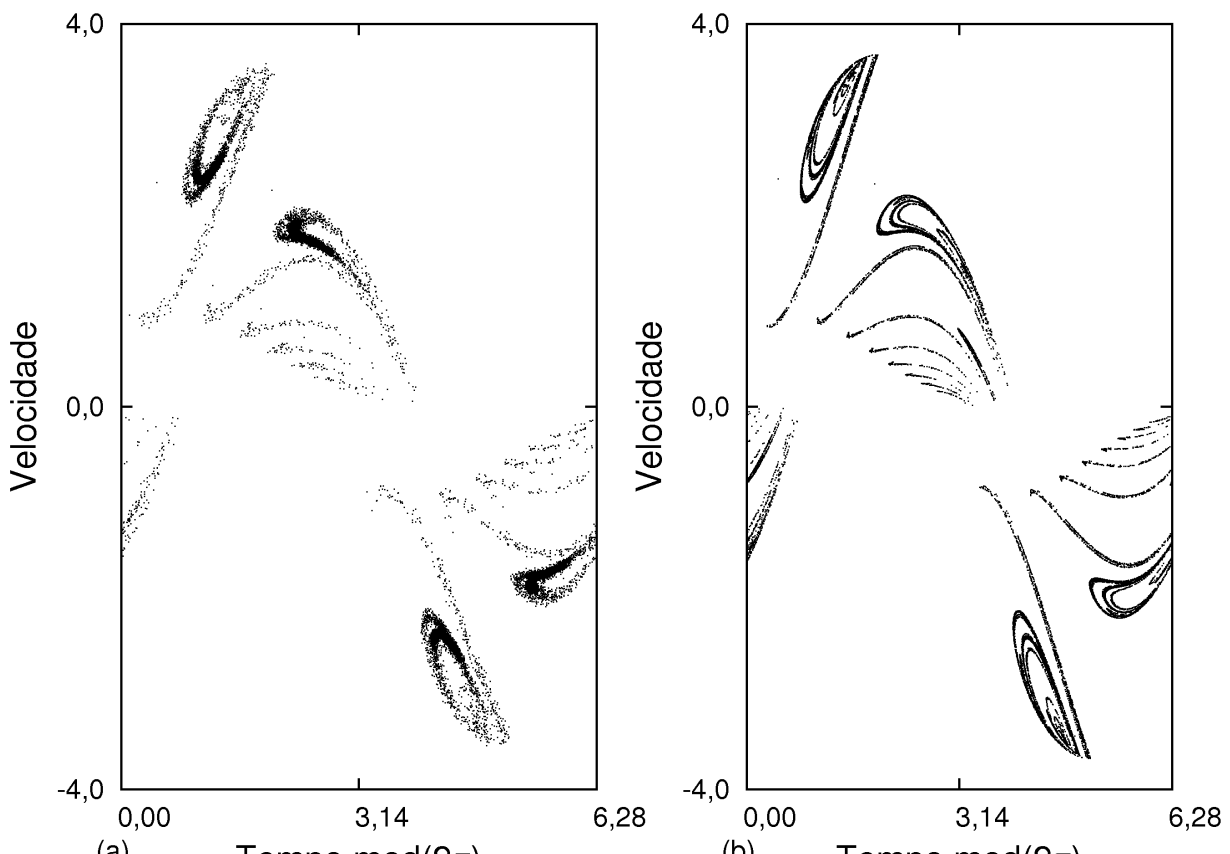

(a) Tempo $\bmod (2 \pi)$

(b) Tempo $\bmod (2 \pi)$

Figura 4.8: (a) Mapa estoboscópico para $A=3.2, r=0.8, \nu=2, \omega_{0}=1$ e $s=0.2$. (b) $\alpha=3.35, \nu=2$, $\omega_{0}=1$ e $s=0$ 


\section{Capítulo 5}

\section{Conclusões}

Nesta dissertação estudamos a existência do comportamento caótico, controle de caos e o mecanismo de salto entre trajetórias de diferentes atratores em um sistema com impactos (não integrável). Para esse estudo, utilizamos o modelo par de impactos, com a solução sendo reinicializada, após cada impacto, com o auxílio da regra de Newton para impactos.

No capítulo 2, a análise das séries temporais das variáveis dinâmicas do sistema estudado, nos planos de fase, revelou, conforme esperado, a existência de múltiplos atratores. A identificação desses atratores, como periódicos ou caóticos, foi feita, inicialmente, pela distribuição de pontos na seção de Poincaré do atrator. A influência dos principais parâmetros de controle na determinação dos atratores foi mostrada em diagramas de bifurcação unidimensionais. A seguir, foram calculados os expoentes de Lyapunov, das trajetórias analisadas, com o método do mapa transcendental. O maior expoente de Lyapunov foi usado para determinar se o atrator era periódico ou caótico. Verificamos a precisão deste método comparando os expoentes obtidos com a dinâmica observadas nos diagramas de bifurcação, para as mesmas trajetórias, nos mesmos intervalos de parâmetros. Escolhemos a amplitude de forçamento e o coeficiente de restituição como os parâmetros principais do sistema, pois quando variados fornecem maior quantidade de fenômenos tais como, bifurcações, coexistência de atratores, caos e janelas periódicas. Observamos em espaços bidimensionais dos parâmetros escolhidos a existência de janelas periódicas em forma de camarão.

Para o sistema par de impactos, no capítulo 3, implementamos o controle de caos 
através de uma perturbação harmônica paramétrica. Essa perturbação foi somada ao forçamento original do sistema. Investigamos os parâmetros da perturbação que controlam os atratores caóticos escolhidos, i. e., que os tornam periódicos. Obtivemos diagramas de bifurcação, aumentando a amplitude da perturbação harmônica do forçamento. Esses diagramas abrangiam intervalos nos quais os valores da amplitude da perturbação começavam com zero e atingiam valores suficientes para o controle do atrator caótico. Para os intervalos de parâmetros considerados, o controle foi atingido para valores da amplitude da perturbação cerca de $0.5 \%$ da amplitude de forçamento original do sistema. A freqüência $\omega$ da perturbação foi obtida através de uma comparação, no espaço de parâmetros, com a freqüência $\omega_{0}$ original do sistema. Verificamos que o controle de um atrator caótico ocorre quando há uma razão racional entre as freqüências.

O controle de caos foi avaliado no espaço de parâmetros do sistema par de impactos. Observamos a presença de janelas periódicas (camarões) no espaço de parâmetros do sistema sem a implementação do controle. Já sob o efeito do controle, no mesmo espaço de parâmetros, observamos o surgimento de novos camarões na vizinhança dos existentes sem controle. À medida que aumentamos o valor da amplitude da perturbação, percebemos que os novos camarões se deslocam no espaço de parâmetros. Concluímos que o controle através de uma perturbação, no sistema par de impactos, ocorre através do surgimento de novos camarões no espaço de parâmetros. Com o aumento da amplitude da perturbação paramétrica, estes novos camarões se deslocam até atingir o par de parâmetros do atrator caótico que se queria controlar. Para essa amplitude o atrator caótico se torna periódico. Nos trabalhos anteriores, o controle de caos foi obtido para alguns parâmetros do sistema. Neste trabalho, investigamos o controle de caos para intervalos dos parâmetros. Com isso, foi possível investigar, de forma inédita, o surgimento de novas janelas periódicas nesse espaço.

No capítulo 4, investigamos, no modelo par de impactos, a ocorrência de saltos, causada pela adição de ruído, entre as trajetórias de diferentes atratores. Para simular o efeito de um ruído branco com uma banda de frequências sobre a evolução do sistema, aplicamos ao modelo uma perturbação composta por uma somatória de harmônicos. Cada termo da somatória possui freqüências e amplitudes constantes, mas fases alteradas, aleatórias 
após cada impacto.

Com a aplicação do ruído, observamos, em várias séries temporais do modelo par de impactos, o salto entre as trajetórias de dois atratores coexistentes. Obtivemos as bacias de atração dos dois atratores coexistentes. Notamos que com a redução da dissipação do sistema (devido aos impactos), torna-se mais incerta a escolha de condições iniciais que levam a seus respectivos atratores. Com isso, investigamos o mecanismo de salto para diferentes valores da dissipação. Constatamos que, o salto entre atratores é facilitado para dissipações menores.

Dada a observação da formação de novas janelas periódicas, no espaço de parâmetros, ao se aplicar o controle paramétrico do sistema par de impactos, seria interessante investigar a existência desse fenômeno em outros sistemas. Principalmente em sistemas mais simples, descritos por mapas, para os quais seria mais fácil analisar analiticamente o surgimentos dos novos camarões, as suas formas e a sua distribuição.

As causas do mecanismo de saltos entre as trajetórias ainda não estão completamente explicadas em sistemas com impactos. As mudanças nas bacias de atração, dos atratores envolvidos nos saltos, devem ser investigadas a partir das variedades do sistema, e das suas alterações com os parâmetros de controle. As mudanças nessas variedades poderão revelar preciosas informações sobre a natureza e a estatística dos saltos.

Nos sistemas com impactos, a obtenção das variedades apresenta dificuldades adicionais pois as soluções são descontínuas. Esse problema pode ser superado pela introdução de mapas transcendentais, que forneçam a evolução das variáveis após cada impacto, como aplicado nesta dissertação.

Por outro lado, seria importante testar a mesma técnica de controle em modelos mais sofisticados de engenharia mecânica, onde a observação desses fenômenos pode ter importante aplicação. 


\section{Bibliografia}

[1] LORENZ, E. N. Deterministic nonperiodic flow. Journal of Atmospheric Sciences, v. 20, p. $130-141,1963$.

[2] SWINNEY, H. L. Observations of order and chaos in nonlinear systems. Physica D, v. 7, p. 3-15, 1983.

[3] DI BERNARDO, M.; GAROFAlO, F.; GLIELMO, L.; VASCA F. Switchings, bifurcations, and chaos in DC/DC Converters. IEEE Transactions on Circuits and Systems: FTA. v. 45, p. 133-141, 1998.

[4] ULLMANN, K.; CALDAS, I. L. A sympletic mapping for the ergodic magnetic limiter and its dynamical analyses. Chaos, Solitons and Fractals, v. 11, p. 991-1010, 2000.

[5] MAY, R. M. Simple mathematical models with very complicated dynamics. Nature, v. 261, p. 459-467, 1976.

[6] PENG, B.; PETROV, V.; SHOWALTER, K. Controlling chemical chaos. The Journal of Physical Chemistry, v. 95, p. 4957-4959, 1991.

[7] PFEIFFER, E.; PRESTL, W. Hammering in diesel-engine driveline systems. Nonlinear Dynamics, v. 5, p. 477-492, 1994.

[8] OSELEDEC, V. I. A multiplicative ergodic theorem Lyapunov characteristic numbers for dynamical systems, Transactions on Moscow Mathematical Society, v. 19, p. 197$231,1968$.

[9] Benettin, G.; GALGAni, L.; GIORGILli, A.; STRELCYN, J. -M. Lyapunov 
characteristic exponents for smooth dynamical systems and for hamiltonian systems: A Method for Computing All of Them. Meccanica, v. 15, p. 9-20, 1980.

[10] SHIMADA, I.; NAGASHIMA, T. A numerical approach to ergodic problem of dissipative dynamical systems. Progress of Theoretical Physics, v. 61, p. 1605-1616, 1979 .

[11] SHAW, R. Strange attractors, chaotic behavior, and information flow. Zeitschrift für Naturforschung, v. 36, p. 80-112, 1981.

[12] GALLAS, J. A. C. Structure of the parameter space of the Hénon map. Physical Review Letters, v. 70, p. 2714-17, 1993.

[13] MARKUS, M.; HESS B. Lyapunov exponents of the logistic map with periodic forcing. Computation \& Graphics, v. 13, p. 553-557, 1989.

[14] TSONIS, A. A. Chaos: from theory to applications. New York: Plenum Press, 1992. 274 p.

[15] OTT, E. Chaos in dynamical systems. Cambridge: Cambridge University Press, 2002. $490 \mathrm{p}$.

[16] MONTEIRO, L. H. A. Sistemas dinâmicos. São Paulo: Editora Livraria da Física, 2006. $625 \mathrm{p}$.

[17] KNUDSEN C. FELDBERG, R.; TRUE H. Bifurcations and chaos in a model of a rolling railway wheelset. Philosophical Transactions: Physical Sciences and Engineering, v. 338, p. 455-469, 1992.

[18] BRAIMAN, Y.; GOLDHIRSCH, I. Taming chaotic dynamics with periodic perturbations. Physical Review Letters, v. 66, p. 2545-2548, 1991.

[19] LIMA, R.; PETTINI, M. Suppression of chaos by resonant parametric perturbations. Physical Review A, v. 41, p. 726-733, 1990. 
[20] KAPITANIAK, T.; BRINDlEy, J.; CZOLCZYNSKI, K. in: G. Chen (Ed.), Controlling chaos and bifurcations in engineering systems. Boca Raton: CRC Press LLC, 1999. pp. $71-86$.

[21] OTT, E.; GREBOGI C.; YORKE, J. A. Controlling chaos. Physical Review Letters, v. 64, p. 1196-1199, 1990.

[22] KRAUT, S.; FEUDEL, U. Multistability, noise and attractor-hopping: The crucial role of chaotic saddles. Physical Review E, v. 66, p. 015207-015211, 2002.

[23] WIESENFELD, K.; BRACIKOWSKI, C.; JAMES, G.; ROY, R. Observation of antiphase states in a multimode laser. Physical Review Letters, v. 65, p. 1749-1752, 1990.

[24] BRAMBILlA, M.; LUGIATO, L. A.; PENNA, V. Transverse laser patterns I. phase singularity crystals. Physical Review A, v. 43, p. 5090-5113, 1991.

[25] MARMillot, P.; KAUFMAN, M.; HERVAGAULT, J. -F. Multiple steady states and dissipative structures in a circular and linear array of three cells: Numerical and experimental approaches. The Journal of Physical Chemistry, v. 95, p. 1206-1214, 1991.

[26] SCHIFF, S.; JERGER, K.; DUONG, D. H.; CHANG, T.; SPANO, M. L.; DITTO, W. L. Controlling Chaos in the Brain. Nature, v. 370, p. 615-621, 1994.

[27] FOSS, J.; LONGTIN, A.; MENSOUR, B.; MILTON, J. Multistability and delayed recurrent loops. Physical Review Letters, v. 76, p. 708-711, 1996.

[28] PRENGEL, F.; WACKER, A.; SCHÖll, E. Simple model for multistability and domain formation in semiconductor superlattices. Physical Review B, v. 50, p. 1705$1712,1994$.

[29] WANG, Z.; GUO, W.; ZHENG, S. Quantum theory of optical multistability in a twophoton three-level configuration medium. Physical Review A, v. 46, p. 7235-7241, 1992. 
[30] KANEKO, K. Dominance of milnor attractors and noise-induced selection in a multiattractor system. Physical Review Letters, v. 78, p. 2736-2739, 1997.

[31] KRAUT, S.; FEUDEL, U.; GREBOGI, C. Preference of attractors in noisy multistable systems. Physical Review E, v. 59, p. 5253-5260, 1999.

[32] JERRELIND, J.; STENSSON, A. Nonlinear dynamics of parts in engineering systems. Chaos, Solitons and Fractals, v. 11, p. 2413-2428, 2000.

[33] DE SOUZA, S. L. T. Caos e controle em sistemas mecânicos com impactos. tese de doutoramento apresentada ao IF-USP, 2002.

[34] KARAGIANNIS, K.; PFEIFFER, F. Theoretical and experimental investigations of gear-rattling. Nonlinear Dynamics, v. 2, p. 367-387, 1991.

[35] BUDD, C.; DUX, F.; CLIFFE, A. The effect of frequency and clearance variations on single degree of freedom impact oscillators. Journal of Sound and Vibration, v. 184, p. 475-502, 1995.

[36] STENSSON A.; NORDMARK, A. Experimental investigation of some consequences of low velocity impacts in the chaotic dynamics of a mechanical system. Philos. Trans. Roy. Soc. London A, v. 347, p. 439-448, 1994.

[37] SAVI, M. A.; DIVENYI, S.; FRANCA, L. F. P.; WEBER, H. I. Numerical and experimental investigations of the nonlinear dynamics and chaos in non-smooth systems. Journal of Sound and Vibration, v. 301, p. 59-73, 2007.

[38] DE SOUZA, S. L. T.; CALDAS, I.L.; VIANA, R.L.; BATISTA, A.M.; KAPITANIAK, T. Noise-induced basin hopping in a vibro-impact system. Chaos, Solitons and Fractals, v. 32, p. 758-767, 2007.

[39] DE SOUZA, S. L. T.; CALDAS, I. L. Controlling chaotic orbits in mechanical systems with impacts. Chaos, Solitons and Fractals, v. 19, p. 171-178, 2004.

[40] DE SOUZA, S. L. T.; CALDAS, I. L. Calculation of Lyapunov exponents in Systems with impacts. Chaos, Solitons and Fractals, v. 19, p. 569-579, 2004. 
[41] LEONEL, E. D.; DA SILVA, J. K. L.; KAMPHORST, S. O. On the dynamical properties of a Fermi accelerator model. Physica A, v. 331, p. 435-447, 2004.

[42] LEOnEL, E. D.; McClintoCK, P. V. E.; DA SILVA, J. K. L. The Fermi-Ulam Accelerator model Under Scaling Analysis. Physical Review Letters, v. 93, p. 1410114104, 2004.

[43] WOLF, A.; SWIFT, J. B.; SWINNEY, H. L.; VASTANO, J. A. Dertermining lyapunov exponents from a time series. Physica D, v. 16, p. 285-317, 1985.

[44] MEDEIROS, E. S.; DE SOUZA, S. L. T.; MEDRANO-T, R. O.; CALDAS, I. L. Periodic window arise in the parameter space of an impact oscillator. Artigo submetido para publicação.

[45] HAN, R. P. S.; LUO, A. C. J.; DENG, W. Chaotic motion of a horizontal impact-pair. Journal of Sound and Vibration, v. 181, p. 231-250, 1995.

[46] BAPAT, C. N.; POPPLEWELL, N.; McLACHLAN, K. Stable periodic motions of an impact-pair. Journal of Sound and Vibrations, v. 87, p. 19-40, 1983.

[47] BAPAT, C. N.; BAPAT, C. Impact-pair under periodic excitation. Journal of Sound and Vibrations, v. 120, p. 53-61, 1988.

[48] BAPTISTA, M. DA S. Perturbando sistemas não-lineares, uma abordagem ao controle de caos, tese de doutorado apresentada ao IF-USP, 1996.

[49] BOnATTO, C.; GALlAS, J. A. C. Accumulation boundaries: codimension-two accumulation of accumulations in phase diagrams of semiconductor lasers, electric circuits, atmospheric and chemical oscillators. Phil. Trans. R. Soc. A, v. 366, p. 505-517, 2008 .

[50] AlBuquerque, H. A.; RUBINGER, R. M.; RECH, P. C. Self-similar structures in a 2D parameter-space of an inductorless Chua's circuit. Physics Letters A, v. 372, p. 4793-4798, 2008. 
[51] CARdoso, J. C. D.; Albuquerque, H. A.; RUBInGER, R. M. Complex periodic structures in bi-dimensional bifurcation diagrams of a RLC circuit model with a nonlinear NDC device. Physics Letters A, v. 373, p. 2050-2053, 2009.

[52] GALLAS, J. A. C. Dissecting shrimps: results for some one-dimensional physical models. Physica A, v. 202, p. 196-223, 1994.

[53] ZHILIN Q.; HU G.; YANG, G.; QIN G. Phase effect in taming nonautonomous chaos by weak harmonic perturbations, Physical Review Letters, v. 74, p. 1736-1739, 1995.

[54] HSIUNG H. K., White noise distribution theory. Boca Raton: CRC Press LLC, 2000.

[55] KAPITANIAK, T. Chaos in systems with noise. Singapore: World Scientific, 1990. 231 p. 